UNIVERSIDADE DE SÃO PAULO

FACULDADE DE ECONOMIA, ADMINISTRAÇÃO E CONTABILIDADE DEPARTAMENTO DE ADMINISTRAÇÃO PROGRAMA DE PÓS-GRADUAÇÃO EM ADMINISTRAÇÃO

O IMPACTO CONJUNTO DO EMPREENDEDORISMO E DAS REDES INTERORGANIZACIONAIS SOBRE O DESENVOLVIMENTO DE INOVAÇÕES GLOBAIS: EVIDÊNCIAS DAS SUBSIDIÁRIAS ESTRANGEIRAS OPERANDO NO PAÍS

Sidney Costa

Orientador: Prof. Dr. Moacir de Miranda Oliveira Junior

SÃO PAULO 

Prof. Dr. Marco Antônio Zago

Reitor da Universidade de São Paulo

Prof. Dr. Prof. Adalberto Américo Fischmann

Diretor da Faculdade de Economia, Administração e Contabilidade

Prof. Dr. Roberto Sbragia

Chefe do Departamento de Administração

Prof. Dr. Moacir de Miranda Oliveira Junior Coordenador do Programa de Pós-Graduação em Administração 



\title{
O IMPACTO CONJUNTO DO EMPREENDEDORISMO E DAS REDES INTERORGANIZACIONAIS SOBRE O DESENVOLVIMENTO DE INOVAÇÕES GLOBAIS: EVIDÊNCIAS DAS SUBSIDIÁRIAS ESTRANGEIRAS OPERANDO NO PAÍS
}

\begin{abstract}
Tese apresentada ao Departamento de Administração da Faculdade de Economia, Administração e Contabilidade da Universidade de São Paulo como parte dos requisitos para a obtenção do título de Doutor em Administração.
\end{abstract}

Orientador: Prof. Dr. Moacir de Miranda Oliveira Junior

Versão Corrigida

(Versão original disponível na biblioteca da Faculdade de Economia, Administração e Contabilidade) SÃO PAULO 
Autorizo a reprodução e divulgação total ou parcial deste trabalho, por qualquer meio convencional ou eletrônico, para fins de estudo e pesquisa, desde que citada a fonte.

O impacto conjunto do empreendedorismo e das redes interorganizacionais sobre o desenvolvimento de inovações globais: evidências das subsidiárias estrangeiras operando no país / Sidney Costa. - São Paulo, 2016.

$135 \mathrm{p}$.

Tese (Doutorado) - Universidade de São Paulo, 2016.

Orientador: Moacir de Miranda Oliveira Júnior.

1. Empresas multinacionais 2. Inovação global 3. Redes de empresas 4. Subsidiárias estrangeiras I. Universidade de São Paulo. Faculdade de Economia, Administração e Contabilidade. II. Título.

$$
\text { CDD }-658.0236
$$


Dedico este trabalho a minha família. 


\section{AGRADECIMENTOS}

- Agradeço a CAPES por ter financiado o meu doutorado sanduíche.

- Agradeço aos funcionários e professores da FEA/USP, em especial, quero agradecer fortemente ao Francisco Oliveira Costa (técnico acadêmico na secretaria de pós-graduação da FEA).

- Quero também registrar um agradecimento a todos os gerentes e executivos que participaram da pesquisa doando seu tempo e conhecimento sobre as temáticas aqui tratadas.

- Agradeço a professora Lourdes Casanova por ter me recebido e orientado no doutorado sanduíche na Johnson Graduate School of Management - Cornell University.

- Agradeço ao professor Felipe Borini parceiro nas pesquisas e que muito contribuiu para o meu crescimento acadêmico.

- Agradeço ao professor Moacir de M. O. Junior por todas as portas abertas ao longo desses anos, pelos momentos de descontração e palavra sincera.

- Finalmente, agradeço a minha esposa Márcia e a minha filha Júlia por toda a energia, entusiasmo e suporte emocional.

\section{Obrigado!}


O que é a ciência? - A ciência é um jeito de ensinar como alguma coisa é conhecida, na medida em que pode ser conhecida.

- Nada é conhecido plenamente.

- É lidar com a dúvida e com a incerteza.

- A ciência nos ensina as regras da evidência.

Richard Feynman, Nobel de Física. 



\section{RESUMO}

As subsidiárias de corporações multinacionais sofrem pressões do ambiente interno e externo. Internamente competem por recursos e reconhecimento da matriz, externamente precisam se preocupar com os concorrentes e demais forças do mercado, de maneira que para desenvolver-se a subsidiária deve explorar as oportunidades de mercado e mostrar o potencial empreendedor que possui. Essas oportunidades podem estar num produto ou processo novo ou substancialmente aprimorado no qual a subsidiária teve o auxílio de um parceiro da rede em que está inserida. Particularmente, essa pesquisa analisa as inovações desenvolvidas localmente (dentro do país hospedeiro) através das subsidiárias instaladas no país, essas inovações são passíveis de serem transferidas para as suas matrizes e então utilizadas pelas demais subsidiárias espalhadas pelo mundo, tornando-se inovações globais. O foco principal deste estudo está em compreender a influência do empreendedorismo e das redes de empresas sobre o desenvolvimento e transferência dessas inovações. Para tanto, o presente estudo analisa uma amostra de 172 subsidiárias estrangeiras que operam no Brasil, a qual foi modelada utilizando-se a técnica de equações estruturais para o teste das hipóteses, mensuração do efeito mediador e comparação multigrupos visando avaliar o efeito moderador referente ao porte das subsidiárias. Os resultados sugerem que o empreendedorismo da subsidiária exerce influência significativa sobre o desenvolvimento das parcerias e consequente enraizamento da subsidiária na rede de empresas do mercado emergente, esse enraizamento na rede é um fator determinante para o desenvolvimento de inovações na subsidiária as quais podem ser transferidas para a matriz e então tornarem-se inovações globais. A partir desses resultados, a pesquisa contribui para um maior entendimento dos direcionadores de inovação nas subsidiárias e aprofunda a discussão sobre o desenvolvimento de inovações globais, particularmente àquelas provenientes de mercados emergentes.

Palavras-chave: Inovação Global, Redes de Empresas, Empreendedorismo, Subsidiárias Estrangeiras. 


\begin{abstract}
The subsidiaries of multinational corporations are under pressure from internal and external environment. Internally compete for resources and recognition of the headquarters, externally have to worry about competitors and other market forces, so that to develop the subsidiary should explore market opportunities and show the potential entrepreneur has. These opportunities may be a product or new or substantially improved process in which the subsidiary had the help of a partner network in which it operates. In particular, this research analyzes the locally developed innovations (within the host country) through subsidiaries established in the country, these innovations are likely to be transferred to their headquarters and then used by other subsidiaries around the world, becoming global innovations. The main focus of this study is to understand the influence of entrepreneurship and business networks on the development and transfer of these innovations. Thus, the present study analyzes a sample of 172 foreign subsidiaries operating in Brazil, which was modeled using the technique of structural equation for the test case, measurement of the mediating effect and multi-groups comparison to assess the moderating effect regarding the size of the subsidiaries. The results suggest that entrepreneurship subsidiary has significant influence on the development of partnerships and consequent rooting subsidiary network of emerging market companies that rooting is a determining factor for the development of innovations in the subsidiary which can be transferred to the headquarter and become global innovation. From these results, the research contributes to a better understanding of the innovation drivers in subsidiaries and deepen the discussion on the development of global innovations, particularly those from emerging markets.
\end{abstract}

Keywords: Global Innovation, Network Business, Entrepreneurship, Foreign Subsidiaries. 


\section{SUMÁRIO}

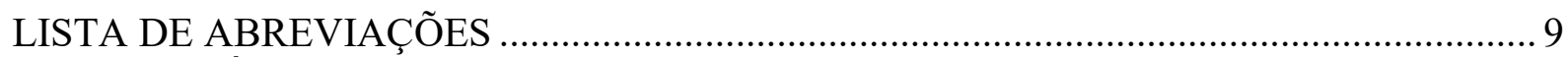

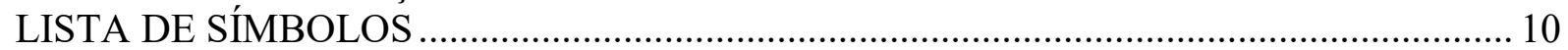

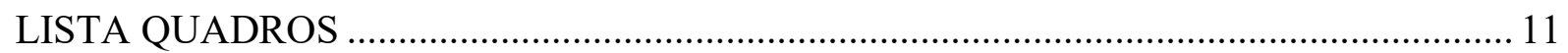

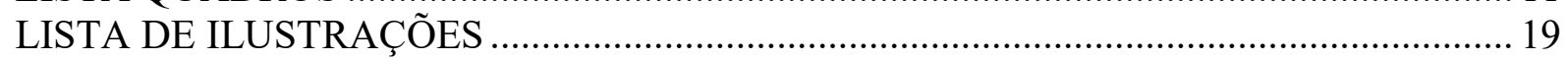

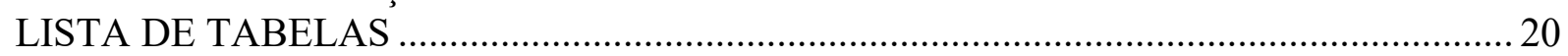

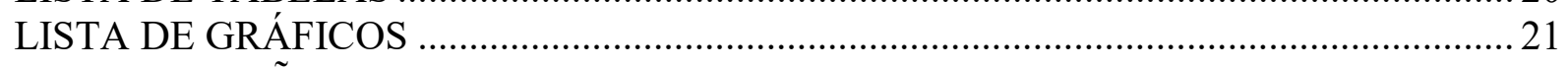

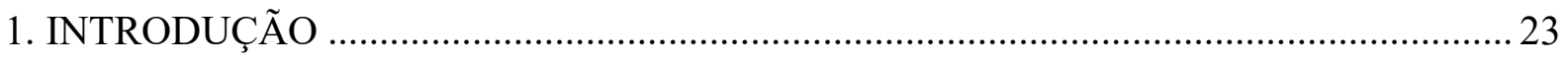

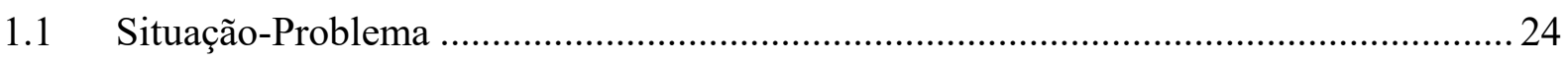

1.2 Formulação do Objetivo e da Questão de Pesquisa ................................................... 27

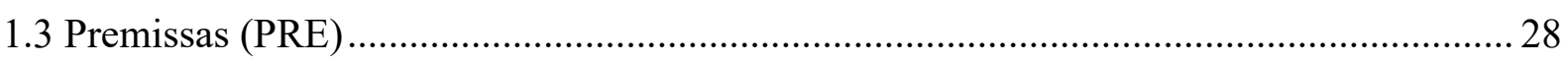

1.4 Motivação, Relevância e Ineditismo da Pesquisa ............................................................ 29

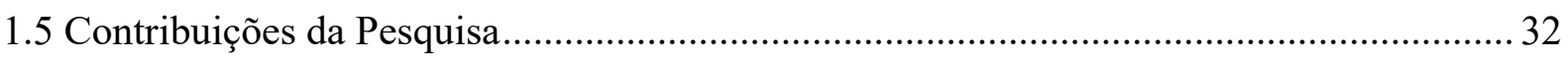

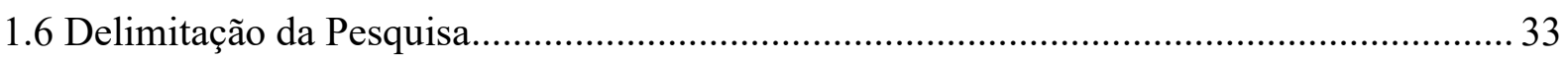

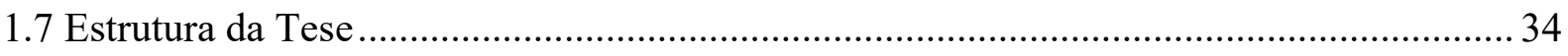

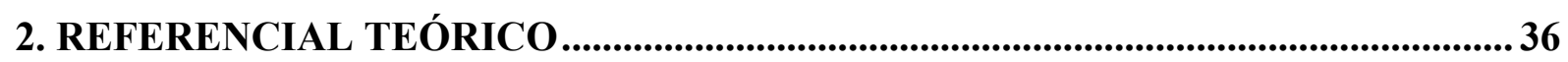

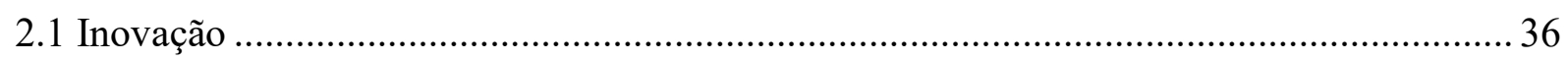

2.1.2 Inovação em Mercados Emergentes - Inovação Local .................................................. 39

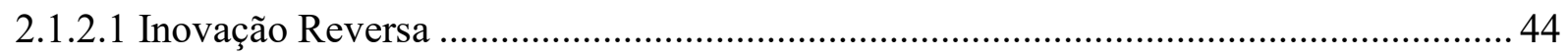

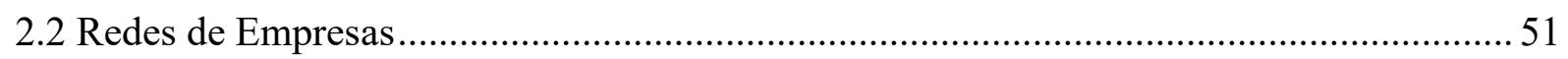

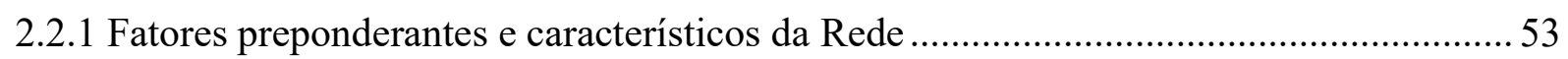

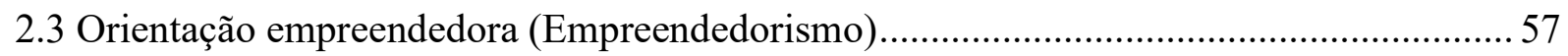

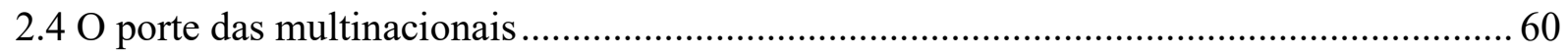

2.5 Considerações finais do capítulo e proposição do modelo teórico ..................................... 60

3. ASPECTOS METODOLÓGICOS DA PESQUISA ....................................................... 64

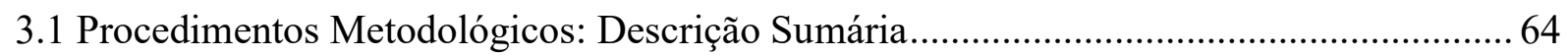

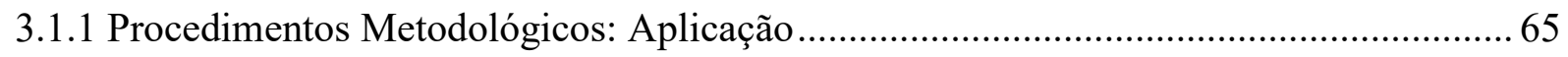

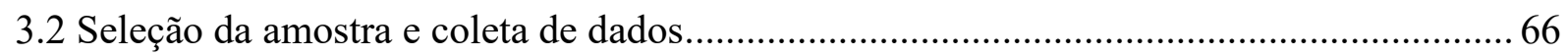

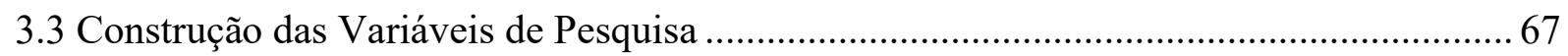

3.4 Modelagem de Equações Estruturais (Structural Equation Modeling - SEM) .................. 70

3.4.1 Pressupostos do Modelo de Equações Estruturais ..................................................... 73

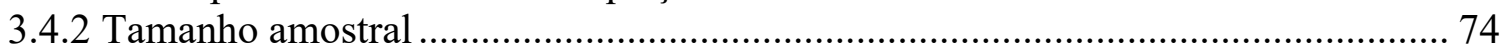

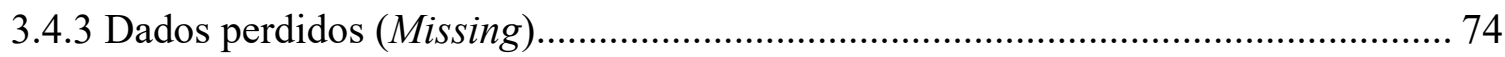

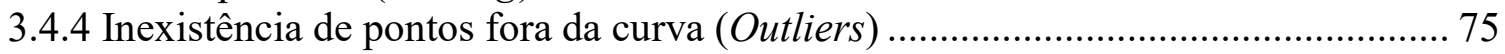

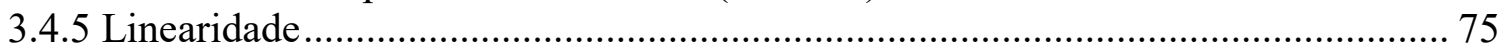

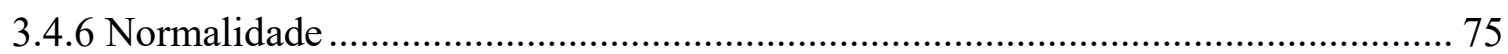

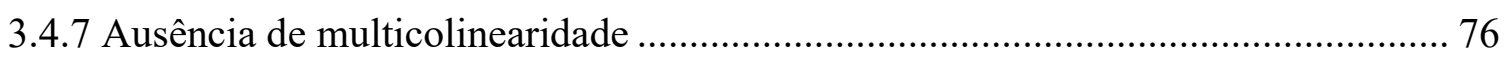

3.4.8 Análise do viés do método comum (Common Method Bias - CMB) ........................ 76

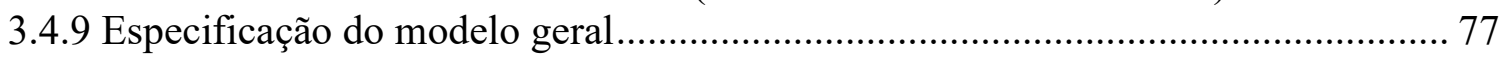

3.4.10 Matriz de entrada dos dados e método de estimação do modelo .......................... 77 


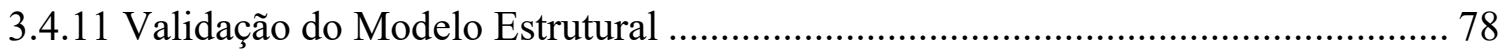

3.4.12 Comparação de modelos (Modelos alternativos) .................................................. 80

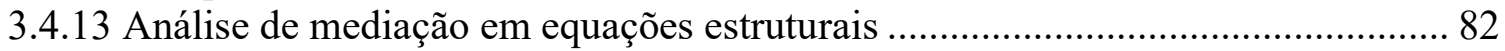

3.4.14 Análise de moderação em equações estruturais ..................................................... 84

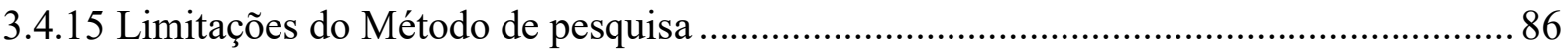

4. APRESENTAÇÃO E ANÁLISE DOS RESULTADOS ............................................... 87

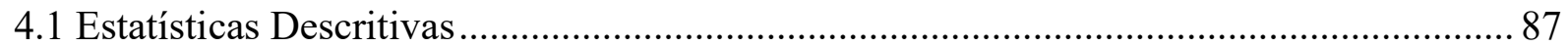

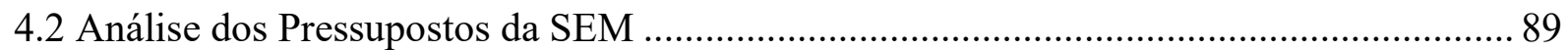

4.3 Índices de ajuste do modelo (Validação do modelo estrutural) ........................................ 90

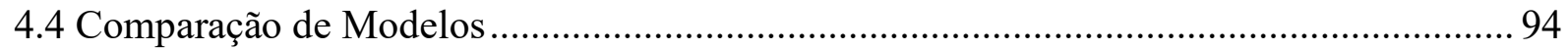

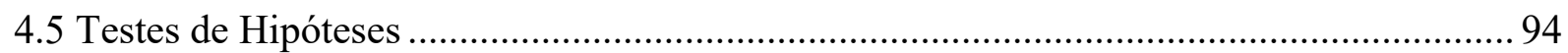

4.6 Análise do Efeito Mediador dos construtos: Redes de empresas e Inovação local............ 96

4.7 Análise do Efeito Moderador da Variável: Tamanho ...................................................... 97

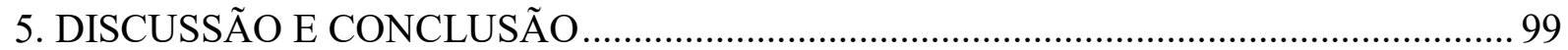

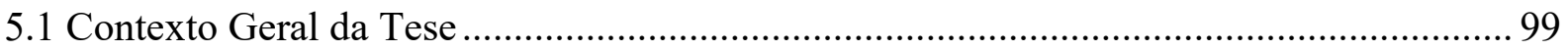

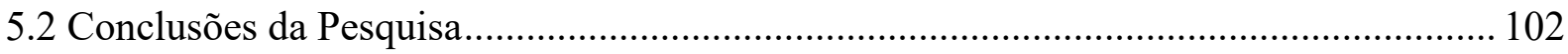

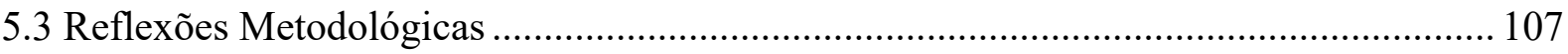

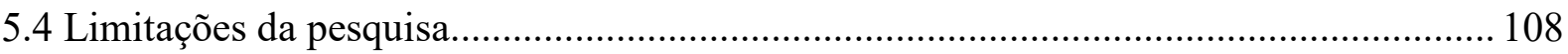

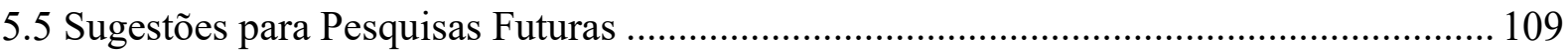

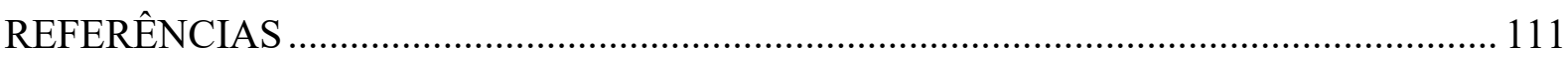

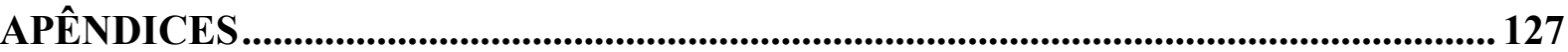

APÊNDICE I - INSTRUMENTO DE PESQUISA......................................................... 128

APÊNDICE II - PREPARAÇÃO DOS DADOS DA PESQUISA: ESTATÍSTICAS

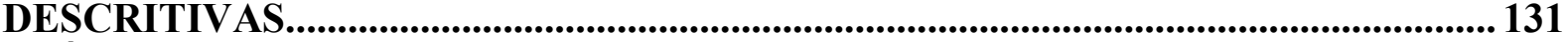

APÊNDICE III - ESTIMATIVAS E PESOS DAS VARIÁVEIS DO MODELO DE

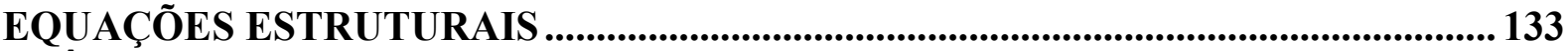

APÊNDICE IV - COMPARAÇÃO ENTRE MODELOS................................................ 135 


\section{LISTA DE ABREVIAÇÕES}

SEM: Modelagem de Equações Estruturais

AFC: Análise Fatorial Combinatória

MLE: Estimação de máxima verossimilhança

CMB: Viés do método comum

CC: Confiabilidade Composta

AVE: Variância Extraída

BRICS: Brasil, Rússia, Índia, China e África do Sul

EMN: Empresa Multinacional

MNC: Empresa Multinacional

GII: Índice de Inovação Global

GE: General Electric

IDE: investimento direto estrangeiro

P\&D: Pesquisa e Desenvolvimento 


\section{LISTA DE SÍMBOLOS}

$\mathbf{n}$ - Tamanho da amostra

$\boldsymbol{\alpha}$ - Alfa de cronbach

$\lambda$ - Pesos padronizados do modelo estrutural

p - Probabilidade de significância

$\mathbf{R}^{\mathbf{2}}$ - Coeficiente de determinação

* - Significativo ao nível de 0,05

** - Significativo ao nível de 0,01

*** - Significativo ao nível de 0,001 


\section{LISTA QUADROS}

Quadro 1 - Fatores preponderantes e característicos da Rede........................................62

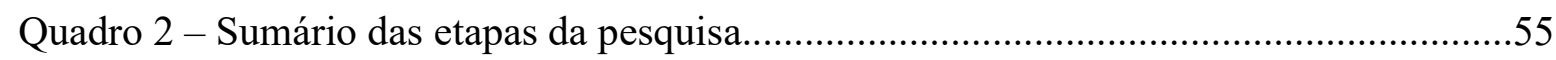

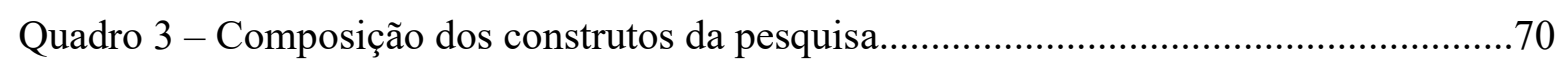

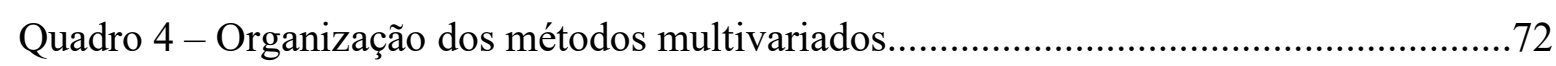

Quadro 5 - Regras para escolher entre PLS-SEM e CB-SEM..........................................73

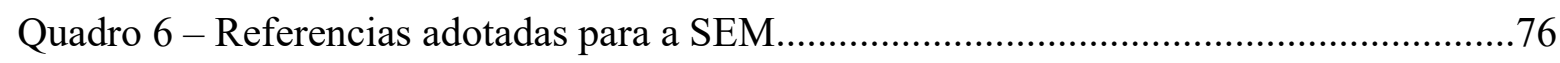

Quadro 7 - Resumo dos resultados dos testes de hipóteses............................................100

Quadro 8 - Resumo dos resultados dos efeitos mediadores e moderadores........................100 



\section{LISTA DE ILUSTRAÇÕES}

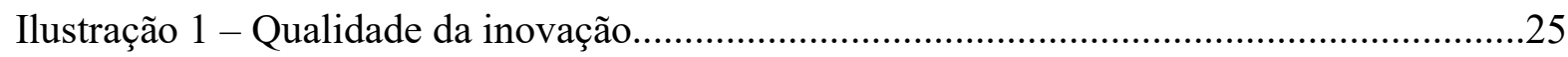

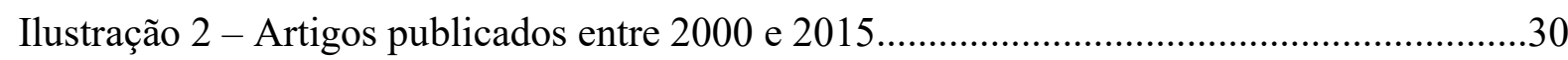

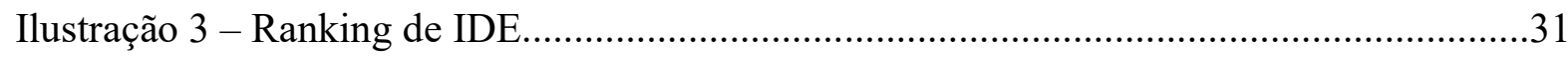

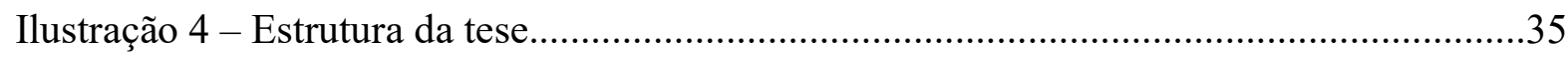

Ilustração 5 - Modelo proposto e hipóteses.....................................................................63

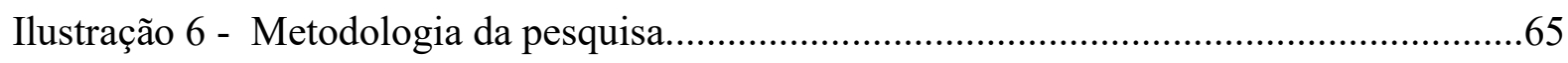

Ilustração 7 - Modelo de equações estruturais...................................................................68

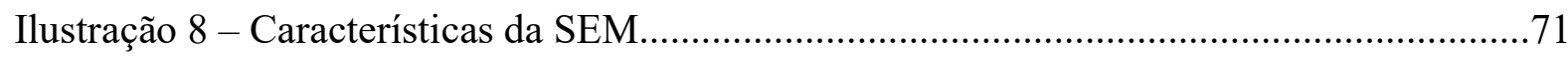

Ilustração 9 - Passos para execução da modelagem de equações estruturais..........................73

Ilustração 10 - Comparação entre modelos (Modelo alternativo)..........................................81

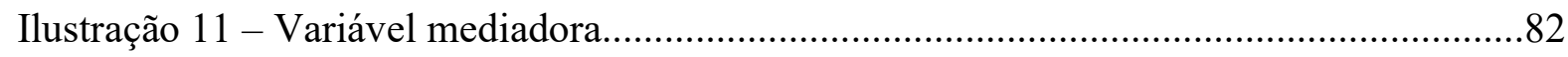

Ilustração 12 - Variáveis mediadoras do modelo proposto..................................................83

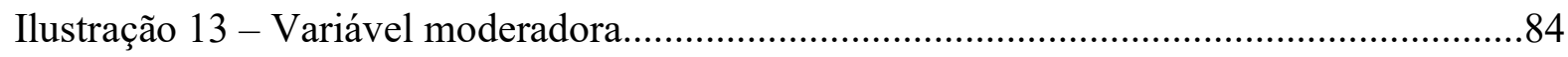

Ilustração 14 - Variável moderadora do modelo proposto....................................................85

Ilustração 15 - Comparação do modelo original com o modelo tratado................................92

Ilustração 16 - Sumário dos resultados da SEM................................................................97

Ilustração 17 - Variável mediadora (Resultados)............................................................98

Ilustração 18 - Resumo dos caminhos significativos no teste de hipóteses..........................104 


\section{LISTA DE TABELAS}

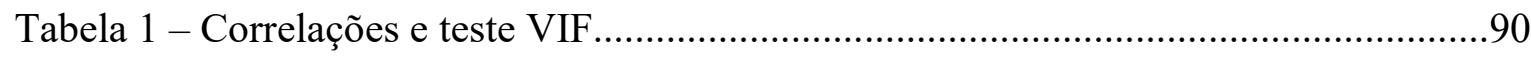

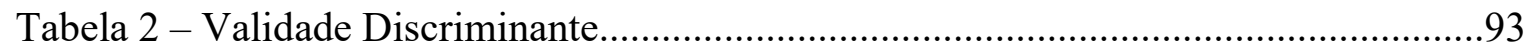

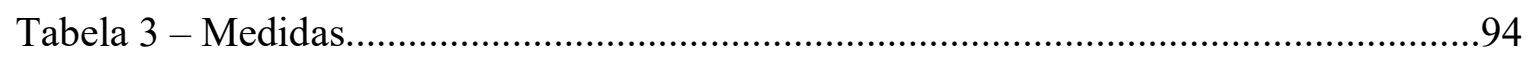

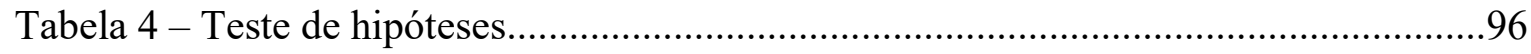

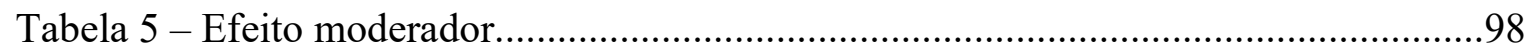




\section{LISTA DE GRÁFICOS}

Gráfico 1 - Fluxos de IDE entre 2001 e 2014 - Principais contribuidores ..........................40

Gráfico 2 - Fluxo de IDE entre 2001 e 2014 por regiões..................................................

Gráfico 3 - Cinco principais fontes de IDE no Brasil......................................................41

Gráfico 4 - Estratégias tradicionais utilizadas pelas multinacionais.................................47

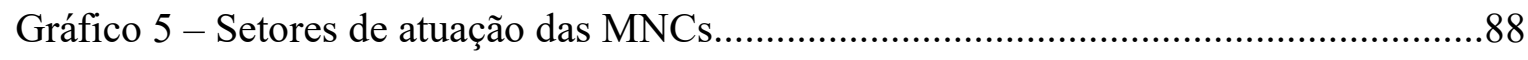

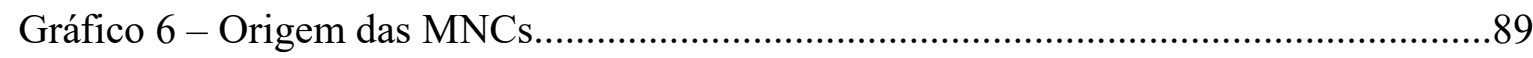

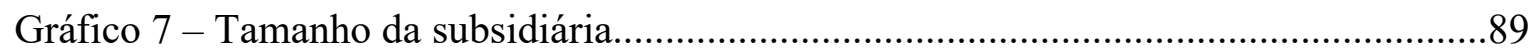




\section{INTRODUÇÃO}

Esta pesquisa investiga a influência conjunta do empreendedorismo e das redes de empresas sobre o desenvolvimento de inovações. O pressuposto é de que tanto a orientação empreendedora das subsidiárias de corporações multinacionais estrangeiras instaladas no país quanto a sua inserção em relacionamentos cooperativos em redes de empresas, impactam positivamente no desenvolvimento e transferência das inovações locais para as suas matrizes, em particular, aquelas inovações com potencial para tornarem-se globais, ou seja, que possam ser comercializadas em vários países. Para tanto, a tese ampara-se em estudos que têm explorado as questões referentes ao desenvolvimento de inovações realizadas pelas subsidiárias e que foram transferidas para a matriz e demais entes da corporação. Complementarmente, também são analisadas as pesquisas que tratam sobre a orientação empreendedora das subsidiárias e a sua inserção em relacionamentos interorganizacionais. A tese aborda, portanto, temáticas emergentes em negócios internacionais e que tem ganhado maior atenção da academia nos últimos anos (SCOPUS, 2016). O foco principal dessa pesquisa está em compreender o impacto da orientação empreendedora das subsidiárias a partir de suas próprias iniciativas, em particular para inovar, o que pode trazer maior visibilidade e atrair mais recursos. A tese também busca ampliar o entendimento sobre o fenômeno da imersão da subsidiária em relacionamentos cooperativos interorganizacionais que contribuam para o desenvolvimento e transferência de inovações.

Propõem-se assim um diálogo entre temáticas em evidência em negócios internacionais, porém pouco exploradas conjuntamente e em contextos de países em desenvolvimento. Essa pesquisa contribui com novas evidências empíricas que sugerem que a exploração das oportunidades de mercado pelas subsidiárias através do aprofundamento das parcerias impacta positivamente no desenvolvimento de inovações. As subsidiárias precisam estar atentas a essas oportunidades intensificando o seu potencial empreendedor a partir da busca por inovações que podem estar num parceiro da rede. Paralelamente foram realizados testes sobre o efeito mediador desempenhado pela inserção em redes de empresas e pelo desenvolvimento de inovações locais sobre o desenvolvimento de inovações globais. Também foram realizados testes sobre o efeito moderador que o porte da subsidiária possa ter a fim de averiguar os seus efeitos sobre o modelo proposto. 
A escolha do objeto de pesquisa: subsidiárias de corporações multinacionais estrangeiras que operam no Brasil, está concatenada com as pesquisas mais recentes, as quais têm explorado as questões que envolvem as subsidiárias (OLIVEIRA JR.; BOEHE; BORINI, 2009), sua importância para a corporação e seu papel como desenvolvedor de competências e inovações (COSTA; BORINI; AMATUCCI, 2013).

\subsection{Situação-Problema}

Dentro da temática da gestão das empresas multinacionais (Multinational Corportations MNCs) pesquisas referentes a transferência de conhecimento e inovação remontam o cerne da estratégia corporativa desde o advento da estratégia transnacional (BARTLETT; GHOSHAL, 1989, 1999). Diversos fatores são elencados para explicar os motivadores e as barreiras para a transferência do conhecimento e inovação (MICHAILOVA; MUSTAFFA, 2012). A última década, refletindo o enfoque dos estudos de negócios internacionais pautados pela teoria das redes, tem destacado o papel da inserção das subsidiárias nas redes do país hospedeiro como um fator determinante para explicar a geração de conhecimento e de inovação nas subsidiárias que depois pode ser transferido para a MNC e utilizado globalmente (ANDERSSON, 2003; ANDERSSON; BJÖRKMAN; FORSGREN, 2005; ANDERSSON; FORSGREN; HOLM, 2002; CIABUSCHI; HOLM; MARTÍN MARTÍN, 2014; DELLESTRAND, 2011; GNYAWALI; HATFIELD, 2007; HEIDENREICH et al., 2012).

Paralelamente ao crescimento da importância das redes para explicar a geração de inovação global, os estudos em gestão de empresas multinacionais foram marcados pela perspectiva evolucionária das subsidiárias (BIRKINSHAW, 1997, 2001; BIRKINSHAW; HOOD; JONSSON, 1998a). Birkinshaw (1997) ao pesquisar o empreendedorismo das subsidiárias abriu caminho para uma série de estudos que investigam o papel da orientação empreendedora e da iniciativa própria das subsidiárias, que podem ter potencial de se transformar numa inovação global (SCHMID; DZEDEK; LEHRER, 2014). Esses dois aspectos acima relatados, a inserção das subsidiárias na rede e a orientação empreendedora levantam uma questão importante em relação ao dilema do escopo geográfico da inovação.

A inovação é o caminho pelo qual as empresas devem trilhar a fim de manterem o sucesso ou 
mesmo sobreviverem (HAMEL; BREEN, 2007). Novas empresas, tecnologias, produtos e mercados são muitas vezes criados em função de inovações que revolucionam os padrões vigentes (SCHUMPETER, 1984), premiando os inovadores e impactando na economia dos países. Exemplos não faltam: veja o caso do sistema operacional Windows presente em $91 \%$ dos computadores no mundo; ou os produtos e serviços desenvolvidos pela gigante de busca Google. Essas empresas estão listadas entre as maiores e mais inovadoras empresas. E, embora a maior parte das inovações tenham sido feitas em mercados desenvolvidos, mercados emergentes como Brasil, Índia, África do Sul, Turquia, México, Argentina, Malásia, Hungria e China (GII $\left.{ }^{1}, 2015\right)$ estão cada vez mais investindo em inovação, não apenas sob a forma de empréstimos e adoção de tecnologias de outros países, como também desenvolvendo inovações voltadas para as suas realidades.

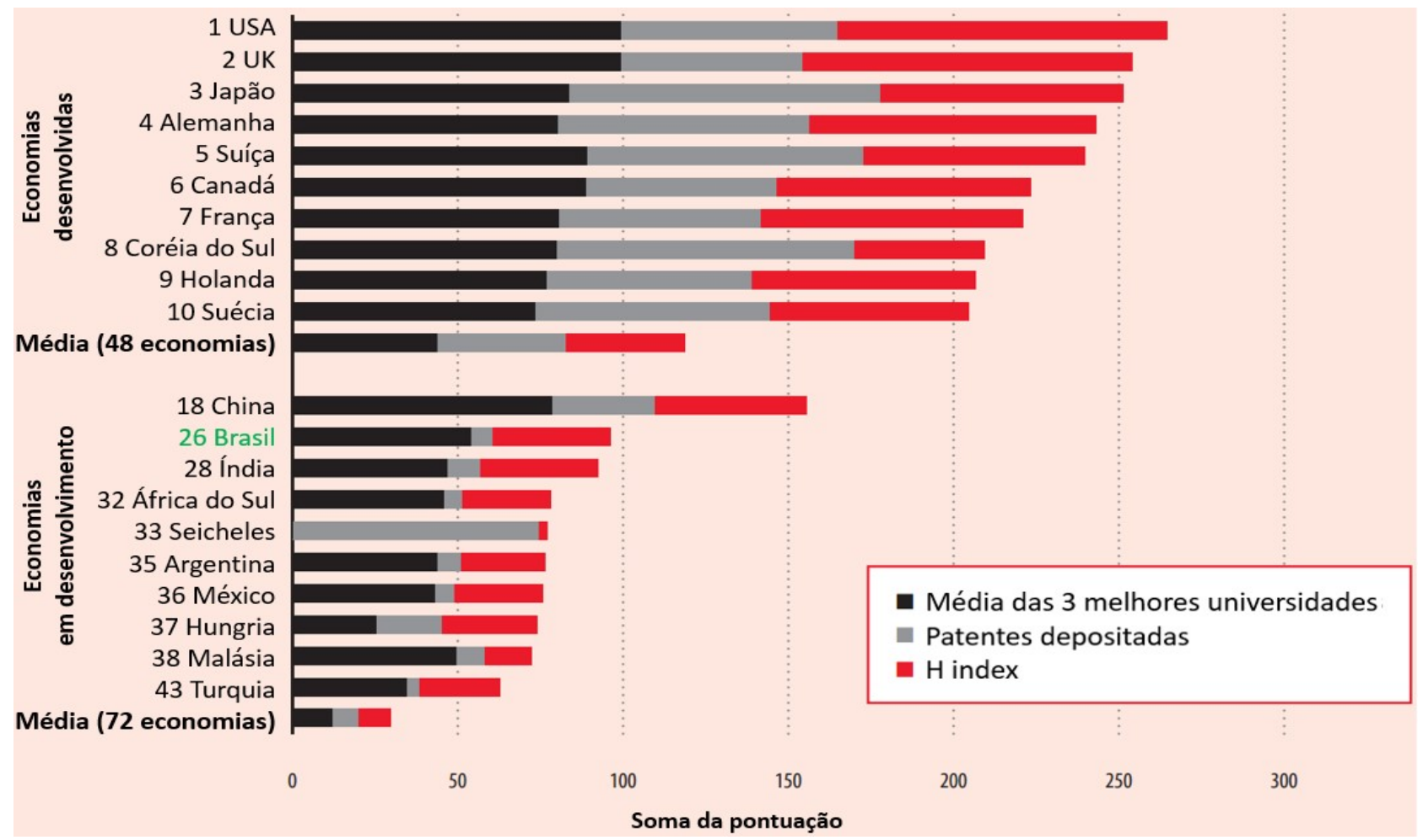

\section{Ilustração 1: Qualidade da inovação}

FONTE: adaptado de GII (2015)

De acordo com o GII (2015) os BRICS estão no topo do ranking de qualidade da inovação entre as economias em desenvolvimento, esse grupo de nações, com exceção da pontuação

\footnotetext{
${ }^{1}$ GII: Índice de Inovação Global anual realizado pelas instituições Cornell University e INSEAD
} 
referente ao número de patentes depositadas pelo o Brasil, aumentou as pontuações nos três indicadores de qualidade da inovação, a saber: Qualidade das universidades; Patentes e Documentos citados no $\mathrm{H}$ index ${ }^{2}$ conforme a Ilustração 1.

A questão da inovação em multinacionais tem sido muito explorada pela literatura acadêmica, Relly e Scott (2014) identificaram novas direções de pesquisa dentro da temática da inovação em subsidiárias sugerindo entre outras questões o aprofundamento das discussões que envolvem a geração de inovações nos mercados emergentes, os autores discutem também sobre a importância das subsidiárias para a vantagem competitiva da corporação a partir do seu potencial inovador e da transferência das inovações, essa transferência de inovações segundo Bartlett e Ghoshal (1986) pode ser influenciada pelo enraizamento nas redes de empresas locais.

Dentro da temática que envolve as corporações multinacionais (MNCs) algumas questões foram propostas visando ampliar o entendimento sobre essas organizações e como elas afetam a teoria em negócios internacionais, de maneira que algumas pesquisas buscaram entender por que as empresas preferem fazer investimento direto no exterior à fazerem investimentos indiretos (HYMER, 1976), outros trabalhos mostraram que as subsidiárias estão transferindo para as suas matrizes os conhecimentos (MCGUINNESS; DEMIRBAG; BANDARA, 2013) e inovações (GOVINDARAJAN, 2012) provenientes das parcerias (ANDERSSON; FORSGREEN; HOLM, 2002) desenvolvidas nas regiões onde atuam, enquanto que o trabalho de Birkinshaw (1997) preocupou-se em entender quais eram as características das subsidiárias empreendedoras, demonstrando que a subsidiária pode ter ações locais (responsividade local) e ter uma capacidade de aprendizado global, de maneira que as empresas empreendedoras precisam se engajar em procurar continuamente por fontes de inovações (YOUNG; DIMITRATOS; DANA, 2003), as quais podem ser acessadas ao enraizarem-se nas redes de empresas (FORSGREN; HOLM; JOHANSON, 2005).

As MNCs que operam em mercados emergentes têm se esforçado em desenvolver uma visão global com um foco intenso nas necessidades e preferências locais. Entretanto, as MNCs já perceberam que o uso das estratégias empregadas nos mercados desenvolvidos não é eficiente

\footnotetext{
${ }^{2} \mathrm{H}$ index: quantifica a produtividade e o impacto da produção científica baseando-se na citação
} 
nos mercados emergentes (GOVINDARAJAN e TRIMBLE, 2012). É preciso ir além da simples adaptação dos seus produtos e buscar por inovações locais e pontuais que dialoguem com os anseios e necessidades das regiões onde atuam. Ou de modo contrário, esse trabalho será realizado pelas multinacionais provenientes dos mercados emergentes, as quais utilizarão essas inovações como plataformas para produtos globais. A partir da ameaça real representada pelas multinacionais emergentes, as MNCs tradicionais estão decidindo investir em inovações nesses mercados emergentes e as tornando globais (GOVINDARAJAN e TRIMBLE, 2012).

Dentro desse contexto, essa pesquisa busca aprofundar o entendimento sobre os direcionadores de inovações nas subsidiárias estrangeiras instaladas no país com foco nas iniciativas dessas empresas para empreender e cooperarem com outras empresas externas a corporação multinacional.

\subsection{Formulação do Objetivo e da Questão de Pesquisa}

Esta pesquisa tem como objetivo central averiguar os fatores que influenciam as subsidiárias a inovar e transferir essas inovações para a matriz e suas irmãs subsidiárias sob a perspectiva das teorias das redes de empresas e do empreendedorismo. O pressuposto é de que a orientação empreendedora que a subsidiária possui está associada positivamente com uma forte inserção da subsidiária na rede interorganizacional (ou rede de empresas externas). Quando a subsidiária tem uma estratégia de maior inserção na rede, a chance de criar produtos/processos totalmente novos é maior, pois a parceria leva ao desenvolvimento de uma diferente configuração estratégica para a inovação, quando comparada as outras subsidiárias e a matriz. Assim, serão apresentadas evidências que demonstram a importância e a influência do empreendedorismo e das redes interorganizacionais para o desenvolvimento de inovações globais.

Para o alcance desse objetivo foram seguidas as seguintes etapas: i) levantamento das principais pesquisas referentes as temáticas e desenvolvimento do questionário/survey; ii) construção do modelo e formulação das hipóteses da pesquisa e iii) teste empírico do modelo a partir do survey com as multinacionais estrangeiras. 
Tem-se como Objetivos Específicos (OE):

OE1: Estabelecer um diálogo entre as abordagens: empreendedorismo, redes de empresas e inovação;

OE2: Medir o grau de impacto do empreendedorismo da subsidiária e da sua inserção em redes sobre o desenvolvimento e transferência das inovações;

OE3: Analisar o impacto conjunto do empreendedorismo e das redes interorganizacionais sobre o desenvolvimento e transferência das inovações.

Uma vez traçados os objetivos, a seguir especifica-se a questão de pesquisa que se buscou responder:

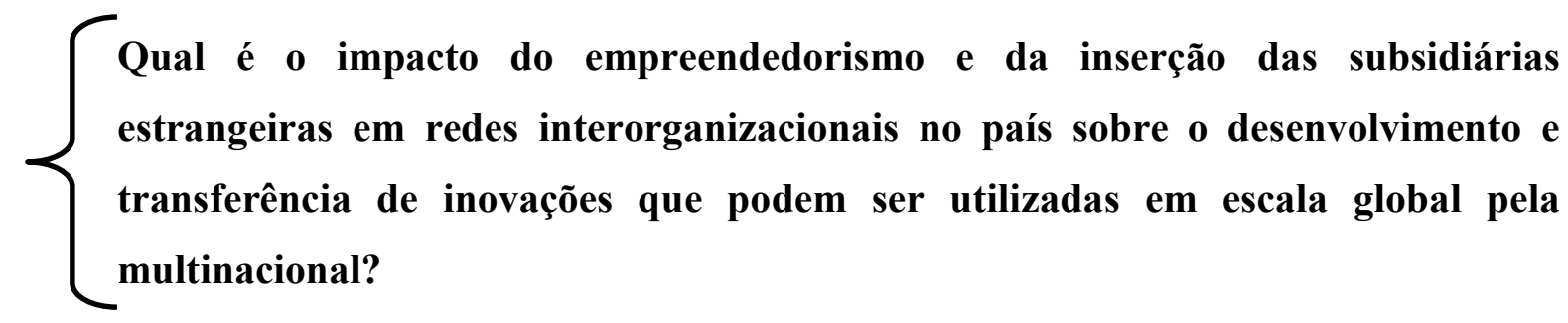

Especificamente, será discutido o papel do empreendedorismo e das redes interorganizacionais sobre o desenvolvimento de inovações realizadas localmente e com potencial de serem exploradas mundialmente, aqui chamada de inovação global.

\subsection{Premissas (PRE)}

As premissas são um ponto de partida para a organização de um raciocínio ou de uma argumentação (DPLP, 2015). Para essa pesquisa, assumem-se as seguintes premissas:

PRE1: As inter-relações propostas no modelo teórico podem ser observadas, ainda que de forma aproximada da realidade, a partir das percepções dos diretores e gerentes das subsidiárias coletadas no survey.

PRE2: Os membros da cúpula diretiva conhecem de forma profunda as atividades estratégicas desenvolvidas pelas subsidiárias e responderam o survey com fidedignidade. 


\subsection{Motivação, Relevância e Ineditismo da Pesquisa}

A motivação principal do estudo, da qual decorre sua relevância, tanto teórica quanto prática é a proposição de um diálogo entre três temáticas em evidência em negócios internacionais: inovação; empreendedorismo e redes de empresas. Essas temáticas necessitam ser mais exploradas e compreendidas, em particular em contextos de economias emergentes, onde muitas multinacionais estão aumentando os seus investimentos, uma vez que os mercados desenvolvidos estão ficando cada vez mais saturados enquanto que os mercados emergentes apresentam uma classe média em crescimento e com potencial para ser explorada. Ademais, os mercados emergentes também podem ser fonte de inovações locais que podem ser exploradas globalmente (GOVINDARAJAN e TRIMBLE, 2012).

Disso resulta o crescimento não somente do interesse da academia como também das multinacionais. Alguns dados justificam essa afirmação:

- Analisando-se os artigos relativos as temáticas abordadas nessa tese e publicados nos últimos dezesseis anos (Ilustração 2) com base nos dados da SCOPUS (2016), verifica-se que os temas Empreendedorismo e Economias Emergentes mantiveram a quantidade de publicações relativamente estável, apresentando um leve crescimento nos últimos anos. Enquanto que, os temas Redes e Inovação tiveram um crescimento substancial. Isso demonstra a relevância das quatro temáticas dentro da área de negócios internacionais. 


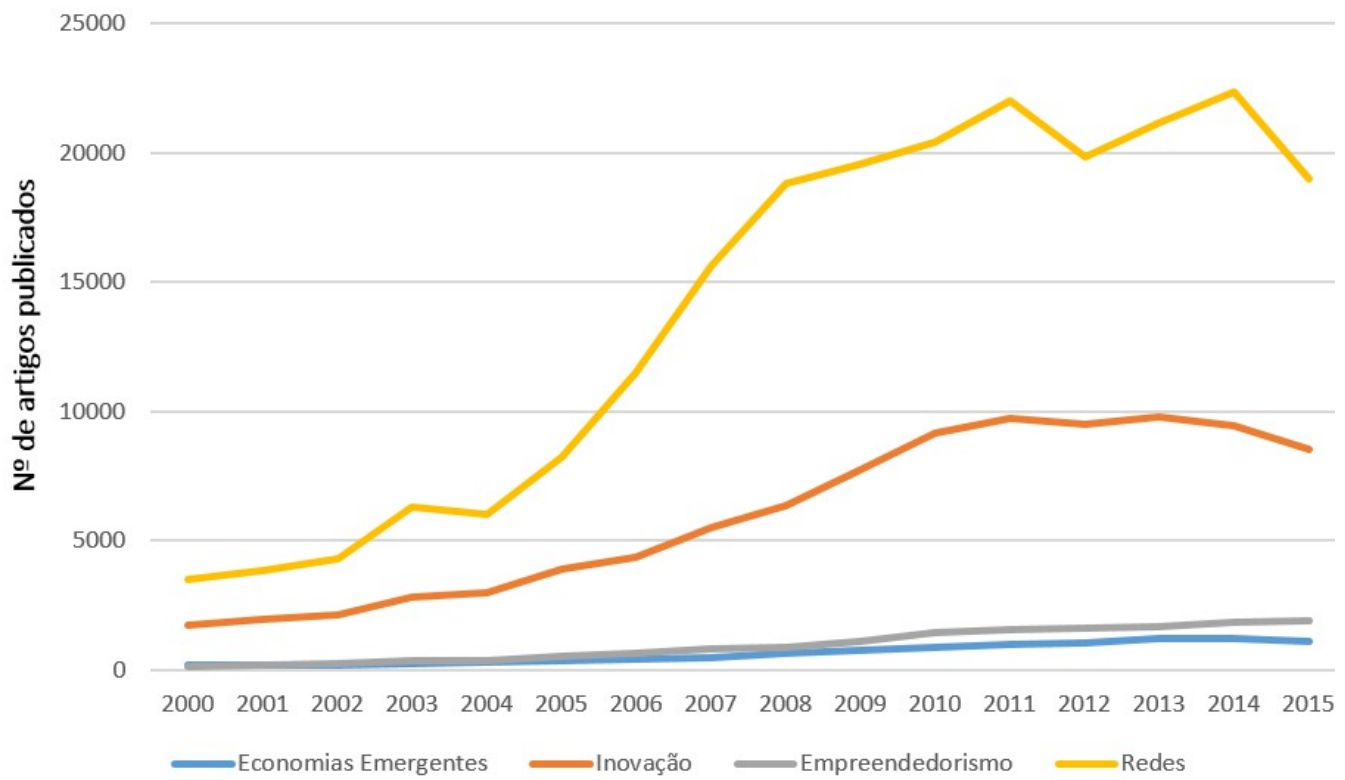

Ilustração 2 - Artigos publicados entre 2000 e 2015

FONTE: o autor com base nos dados da SCOPUS (2016)

- Analisando-se o ranking com os dez maiores destinos de $\operatorname{IDE}^{3}$ no mundo (Ilustração 3), o Brasil subiu da $7^{\mathrm{a}}$ posição em 2013 para a 6 $6^{\mathrm{a}}$ posição em 2014 no ranking dos destinos mais atrativos para investimentos produtivos, segundo relatório da agência da ONU para o Comércio e Desenvolvimento - $\mathrm{UNCTAD}^{4}$ (2015). Isso sugere um comprometimento das multinacionais com projetos de longo prazo e que impactam diretamente no desenvolvimento econômico do país, demonstrando a importância da temática das multinacionais.

${ }^{3}$ IDE: Investimento Direto Estrangeiro

${ }^{4}$ UNCTAD: Conferência das Nações Unidas sobre Comércio e Desenvolvimento 


\begin{tabular}{|c|c|}
$\begin{array}{l}\text { Ranking de Investimento Estrangeiro Direto } \\
\text { (em US\$ bilhões) }\end{array}$ \\
\hline País & $\mathbf{2 0 1 4}$ \\
\hline $1^{\circ}$ - China & 129 \\
\hline $2^{\circ}$ - Hong Kong & 103 \\
\hline $3^{\circ}$ - Estados Unidos & 92 \\
\hline $4^{\circ}$ - Reino Unido & 72 \\
\hline $5^{\circ}$ - Cingapura & 68 \\
\hline $\mathbf{6}^{\mathbf{0}}$ - Brasil & $\mathbf{6 2}$ \\
\hline $7^{\circ}$ - Canadá & 54 \\
\hline $8^{\circ}-$ Austrália & 52 \\
\hline $9^{\circ}$ - India & 34 \\
\hline $10^{\circ}$ - Holanda & 30 \\
\hline
\end{tabular}

\section{Ilustração 3 - Ranking de IDE}

FONTE: UNCTAD (2015)

Em termos prospectivos, o relatório da UNCTAD (2015) aponta o Brasil como um dos cinco principais destinos para investimentos estrangeiros nos próximos anos. O fluxo de IED é utilizado para a construção de fábricas, infraestrutura, empréstimos internos feitos por multinacionais e para fusões e aquisições de empresas. Trata-se, portanto, de um investimento importante para o país realizado em grande medida pelas MNCs estrangeiras, as quais realizam as suas operações a partir da instalação das suas subsidiárias - foco desse trabalho.

Além da importância econômica para o país, as subsidiárias também contribuem com inovações e tecnologias provenientes da matriz. Entretanto, essa pesquisa se preocupa com as inovações desenvolvidas localmente e que são transferidas para as MNCs, o que contraria o sentido habitual do fluxo das inovações e que é chamada de inovação reversa (GOVINDARAJAN e TRIMBLE, 2012). Esse é um assunto que tem despertado a atenção da academia e que será base para as discussões aqui apresentadas em conjunto com as abordagens de empreendedorismo e redes interorganizacionais. 
Embora essas temáticas sejam emergentes em negócios internacionais e a operação das MNCs sejam importantes para a economia e desenvolvimento do país, poucas são as pesquisas que endereçaram o assunto com foco no contexto brasileiro, ainda que analisando os temas aqui abordados separadamente. Nesse sentido, a pesquisa inova ao propor o estudo em conjunto dessas temáticas analisando uma amostra composta por cento e setenta e duas empresas multinacionais estrangeiras instaladas no Brasil a partir da modelagem de equações estruturais, metodologia que permite o teste e a análise conjunta das teorias aqui abordadas simultaneamente.

\subsection{Contribuições da Pesquisa}

Buscou-se com essa pesquisa ampliar a compreensão sobre os fenômenos que envolvem as subsidiárias de corporações multinacionais estrangeiras instaladas no país a partir do relacionamento empírico-teórico das abordagens de inovação, empreendedorismo e redes interorganizacionais. Especificamente, o presente esforço de pesquisa traz as seguintes contribuições:

\section{No Plano Teórico}

* Identificação dos fatores que influenciam no desenvolvimento de inovações nas subsidiárias;

* Exploração do modelo causal a partir da modelagem de equações estruturais realizada com base no referencial teórico desenvolvido e a obtenção de evidências empíricas sobre o desenvolvimento de inovações nas subsidiárias e eventual transferência dessas inovações para as MNCs, sob a perspectiva das abordagens de redes e empreendedorismo;

* Essa pesquisa traz contribuições metodológicas ao proceder testes exaustivos na amostra, servindo de guia para outras pesquisas.

\section{No Plano Gerencial}

O presente estudo traz contribuições específicas para os gerentes ao analisar questões que impactam na visibilidade da subsidiária como o desenvolvimento de iniciativas e de parcerias, e que podem auxiliar na compreensão do processo de desenvolvimento das inovações: 
* A identificação dos fatores que influenciam no desenvolvimento de inovações nas subsidiárias fornece informações que podem auxiliar na tomada de decisão dos executivos;

* Os investimentos estrangeiros são importantes para o país, de maneira que essa pesquisa sugere aos formuladores de políticas públicas a investirem no parque industrial nacional a fim de desenvolver potenciais parceiros na rede em que a subsidiária irá se inserir;

* Essa pesquisa também contribui ao fornecer evidências quanto ao empreendedorismo da subsidiária, uma vez que esse movimento estratégico é importante para aumentar a visibilidade da subsidiária e os recursos provenientes da matriz.

\subsection{Delimitação da Pesquisa}

O objeto de estudo nessa pesquisa são as subsidiárias de corporações multinacionais estrangeiras que operam no país a partir de dados oriundos de uma base amostral não probabilística por conveniência.

Três correntes teóricas embasam essa pesquisa: redes interorganizacionais, empreendedorismo e inovação. Essas abordagens teóricas se inter-relacionam, em particular, quanto as questões que envolvem o desenvolvimento e transferência das inovações realizadas nas subsidiárias. Assim sendo, essa pesquisa se aproxima de outros estudos (BARTLETT; GHOSHAL, 1986; ANDERSSON; FORSGREN; HOLM, 2002; BIRKINSHAW, 1997; GOVINDARAJAN, TRIMBLE, 2012) que endereçaram as questões inovativas dentro das empresas tanto em escopo local quanto global.

Por outro lado, essa pesquisa não pretende abordar a aplicação das abordagens aqui citadas com a finalidade de compreender os fatores que compõem o ambiente interno do país (PORTER, 1998) ou externo (MOON; RUGMAN; VERBEKE, 1998), como também não aprofundará aspectos relativos a rede interna das MNCs (ACHCAOUCAOU, MIRAVITLLES E LEON-DARDER, 2013), concentrando os esforços no entendimento das redes externas ou aqui também chamadas redes interorganizacionais. 
Particularmente, essa pesquisa investiga a importância das redes externas (interorganizacionais) e do empreendedorismo da subsidiária para o desenvolvimento de inovações. São discutidos os fatores essenciais e preponderantes para uma forte inserção das subsidiárias nas redes de empresas nacionais bem como as questões relacionadas com empreendedorismo da subsidiária, buscando entender as principais iniciativas que levam a subsidiária a aumentar a sua relevância dentro da corporação multinacional. A hipótese central é de que tanto o empreendedorismo da subsidiária quanto a sua inserção em redes interorganizacionais impactam positivamente no desenvolvimento e transferência das inovações. Paralelamente, são testados os efeitos mediadores e moderadores sobre o modelo proposto, onde buscou-se aferir o efeito mediador dos construtos redes de empresas e inovação local como também do efeito moderador que o porte da subsidiária possa ter sobre o modelo. $\mathrm{O}$ porte da subsidiária tem sido amplamente estudado pela comunidade acadêmica e reconhecido como sendo uma variável relevante.

\subsection{Estrutura da Tese}

A tese está estruturada em cinco capítulos que se iniciam com essa introdução. Buscou-se incialmente contextualizar a temática dentro da área de negócios internacionais mostrando onde a pesquisa se enquadra, a problemática que envolve o assunto bem como o objetivo, motivação e contribuições da pesquisa.

O segundo capítulo apresenta o referencial teórico que embasa as hipóteses e o modelo proposto. Em síntese, são discutidos os assuntos relacionados a temática de inovação, como: inovação em MNCs e inovação em mercados emergentes, cada qual com suas respectivas subdivisões e aprofundamentos. Em seguida são apresentadas as abordagens de redes interorganizacionais e empreendedorismo, onde serão discutidas as suas características e influências sobre o desenvolvimento e transferência de inovações realizadas nas subsidiárias. Por fim, tem-se um fechamento do referencial teórico apresentando os principais pontos do capítulo e a proposição do modelo teórico da tese.

O terceiro capítulo apresenta as regras e diligências estabelecidas para realizar essa pesquisa a fim de embasar os resultados e as conclusões aqui apresentadas. Assim, são descritas as etapas metodológicas adotadas, sua justificativa, operacionalização e limitações. Em síntese, 
essa pesquisa caracteriza-se como sendo quantitativa, faz uso de dados primários (survey) os quais foram submetidos a técnica estatística de equações estruturais.

O quarto capítulo apresenta os resultados encontrados e sua devida interpretação.

Por fim, o quinto capítulo reúne as conclusões, englobando considerações sobre diversos aspectos da pesquisa, limitações e sugestões para trabalhos futuros.

Em síntese a tese está estruturada conforme a Ilustração 4:

\begin{tabular}{|c|c|c|}
\hline \multicolumn{3}{|c|}{ CORPORAÇÕES MULTINACIONAIS ESTRANGEIRAS INSTALADAS NO BRASIL } \\
\hline INOVAÇÃO & EMPREENDEDORISMO & REDES \\
\hline $\begin{array}{l}\text { i. Importância da Subsidiária; } \\
\text { ii. Ganhos competitivos; } \\
\text { iii. Exploração das ideias locais. }\end{array}$ & $\begin{array}{l}\text { i. Iniciativas da subsidiária; } \\
\text { ii. Visibilidade da subsidiária; } \\
\text { iii. Atividades inovadoras. }\end{array}$ & $\begin{array}{l}\text { i. Processo de internacionalização; } \\
\text { ii. Desenvolvimento de inovações; } \\
\text { iii. Transferência de inovações. }\end{array}$ \\
\hline \multicolumn{3}{|c|}{$\begin{array}{l}\text { Qual é o impacto do empreendedorismo e da inserção das } \\
\text { subsidiárias estrangeiras em redes interorganizacionais no país } \\
\text { sobre o desenvolvimento e transferência de inovações globais? }\end{array}$} \\
\hline \multicolumn{3}{|c|}{ HIPÓTESES E DESENVOLVIMENTO DO QUESTIONÁRIO } \\
\hline \multicolumn{3}{|c|}{ PROCEDIMENTOS METODOLÓGICOS } \\
\hline \multicolumn{3}{|c|}{ RESULTADOS } \\
\hline \multicolumn{3}{|c|}{ CONCLUSÕES } \\
\hline
\end{tabular}

Ilustração 4: Estrutura da tese

FONTE: o autor 


\section{REFERENCIAL TEÓRICO}

Quatro seções nortearão o referencial teórico. Inicialmente será discutido o papel da inovação e sua importância para as subsidiárias, bem como os seus desdobramentos sobre a estratégia da multinacional. Dentro dessa seção serão discutidas ainda características dos mercados emergentes e sua importância para a estratégia de inovação das corporações multinacionais. A seção seguinte versará sobre as redes de empresas, onde serão abordados os fatores que caracterizam as redes e sua influência sobre o desenvolvimento de competências e inovações na subsidiária. A terceira seção explanará sobre a orientação empreendedora das subsidiárias e o seu relacionamento com os demais temas. Por fim, há uma discussão sobre o porte da subsidiária e a sua influência sobre a estratégia.

\subsection{Inovação}

A partir do desenvolvimento industrial e tecnológico advindos da revolução industrial e consequente industrialização dos países, a temática da inovação começou a ser mais amplamente discutida. Muitas pesquisas desenvolvidas nos últimos anos sobre a temática da inovação estão ancoradas, sobretudo, no manual de Oslo (OCDE, 2004). O governo brasileiro tem desenvolvido pesquisas sobre a temática da inovação em consonância com o manual de Oslo (PINTEC, 2013).

A inovação por si só não provê uma mensuração direta (GAULT, 2013) e isso tem sido um grande desafio para os pesquisadores. Entretanto, ao longo dos últimos trinta anos muitas diretrizes têm sido propostas a fim de guiar, servir de subsídios para a avalição da inovação e permitir a reprodutibilidade ao longo do tempo e sua comparabilidade. Dentre esses esforços destaca-se o manual de Oslo (OCDE, 2004) a partir da investigação de alguns indicadores importantes para a averiguação da inovação. Muitos dados são utilizados para a construção de um indicador como amostras provenientes de surveys e patentes, os quais são utilizados como uma proxy para mensurar a inovação. Os indicadores provenientes das surveys desenvolvidas pela OCDE (2004) e pela PINTEC (2013) mostram o esforço realizado pelas empresas para promover a inovação. Outra medida de inovação amplamente adotada, embora controversa, são as patentes. As patentes assim como os surveys são utilizados como um indicador proxy 
para a inovação. E possuem a vantagem de estarem disponíveis e de serem compreensíveis (GAULT, 2013).

Essa tese faz uso das variáveis provenientes de um survey para tentar compreender mais detalhadamente os fatores que antecedem o desenvolvimento e transferência das inovações realizadas na subsidiária. Inicialmente pensou-se em utilizar os dados provenientes das patentes, entretanto, os dados de patentes são escassos para as empresas que operam no Brasil (GII, 2015) e por essa razão resolveu-se trabalhar apenas com os dados primários provenientes do survey.

A OCDE (2004) em nível internacional e a PINTEC (2013) no Brasil tem organizado surveys a fim de entender o estado atual da inovação e sua comparabilidade com as diferentes regiões do globo. E segundo essas pesquisas, uma empresa pode desenvolver ou manter sua vantagem competitiva a partir de uma inovação que propicie um aumento da demanda pelos seus produtos (melhor qualidade, novos produtos, novos mercados); diminuição dos custos (com a produção, compras, distribuição ou transação); ou a partir do aumento de sua capacidade para desenvolver novos processos. Sob a perspectiva das inovações em processo, elas baseiam-se, sobretudo, em melhorias tecnológicas, sendo difícil a detenção e proteção dessas tecnologias por muito tempo, abrangendo tanto métodos de produção ou logística novos quanto significativamente aperfeiçoados, o que implica fazer uso de novas ou aperfeiçoadas técnicas, equipamentos ou softwares de maneira a aumentar a eficiência produtiva ou logística seja pela diminuição dos custos ou elevação da qualidade dos bens e serviços. Sob a perspectiva das inovações em produtos, esses referem-se tanto a produtos novos quanto a aperfeiçoados (ex.: smartphones mais rápidos ou com novas funcionalidades) o que pode levar uma empresa a adquirir um alto status rapidamente e até mesmo estabelecer o padrão de mercado.

A inovação pode ser entendida como a implementação de um produto (bem ou serviço) ou de um processo novo ou significativamente melhorado, sendo que a sua concretização se dá somente depois que esse produto é oferecido ao mercado, ou depois da implementação do processo (OECD, 2004; TIDD; BESSANT e PAVITT, 2008). Hamel e Breen (2007) apontam que os dois tipos de inovações mais pesquisadas são as inovações em produto e processo. Nesse sentido, essa tese focou no estudo das inovações ocorridas em produto e processo. 
Quanto a fonte da inovação, Chesbrough (2012) esclarece que ela pode vir de dois caminhos distintos:

i. De dentro da empresa, baseado principalmente no P\&D interno;

ii. Fontes externas à empresa, baseado nas parcerias e redes de colaboração.

De modo geral, as empresas se especializaram em desenvolver suas inovações de forma solitária a partir tão somente dos seus centros de pesquisas. Entretanto, esse modelo encontrou barreiras quanto a limitação das ideias e do encarecimento do desenvolvimento das inovações, que passaram a ter seus ciclos de desenvolvimento cada vez mais curtos. Em oposição a esse modelo, as empresas podem utilizar não somente as ideias desenvolvidas internamente como também as provenientes de fontes externas como: fornecedores, clientes e universidades. Aumentando assim as possibilidades de inovação da empresa, ao que é chamado de inovação aberta. A inovação aberta é baseada na busca por vantagens competitivas a partir da intensificação dos relacionamentos com os parceiros externos (CHESBROUGH, 2012).

As ideias expostas por Chesbrough (2012) dialogam com outros estudos (TANG; MU; MACLACHLAN, 2008; UZZI; LANCASTER, 2003; FORSGREN; HOLM; JOHANSON, 2005; ANDERSSON; FORSGREN; HOLM, 2002) que mostraram que a inserção das subsidiárias em redes interorganizacionais influencia significativamente no desenvolvimento e transferência de competências e inovações.

Uma característica marcante da multinacional é a sua capacidade de adquirir e utilizar conhecimentos em diferentes partes do mundo a partir de suas subsidiárias (GUPTA; GOVINDARAJAN, 2000; MICHAILOVA; MUSTAFFA, 2012), de maneira que estes conhecimentos podem impactar no desenvolvimento de inovações. Nesse sentido Dellestrand (2011) acrescenta que a inovação nas subsidiárias é uma atividade chave para a multinacional, uma vez que essa inovação pode ser transferida e utilizada por toda a corporação.

A partir dos anos 1980 surgiram outras conceituações, originando a ideia de que o conhecimento adquirido pelas subsidiárias pode gerar vantagem competitiva para a corporação como um todo, o que torna as subsidiárias participantes ativas na formulação e aplicação de estratégias (BARTLETT; GHOSHAL, 1989; BIRKINSHAW et al., 1998; 
MICHAILOVA; MUSTAFFA, 2012; RUGMAN; VERBEKE; YUAN, 2011). Com a alteração da visão hierárquica para uma visão da empresa por meio de redes, um número crescente de estudos passou a considerar as subsidiárias, além da matriz, como ponto central de análise (ANDERSSON; FORSGREN; HOLM, 2002; MICHAILOVA; MUSTAFFA, 2012; RUGMAN et al., 2011). ,

Dentro do contexto geográfico e econômico em que operam, as subsidiárias podem produzir inovações que podem extrapolar as fronteiras tornando-se inovações globais. Nesse sentido, a indústria automotiva fornece muitos exemplos, a Renault comercializa no Brasil carros que foram desenvolvidos no leste europeu, enquanto que a Ford desenvolveu um modelo de utilitário no Brasil que hoje é vendido em vários países. Essa temática será mais explorada na próxima seção, onde serão aprofundadas as questões que envolvem os mercados emergentes e o desenvolvimento de inovações voltadas para a realidade desses países.

\subsubsection{Inovação em Mercados Emergentes - Inovação Local}

São crescentes os estudos sobre as economias emergentes, em especial Brasil, Rússia, Índia e China - BRICs (O`NEILL, 2001). Dentre as previsões realizadas nos últimos anos (GOLDMAN SACHS, 2010; 2003) acredita-se que a economia dos BRICs contribua com quase a metade do crescimento do PIB mundial e que suas economias em conjunto possam se tornar daqui a menos de quarenta anos maiores que as dos seis países mais desenvolvidos do mundo. Esse cenário tem orientado a estratégia das multinacionais que buscam intensificar seus esforços e investimentos nos mercados emergentes (UNCTAD, 2010).

A classe média nos mercados emergentes tem crescido fortemente (GOLDMAN SACHS, 2010), no Brasil ela já responde por mais da metade da população (BRASIL, 2012), esse crescimento traz consigo novas oportunidades para as empresas que podem ter suas vantagens competitivas aumentadas com a introdução de inovações que possam suprir necessidades pouco exploradas pela estratégia do menos por menos, onde as empresas trabalham com margens de lucro muito baixas para vender produtos a baixo custo e não raro faltando muito dos opcionais presentes em mercados desenvolvidos. 
De acordo com os dados do Gráfico 1 fornecidos pelo $\mathrm{BACEN}^{5}$ (2015) os dez países que mais investiram no Brasil nos últimos quatorze anos são, em ordem decrescente: Países Baixos; Estados Unidos; Luxemburgo; Espanha; Japão; França; Suíça; Ilhas Cayman (território Britânico); Alemanha e Canadá.

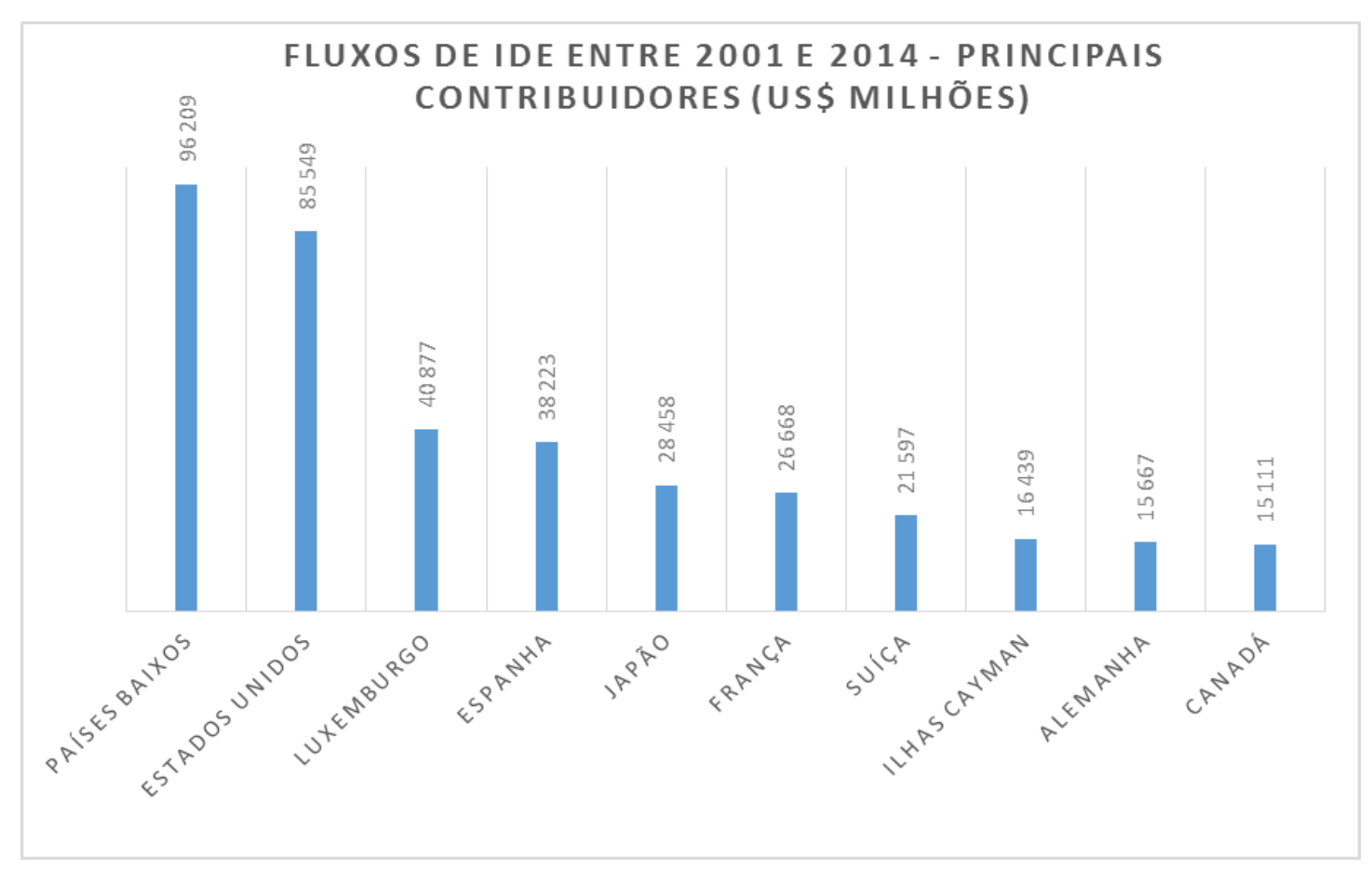

Gráfico 1: Fluxos de IDE entre 2001 e 2014 - Principais contribuidores FONTE: o autor com base nos dados do BACEN (2015)

Os dados do BACEN (2015) também permitem analisar quais foram as regiões que mais investiram no Brasil:

${ }^{5}$ BACEN: Banco Central do Brasil 
Gráfico 2: Fluxo de IDE entre 2001 e 2014 por regiões

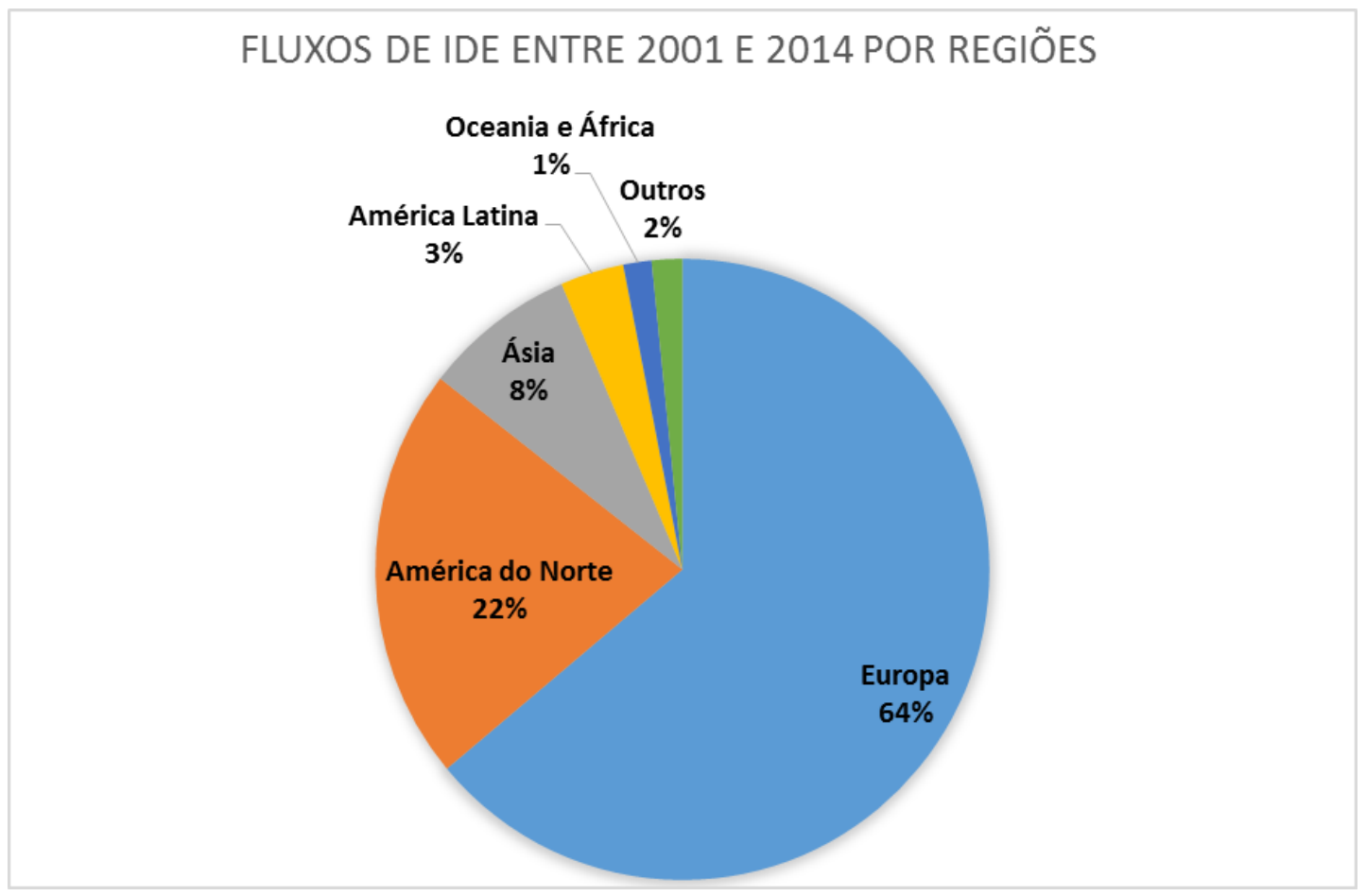

FONTE: o autor com base nos dados do BACEN (2015)

A partir da análise de crescimento dos cinco principais países que mais investiram, nota-se que os investimentos cresceram ao longo da série temporal.

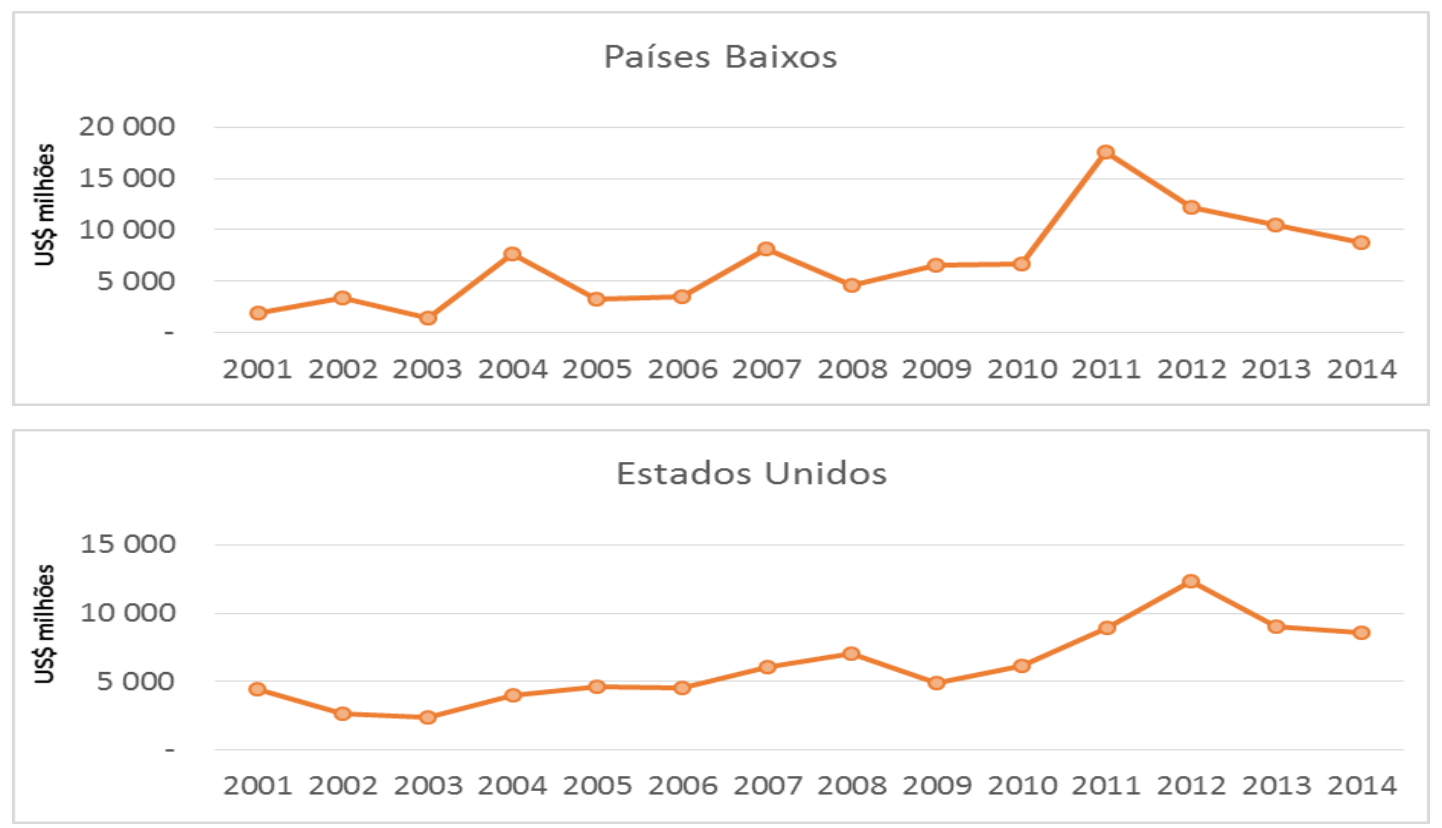




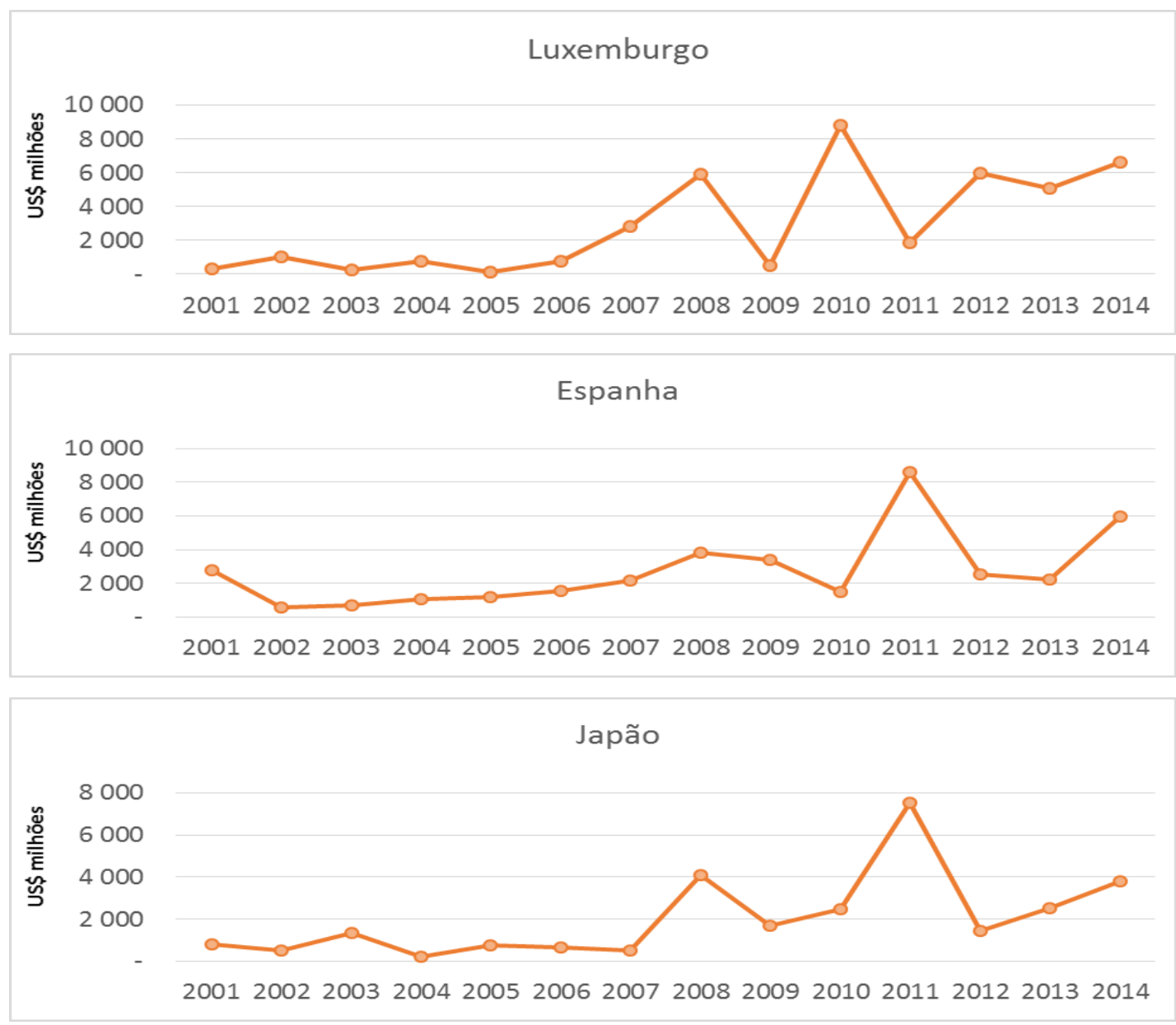

Gráfico 3: Cinco principais fontes de IDE no Brasil

FONTE: o autor com base nos dados do BACEN (2015)

Esses dados sugerem o quão interessante é o mercado brasileiro e que as multinacionais estrangeiras estão dispostas a fazerem investimentos de longo prazo. Esses investimentos podem ser direcionados para o desenvolvimento de inovações, ao passo que o governo brasileiro tem feito esforços para estimular a inovação na indústria. Um desses esforços é o programa federal Inovar-Auto, que visa não somente fomentar a inovação na indústria automotiva como também investir na capacitação da rede de empresas fornecedoras (MDIC, 2016). O desenvolvimento dessas inovações pode ser potencializado quando as subsidiárias se inserem nas redes de empresas locais, uma vez que os parceiros permitem suplantar problemas institucionais (KHANA; PALEPU; BULLOK, 2010) além da utilização dos parceiros como intermediadores (LONDON; HART, 2004), situações que costumam ocorrer com as multinacionais oriundas de países desenvolvidos atuando em mercados emergentes (EYRING et al., 2011). Ademais, a qualidade das relações entre os parceiros na rede está 
associada com o desenvolvimento de inovações que por sua vez impactam no desempenho dos negócios da subsidiária (HALLIN et al., 2011).

Se nos modelos tradicionais o desenvolvimento de inovações e capacidades era centralizado na matriz, posteriormente foi alocado em subsidiárias, tanto que, a transferência de inovação das subsidiárias a matriz tem encontrado apoio em discussões de subsidiárias de empresas multinacionais nos países desenvolvidos (HAKANSON; NOBEL, 2000; MINBAEVA, 2008; YANG et al., 2008) e de países emergentes conforme mostraram (D’AGOSTINO; SANTANGELO, 2012) ao identificarem em seu estudo empresas multinacionais instaladas nos países dos BRICSTs (Brasil, Rússia, Índia, China, Cingapura e Taiwan) os quais contribuem para a criação de conhecimento no país sede dessas empresas (matriz).

Entretanto, por décadas, uma das partes fundamentais da estratégia das multinacionais tem sido o fluxo de inovação de mercados ricos para mercados pobres. Tendo desenvolvido produtos para os mercados domésticos, as empresas os modificavam, na maioria das vezes tirando muitas de suas características, e depois os distribuíam ao redor do mundo a preços mais baixos (GOVINDARAJAN, 2012). Algumas empresas ainda acreditam que para vencer em mercados emergentes é preciso utilizar a estratégia do menos por menos. Entretanto, este modelo é insuficiente para suprir as necessidades dos mercados emergentes (EYRING; JOHNSON; NAIR, 2011; MARKIDES, 2012).

As nações emergentes não são mais apenas receptoras de inovação e capacidades desenvolvidas por multinacionais de nações desenvolvidas, são também fonte de vantagem competitiva para as subsidiárias estrangeiras que operam nesses países (GOVINDARAJAN; RAMAMURTI, 2011; GOVINDARAJAN; TRIMBLE, 2012). Tal como mostram alguns artigos que tem como objeto de estudo subsidiárias localizadas em mercados emergentes, como o Brasil (BOEHE, 2010; FIGUEIREDO, 2011). 


\subsubsection{Inovação Reversa}

A temática da inovação reversa tem movimentado estudiosos e empresários, entretanto, sua operacionalização tem se mostrado um desafio para as empresas, sendo mais fácil aceitá-la do que colocá-la em prática. E, embora as grandes multinacionais não questionem os benefícios que podem ser colhidos a partir dessa estratégia, poucas foram as multinacionais que conseguiram emplacar produtos ou serviços globais utilizando-se da inovação reversa, notadamente: Microsoft, GE, Nestlé, PepsiCo, Renault, Procter \& Gamble e Coca-Cola. Mesmo gigantes provenientes dos mercados emergentes como o grupo Tata ou a Mahindra \& Mahindra tem tido dificuldade em criar produtos que atendam a mercados tão distintos quanto são os mercados desenvolvidos e os em desenvolvimento (WINTER; GOVINDARAJAN, 2015).

A fim de diferenciar o processo de inovação convencional e o orientado para os mercados em desenvolvimento, importa compreender o fluxo dessas inovações, se elas fluem dos mercados desenvolvidos para os mercados emergentes ou se, de modo contrário ao tradicional, essas inovações foram desenvolvidas para os mercados emergentes e então transferidas para os mercados desenvolvidos, ainda que com pequenas variações. Assim, define-se o processo de transferência de inovações destinadas a atender especificidades de países menos desenvolvidos para países desenvolvidos de inovação reversa a qual será chamada nessa tese como inovação local.

A inovação local requer uma mudança cultural que desloque o foco de exportar para o mercado emergente para um foco em inovar para mercados emergentes. Os clientes nos mercados emergentes vivem em contextos diferentes os quais não raro geram necessidades diferentes, de maneira que para aproveitar as oportunidades é necessário projetar novos produtos voltados para as suas realidades. A partir da inovação reversa as empresas podem capturar as oportunidades de negócios somente quando desenham produtos apropriados.

Alguns casos bem-sucedidos ocorridos em multinacionais renomadas como Coca-Cola, Microsoft, PepsiCo, Procter \& Gamble e outras, ilustram e nos ajudam a responder as questões aqui levantadas. Um caso bastante ilustrativo é o da empresa General Electric (GE). 
Há alguns anos a GE entendeu que para ser bem-sucedida nos Estados Unidos seria necessário ser bem-sucedida nos mercados emergentes. Os mercados desenvolvidos estão ficando cada vez mais saturados enquanto que os mercados emergentes apresentam uma classe média em crescimento e com potencial para ser explorada. A GE vislumbrou que poderia aumentar a sua vantagem competitiva ao buscar e desenvolver inovações em países em desenvolvimento e transferi-las para os mercados desenvolvidos (GOVINDARAJAN; TRIMBLE, 2012). Ou em outros termos, apesar de as empresas contarem com centenas de cientistas em seus centros de $\mathrm{P} \& \mathrm{D}$ trabalhando incansavelmente em projetos de inovação, a produtividade da inovação está em declínio enquanto os custos de desenvolvimento de novos produtos estão crescendo. Em sentido contrário, os ciclos de tempo da indústria e os ciclos de vida dos produtos continuam sendo reduzidos rapidamente (NAMBISAN; MOHANBIR, 2011). A partir desse cenário, as multinacionais estão promovendo uma mudança da inovação centrada apenas na matriz para uma inovação onde as demais empresas do grupo (subsidiárias) participem cada vez mais do processo de inovação dentro da corporação.

Dentro dessa perspectiva, houve também uma mudança na estratégia da GE que antes atuava de forma tradicional vendendo produtos globais com algumas adaptações as necessidades locais. O que resulta em muitos casos no não atendimento das demandas locais devido a pouca atenção aos mercados regionais e suas peculiaridades, perdendo assim o diferencial estratégico que lhe poderia proporcionar maior adequação ao mercado. A GE insistiu na estratégia de fazer pequenas adaptações em seus produtos e então vende-los no mercado indiano, entretanto, os resultados ficaram abaixo do esperado o que forçou a empresa a repensar sua estratégia de adaptação dos produtos e a buscar por inovações apropriadas a realidade local (GOVINDARAJAN; TRIMBLE, 2012).

A partir dessa mudança estratégica, a GE começou a pensar em inovações voltadas para a realidade local onde a sua subsidiária atua. Foi assim que surgiu o aparelho de eletrocardiograma MAC 400, projetado e construído pela divisão de equipamentos médicos da GE na Índia. Por fim, o MAC 400 recebeu todas as certificações internacionais de regulamentação podendo assim ser vendido globalmente. E embora tenha sido concebido para as idiossincrasias rurais da Índia, teve boa receptividade nos mercados desenvolvidos, onde médicos em consultórios que não podiam arcar com equipamentos mais sofísticados o 
adquiriram. O MAC 400 teve ampla divulgação em exposições internacionais sendo vendido globalmente com exceção dos USA e do Canadá onde são vendidos um modelo desenvolvido na China o MAC 800. O MAC 800 é um equipamento substancialmente mais desenvolvido que o MAC 400 possuindo uma versão mais sofisticada de software, teclado integrado, monitor com tela de 7 polegadas, impressora maior e maior complexidade técnica. O MAC 800 foi desenvolvido pela equipe de equipamentos médicos da GE na China no mesmo período em que a equipe indiana desenvolvia o MAC 400, de maneira que são projetos distintos, porém com algumas características semelhantes como:

\footnotetext{
므 É portátil, embora substancialmente mais pesado;

․ Funciona com corrente ou com sua bateria interna recarregável;

- Embora destinado para cidades também se adequa a áreas rurais.
}

A exploração dessas oportunidades pela multinacional pode ser realizada através de suas subsidiárias espalhadas pelo globo a exemplo do desenvolvimento do MAC 400 pela subsidiária indiana da GE, a qual após constatar um problema regional utilizou com excelência os conhecimentos sobre as necessidades locais e sobre o mercado a partir do uso da poderosa infraestrutura propiciada pela multinacional, o que resultou no desenvolvimento de um produto que superou as expectativas locais e se tornou global.

O desenvolvimento de inovações pelas multinacionais tem se dado, sobretudo, nos países desenvolvidos. Tradicionalmente essas multinacionais tem tido sucesso em concentrar suas expertises e pontos fortes na matriz em seus países de origem e apenas fazer um clone de suas operações e habilidades no resto do mundo, ou terceirizando a manufatura dos seus produtos. Um exemplo disso ocorre com o Iphone da Apple, o qual é desenvolvido nos Estados Unidos e produzido pela Foxconn em países como Brasil e China, sendo essa estratégia amplamente adotada por inúmeras multinacionais.

A vasta literatura sobre a internacionalização das empresas, especificamente a que trata sobre as estratégias utilizadas pelas multinacionais, revela que as três estratégias mais utilizadas são: i) estratégia global; ii) estratégia multidoméstica e iii) estratégia transnacional. As grandes multinacionais possuem escopo global e algumas mantêm-se atentas as diferenças regionais, procurando adequar-se as necessidades locais. Esse tipo de estratégia é chamada de 
transnacional, onde a corporação multinacional busca agregar as vantagens das estratégias global e multidoméstica, procurando simultaneamente a eficiência global e a sensibilidade as peculiaridades locais. A estratégia transnacional está no cerne da inovação reversa, pois alinha uma visão global com um foco intenso nas necessidades e preferências locais.

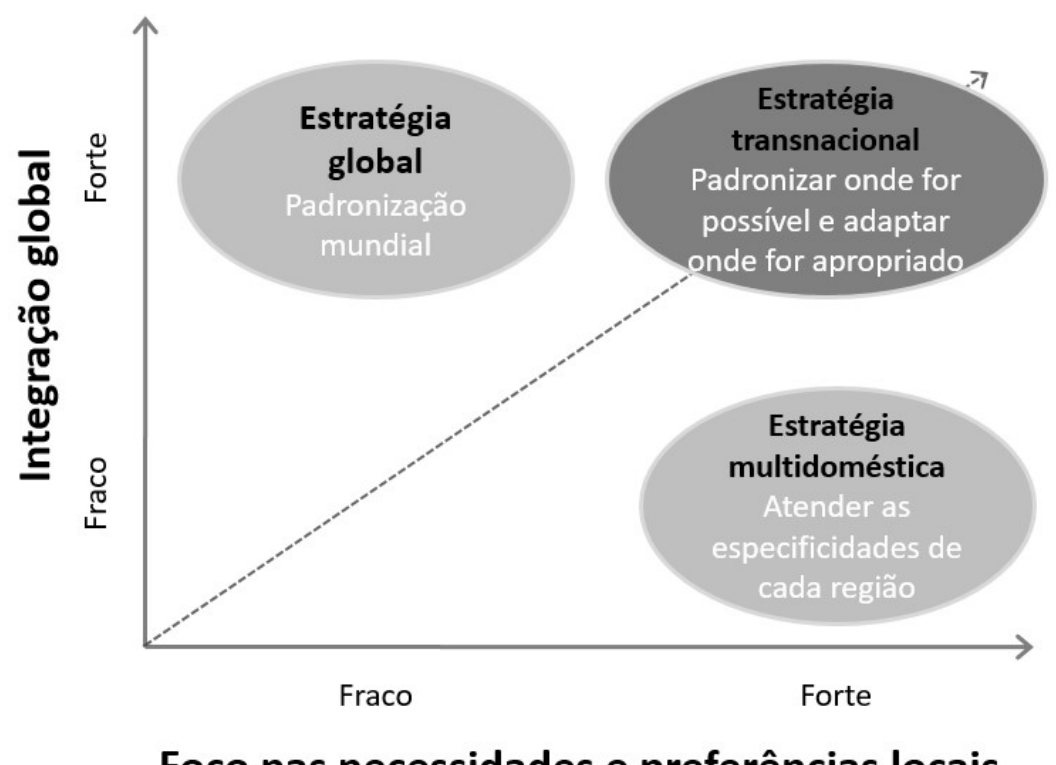

Foco nas necessidades e preferências locais

\section{Gráfico 4 - Estratégias tradicionais utilizadas pelas multinacionais}

FONTE: Costa (2012)

Voltando ao caso do desenvolvimento do MAC 400, a GE estava se esforçando para seguir as diretrizes da estratégia transnacional ao decidir descentralizar o P\&D da empresa e inaugurar o primeiro centro de pesquisa fora dos Estados Unidos, o qual seria mais tarde responsável por desenvolver o MAC 400. A criação de P\&D fora da matriz com consequente desenvolvimento de competências na subsidiária é outra característica marcante da estratégia transnacional. Característica essa compartilhada pelas empresas mencionadas no início do capítulo, as quais possuem centros de pesquisa e desenvolvimento em muitos países emergentes.

A expansão para as economias emergentes não se dá à toa, alguns fatores chave ajudam a compreender essa estratégia das multinacionais:

- Saturação dos mercados desenvolvidos;

- Surgimento de um conjunto de países emergentes os quais respondem por quase a metade da riqueza gerada no mundo; 
- Crescimento da classe média nesses países.

Esses fatores têm reforçado a necessidade de uma mudança na atenção e tratamento dado aos consumidores dos países emergentes. Um caminho motivado pela rentabilidade e expansão da corporação multinacional ancorados nas atividades de pesquisa e desenvolvimento e que agora, começa a ser trilhado mais seriamente fora dos grandes mercados desenvolvidos a partir da inovação reversa.

Alguns exemplos têm demostrado que os países emergentes podem atuar como protagonistas no desenvolvimento de inovações desenhadas para as suas realidades e eventual transferência dessas inovações para os mercados desenvolvidos, promovendo uma inversão dos papéis tradicionais e por isso mesmo sendo chamada de inovação reversa.

Embora a inovação reversa guarde estreita relação com a estratégia transnacional, o caso do MAC 400 mostra que a GE precisou repensar a sua estratégia de "padronizar onde for possivel e adaptar onde for apropriado" e partir para uma verdadeira inovação voltada para realidade local, sem com isso abrir mão dos seus anseios globais. A partir da necessidade da empresa de ter baixo custo e de descentralizar o desenvolvimento das inovações, ela concedeu o desenvolvimento a equipe regional de um produto voltado para as necessidades locais. $\mathrm{E}$ embora as teorias de estratégia das multinacionais tenham sido bem-sucedidas em explicar o desenvolvimento e transferência de inovações entre mercados desenvolvidos, pouco foi dito sobre a possibilidade dessas inovações fluírem dos mercados em desenvolvimento para os mercados desenvolvidos. Ademais, se a estratégia vigente tivesse sido satisfatória para o desenvolvimento do MAC 400 não teria havido a necessidade de reformula-la.

O mundo mudou e as estratégias que antes davam lucro e sucesso as multinacionais precisam ser repensadas. O velho modelo de replicar os conhecimentos e técnicas da matriz ao redor do mundo não é mais a maneira mais eficiente de fazer negócios. Os executivos devem flexibilizar a empresa ao ponto de romper as fronteiras e fazer uso dos conhecimentos e técnicas desenvolvidos em outras regiões no mundo sem perder a visão global de suas operações. E entender que o uso das estratégias empregadas nos mercados desenvolvidos não é eficiente nos mercados emergentes. 


\section{Mas afinal o que é mesmo inovação reversa?}

Uma vez construída a ponte entre inovação e as estratégias das multinacionais, importa agora compreender o fluxo dessas inovações, se elas fluem dos mercados desenvolvidos para os mercados emergentes ou se, de modo contrário ao tradicional, essas inovações foram desenvolvidas para os mercados emergentes e então transferidas para os mercados desenvolvidos? Outras questões relevantes são: - O produto desenvolvido é apenas uma adaptação ou totalmente novo? - Fazer apenas uma adaptação do produto será suficiente para alcançar os objetivos corporativos? Essas indagações estão na base da definição da inovação reversa.

Segundo Govindarajan e Trimble (2012), historicamente as inovações reversas têm sido raras. O motivo de a grande maioria das inovações fluírem dos mercados desenvolvidos para os em desenvolvimento é que os clientes de países ricos conseguem pagar e por isso exigem produtos melhores e mais recentes. Assim, as multinacionais têm desenvolvido os seus produtos orientando-se pelos clientes ricos e quando exportam esses produtos para mercados em desenvolvimento remetem versões simplificadas ou com menos recursos, o que leva a uma inadequação as necessidades locais. Habilmente, a GE percebeu que apenas a adaptação dos produtos prevista pela estratégia transnacional não seria suficiente para abraçar as complexidades e diferenças dos mercados emergentes. Ademais, embora a GE não soubesse disso no momento do desenvolvimento do MAC 400, a partir de um produto inovador construído para atender necessidades típicas de países em desenvolvimento, é possível que surjam produtos capazes de surpreender e atrair clientes em mercados desenvolvidos.

A inovação reversa requer uma mudança cultural que desloque o foco de exportar para o mercado emergente para um foco em inovar para mercados emergentes. Os clientes nos mercados emergentes vivem em contextos diferentes os quais não raro geram necessidades diferentes, de maneira que para aproveitar as oportunidades é necessário projetar novos produtos voltados para as suas realidades.

Além da mudança de foco, as multinacionais precisam estar atentas a ameaça representada pelas multinacionais provenientes desses mercados emergentes. Essas multinacionais emergentes estão dispostas a competirem globalmente. E as multinacionais estabelecidas, ou provenientes dos mercados desenvolvidos, temem muito mais competir contra uma 
multinacional emergente a qual eles não conhecem do que competir contra uma multinacional renomada e bem conhecida, pois contra os grandes competidores elas já estão habituadas a lidar, atacar e se defender. Não são poucas as multinacionais que estão decidindo investir em inovações nesses mercados emergentes e as tornando globais, pois de modo contrário esse trabalho será realizado pelas multinacionais emergentes, as quais utilizarão essas inovações como plataformas para produtos globais. Então, ao contrário do que poderia parecer em outros tempos, os riscos agora são globais e não locais, uma vez que as multinacionais emergentes de hoje podem ser as multinacionais estabelecidas de amanhã. Assim, a mensagem que fica é: deixar de fazer inovação reversa não é apenas perder uma oportunidade no exterior, mas pode significar uma perda no próprio mercado doméstico, tendo-se em mente que, manter a vantagem competitiva sobre os concorrentes é um fator determinante para o sucesso duradouro.

Pesquisas anteriores (BARTLETT e GHOSHAL, 1990) já haviam repostado que inovações desenvolvidas pelas subsidiárias para atender especificidades locais poderiam frequentemente serem comercializadas globalmente. Govindarajan e Trimble (2012) exploraram essa ideia e evidenciaram que esse movimento está aumentando.

A partir do entendimento de que as inovações desenvolvidas em mercados em desenvolvimento são passíveis de se tornarem globais, propõem-se a primeira hipótese:

H1: O desenvolvimento de inovações locais impacta positivamente no desenvolvimento de inovações globais 


\subsection{Redes de Empresas}

“Toda organização é afetada pelo avanço das redes. Já não há quase lugares sossegados onde os gestores possam confortavelmente encarar seu trabalho de uma perspectiva centrada na empresa" (KLEINDORFER; WIND e GUNTHER, 2012, p. 7).

Alguns estudos (TANG; MU; MACLACHLAN, 2008; UZZI; LANCASTER, 2003) têm mostrado que a criação de conhecimento e sua transferência estão positivamente relacionados com a inserção em redes de empresas. Outros autores têm investigado a relação entre a inserção na rede e o desenvolvimento de inovações na subsidiária (FORSGREN; HOLM; JOHANSON, 2005).

Essa inserção na rede pode ser caracterizada por um alto nível de confiança entre os parceiros, compartilhamento de informações, relacionamento próximo e de longa duração (ANDERSSON; FORSGREN; HOLM, 2001; KALE; SINGH; PERLMUTTER, 2000; DYER; NOBEOKA, 2000), o que permite a subsidiária acessar novos conhecimentos, ideias e oportunidades no país hospedeiro (ANDERSSON; FORSGREN; HOLM, 2002). Li (2012) acrescenta que uma forte inserção na rede não somente ajuda as empresas a superarem as barreiras de transferência de conhecimento como também reduz o custo dessas transferências com as empresas locais.

As estratégias de inovação das subsidiárias estrangeiras são importantes para a constituição da vantagem competitiva das multinacionais (BIRKINSHAW, 2001), de maneira que os estudos que abordam a temática das empresas multinacionais enveredaram por entender quais fatores estão associados ao desenvolvimento da inovação. Dentre as correntes de pesquisa uma tem ganhado cada vez mais destaque: a teoria das redes de empresas. Essa teoria busca entender como as estratégias de inovação das subsidiárias são impactadas por fatores associados à inserção nas redes no exterior (ANDERSSON; FORSGREN, 2006). Tem-se constatado que a inserção das subsidiárias em redes no exterior tem tido papel importante no processo de internacionalização (REZENDE; VERSIANI, 2007), para o desenvolvimento de inovações (BORINI; FLEURY; FLEURY; OLIVEIRA Jr, 2009) e para a transferência de inovações (DELLESTRAND, 2011). Outras pesquisas têm mostrado que ao inserirem-se numa rede as subsidiárias estrangeiras buscam tirar o máximo proveito dos recursos locais e minimizar a saída dos seus recursos para os concorrentes (SANTANGELO, 2012) além de desenvolverem 
competências que aumentam a sua relevância e poder dentro da corporação multinacional (NAJAFI-TAVANI; GIROUD; ANDERSSON, 2013).

Portanto, a inserção das subsidiárias estrangeiras em redes interorganizacionais (ou redes externas) é um assunto que merece ser investigado em profundidade, particularmente nos mercados emergentes como o Brasil, o qual segundo previsões do Goldman Sachs (2010), a economia do Brasil será maior que a Itália em 2020; enquanto Índia e Rússia estarão a frente de economias como Canadá e Itália. Tal cenário estimula às multinacionais estrangeiras a não somente instalarem-se como também fazer alianças com as empresas locais, as quais em virtude do contexto altamente competitivo e diverso, ofertam além da usual parceria de negócios, informações e expertises que impactam na inovação de produtos e processos em suas subsidiárias (COSTA; BORINI; AMATUCCI, 2013). Sendo que, uma das questões pertinentes está relacionada com os fatores que caracterizam as redes e que impactam na parceria, influenciando no desenvolvimento de inovações nas subsidiárias.

A importância da cooperação entre os indivíduos tem sido foco de amplas discussões nos mais variados campos de pesquisas, desde a antropologia até a economia e a administração onde se busca entender o impacto econômico e social, de maneira que estudos mais modernos têm explorado a ideia de que as empresas são entidades sociais que podem auferir vantagens ao associarem-se a outras empresas (ANDERSSON; FORSGREN; HOLM, 2002; JOHANSON; VAHLNE, 2009; ULRICH, 2011; COSTA; BORINI; AMATUCCI, 2013). Assim, ao delinearem as suas estratégias, as organizações devem estar atentas e abertas as possibilidades provenientes de outras organizações que estão além dos seus muros tais como: fornecedores, distribuidores e terceirizados. Nesse sentido, torna-se necessário entender em profundidade as conexões que envolvem as empresas, suas características e as consequências sobre o desenvolvimento de inovações.

As multinacionais estão inseridas em várias redes (intraorganizacionais e interorganizacionais), referindo-se a rede intraorganizacional a rede interna da organização, exemplo: o relacionamento entre a matriz e as suas subsidiárias e das subsidiárias entre si; e a rede interorganizacional referindo-se ao relacionamento com os parceiros externos, exemplo: o relacionamento da subsidiária com os fornecedores, distribuidores e terceirizados. Assim, as 
empresas estão inseridas numa teia de redes múltiplas (DYER; HATCH, 2006). Nessa tese será explorado o conceito de redes interorganizacionais ou redes externas.

As redes são conjuntos de organizações interligadas por meio de vínculos em geral diversos, sendo compostos por nós (empresas) e por laços (relacionamentos) que interligam os nós (HAKANSSON; FORD, 2002). Os relacionamentos são laços duradouros os quais podem incluir parcerias estratégicas (GULATI; NOHRIA; ZAHEER, 2000), desde parcerias mais fracas, exemplo: o relacionamento de um comprador e um certo supridor infrequente, ou parcerias fortes, exemplo: uma parceria entre as atividades de marketing e produção de uma empresa. Do ponto de vista da subsidiária alguns autores (ANDERSSON; FORSGREN; HOLM, 2002; AHARONI; BROCK, 2010) revelam que as subsidiárias podem ganhar acesso a novos recursos a partir do estreitamento dos laços com as empresas pertencentes à rede externa. De tal forma que, os relacionamentos se caracterizam como importantes fontes de vantagens competitivas (FORSGREN; HOLM; JOHANSON, 2005; JOHANSON; VAHLNE, 2009). Assim, a essência da relação cooperativa é, portanto, a possibilidade concreta de que a união dos parceiros seja capaz de gerar uma sinergia que, em isolamento, não poderia ser obtida (DYER; SINGH, 1998).

Uma forte inserção da subsidiária na rede externa está positivamente associada com uma série de outros fatores tais como: i) ao desenvolvimento de inovações incrementais (HALLIN et al., 2011) e ii) performance dos produtos sob vários aspectos, tais como custo, velocidade de mercado, reputação e maior retorno financeiro (JOHANSON; VAHLNE, 2009; ULRICH, 2011). Ademais, Santangelo (2012) acresce que as forças competitivas afetam positivamente na inserção das subsidiárias nas redes, isso se deve as pressões concorrenciais as quais forçam a busca por recursos distintos que promovam vantagem competitiva. Nessa tese, consideramse parceiros na rede interorganizacional/externa: fornecedores, distribuidores e terceirizados.

\subsubsection{Fatores preponderantes e característicos da Rede}

Quanto maior a inserção da subsidiária nas redes locais no estrangeiro maior a possibilidade de a subsidiária ganhar acesso a novos conhecimentos que podem garantir o desenvolvimento de competências e inovações (ANDERSSON et al., 2002). Seguindo essa mesma linha Hallin 
et al., (2011) argumentam que fatores como a adaptação, relacionamento de longo prazo, interdependência e confiança mútua são importantes para o desenvolvimento de inovações.

A temática da confiança nos negócios ganhou novos contornos a partir dos estudos de Granovetter $(1983,1985)$ e o conceito de imersão social (embeddedness), também entendido como sendo uma forte inserção na rede. A forte inserção na rede traduz-se na relação entre os parceiros e a geração da confiança nas transações comerciais, levando ao entendimento de que a ação econômica só pode ser compreendida quando observada a partir das relações sociais. Ademais, essas relações em rede desencorajam comportamentos oportunistas de ambas as partes em função do contexto social e organizacional no qual os contratos estão envolvidos e a avaliação dos riscos de punição relacionados com as normas e regras estabelecidas (Williamson, 1993). Sobre o conceito de imersão social ou aqui chamado de forte inserção na rede Granovetter (1985) diz:

“O argumento da imersão enfatiza, por sua vez, o papel das relações pessoais concretas e as estruturas (ou redes) dessas relações na origem da confiança e no desencorajamento da má-fé. A preferência dominante em fazer transações com indivíduos de reputação conhecida implica que poucos estão realmente dispostos a confiar na moralidade generalizada ou nos dispositivos institucionais para evitar problemas".

A confiança mútua é uma característica bastante recorrente na literatura que trata a temática das redes de empresas e sobre esse fator Johanson e Vahlne (2009) mostraram como os relacionamentos se desenvolvem por meio da interação entre as empresas e da construção da confiança mútua resultando num forte vínculo e comprometimento. Logo, espera-se que níveis altos de confiança mútua exerçam considerável influência sobre o desenvolvimento de inovações nas subsidiárias.

Outro fator discutido na literatura e que caracteriza uma rede interorganizacional é a adaptação entre os parceiros. Alguns estudos (LI, 2012; ANDERSSON; FORSGREN; HOLM, 2002; HALLIN et al., 2011) que frisam que as empresas se beneficiam da inserção na rede externa quando o relacionamento é caracterizado por uma forte adaptação de 
comportamentos de ambas as partes (rotinas de negócios, sistemas de planejamento, informações, etc).

Além dos fatores confiança e adaptação, a literatura sobre as redes de empresas tem abordado outros fatores: (i) a comunicação entre os parceiros e a (ii) longevidade e interdependência. Esses dois fatores foram agrupados nessa pesquisa e receberam o nome de "Laços estruturais".

O primeiro fator, comunicação entre os parceiros, foi abordado na pesquisa de Lakshman e Parente (2008) em seu estudo sobre a indústria automotiva, onde os autores verificaram a partir da literatura sobre o relacionamento com os fornecedores que: níveis crescentes de compartilhamento de conhecimento entre as empresas e seus fornecedores impactam positivamente na vantagem competitiva ao prover uma capacidade mais eficiente de adaptação as mudanças ambientais. Lakshman e Parente (2008) esclarecem que os esforços para o compartilhamento de conhecimento em redes especializadas têm gerado significativas vantagens competitivas nas cadeias de suprimento. Outro estudo conduzido por Sbragia e Lima (2013) concluiu que quanto mais bem disseminada for a informação dentro do projeto de desenvolvimento de novos produtos da empresa, mais os departamentos terão chance de ajudar uns aos outros, sendo possível, assim, desenvolver uma comunicação mais aberta. Embora os autores estejam se referindo a comunicação interna da empresa, é razoável supor que o mesmo deve se dar entre as equipes e departamentos das empresas parceiras que trabalham num mesmo projeto. Nesse sentido Aharoni e Brock (2010) acrescentam que a aprendizagem conjunta e além das fronteiras constitui um quadro de evolução global para a multinacional. Em particular, os autores referem-se às parcerias como uma forma especial de troca e intercâmbio de informações. Quando uma subsidiária está fortemente inserida numa rede externa altos níveis de difusão de conhecimentos são esperados (HALLIN; LIND, 2012).

O segundo fator que compõem os laços estruturais é a longevidade e interdependência entre os parceiros, também chamada em alguns estudos como a força do relacionamento. Enquanto Andersson et al., (2002) construíram a sua lógica relacional das redes técnicas e de negócios estabelecendo que num extremo o relacionamento é marcado por uma forte inserção na rede e consisti numa alta interdependência entre as empresas em termos de desenvolvimento de produto e processos de produção (redes técnicas) e noutro um relacionamento mais fraco e 
sem compromisso (rede de negócios), outros estudos (CAPALDO, 2007, FRITSCH; KAUFFELD-MONZ，2008; GRANOVETTER，1983， 1985; UZZI， 1996) também ressaltaram a importância da força do relacionamento. Granovetter (1983) denominou os extremos relacionais como: laço fraco e laço forte e segundo essa teoria um relacionamento de laço forte é caracterizado por interações frequentes, que fornecem acesso a informações e recursos disponíveis nos próprios círculos sociais. Por outro lado, um relacionamento de laço fraco é caracterizado por interações esporádicas. A força do laço é representada pelo investimento das partes no desenvolvimento e manutenção do relacionamento como: tempo dispendido com o relacionamento, frequência e reciprocidade das relações. Entretanto, a simples relação de compra e venda é caracterizada como sendo um laço fraco, uma vez que não propicia a formação de vínculos mais duradouros (ALDRICH; ZIMMER, 1985; ALDRICH; ELAM; REESE, 1997).

Corroborando com o pensamento exposto, alguns autores (CAPALDO, 2007; FRITSCH; KAUFFELD-MONZ, 2008) afirmam que a força da relação pode ser expressa em termos de duração total do relacionamento, frequência ou intensidade da colaboração. Nesse sentido, é possível inferir que uma subsidiária que se relacione fortemente com outros membros da rede pode auferir vantagens competitivas a partir de duas maneiras previstas por Andersson et al., (2002): primeiro, pode ser assumido que a subsidiária, tendo acesso aos recursos da rede, terá um impacto na competitividade em seu mercado; segundo, sendo possível a transferência dessas capacidades para outras unidades da rede interna da multinacional, o acesso à rede externa acaba por representar uma fonte de competência para toda a multinacional, uma vez que uma forte inserção da subsidiária na rede externa está positivamente associada ao desenvolvimento de inovações incrementais ou com competências que as empresas parceiras já detêm (HALLIN et al., 2011).

Alguns estudos (HALLIN; HOLM; SHARMA, 2011; HALLIN; LIND, 2012; LI, 2012; LIN; FANG; FANG; TSAI, 2009) abordando a temática das redes tem modelado esse conceito com todos os fatores aqui abordados (confiança, duração do relacionamento e laços estruturais), nomeando-o de embeddedness (enraizamento ou imersão). Assim, nessa tese o termo embeddedness também faz menção a todos esses fatores. 
Uma vez expostos os fatores que caracterizam uma forte inserção na rede (embeddedness) é possível inferir que quanto mais inserida estiver a subsidiária na rede de parceiros (fornecedores, distribuidores e terceirizados) maior será o impacto sobre o desenvolvimento de inovações (novos produtos ou processos). Assim são propostas as seguintes hipóteses:

H2a: O enraizamento na rede pela subsidiária impacta positivamente no desenvolvimento de inovações globais

H2b: O enraizamento na rede pela subsidiária impacta positivamente no desenvolvimento de inovações locais

\subsection{Orientação empreendedora (Empreendedorismo)}

As subsidiárias de corporações multinacionais podem ser definidas como entidades com potencial para empreender (BIRKINSHAW; HOOD; YOUNG, 2005), ou em outras palavras, são entidades aptas a inovar e implementar novas possibilidades para o desenvolvimento econômico (SCHUMPETER, 1951).

Empreendedorismo em MNCs é associado a iniciativas da subsidiária o que pode ser entendido como alguma atividade inovadora realizada com os recursos e sob a responsabilidade da própria subsidiária estrangeira (BIRKINSHAW, 1997). As iniciativas da subsidiária são três: oportunidades no mercado local (inovações locais); oportunidades em mercados globais (inovações locais que se tornam globais) e por fim, as iniciativas podem ser focadas em oportunidades internas (racionalização de atividades existentes ou a promoção de novas atividades), em síntese as iniciativas são essencialmente um processo que começa com a identificação da oportunidade e culmina com a combinação de recursos que permitem aproveitar a oportunidade (BIRKINSHAW, 1997). Hitt et al. (2001) acrescenta que empreender está relacionado com a criação de novos recursos ou uma configuração diferenciada para os recursos existentes que permitam desenvolver e comercializar novos produtos em novos mercados ou mesmo captar novos clientes. 
A orientação empreendedora da subsidiária (BIRKINSHAW, 1997; BIRKINSHAW et al., 1998a; SCHMID et al., 2014) pressupõe o apoio da MNC para que a filial assuma decisões de risco e inovação por conta própria. Assim, a orientação empreendedora é essencial para a criação de inovação nas subsidiárias (KEUPP; GASSMANN, 2009; SCOTT; GIBBONS; COUGHLAN, 2010; WILLIAMS, 2009).

A orientação empreendedora é muito mais que a criação de um novo negócio, ou um novo modo de produzir. Passa por questões de credibilidade e sugere uma disposição da empresa para uma atividade proativa, diante de um ambiente de tomada de decisões de risco (BIRKINSHAW, 1997).

Algumas pressões podem incentivar as subsidiárias a empreender, como: i) a sua dispersão por diversas áreas geográficas e ii) ambientes hipercompetitivos (BIRKINSHAW, 1998; CHRISTENSEN, 2004). Dentre esses fatores, o segundo pode ser o mais decisivo para o contexto brasileiro, uma vez que algumas pesquisas já constataram que o ambiente de negócios no país é de alta competitividade (OLIVEIRA JR.; BOEHE; BORINI, 2009; COSTA; BORINI; AMATUCCI, 2013).

Parece haver consenso acadêmico quanto a correlação entre a orientação empreendedora e o desenvolvimento de inovações (BIRKINSHAW, 1997; ZHAO, 2005), de maneira que essa configuração proporciona vantagens que ajudam a competir em ambientes dinâmicos.

Oviatt e Mcdougall (1995) explicam que uma empresa ao empreender internacionalmente demonstra ter uma visão global, uma boa equipe e uma rede de parceiros. Nesse sentido, Dimitratos e Plakoyiannaki (2003) ressaltam que a capacidade de estabelecer relacionamentos representa a principal fonte empreendedora de uma empresa, o que sugere que a inserção da subsidiária em redes interorganizacionais deva impactar substancialmente no desenvolvimento de inovações.

Dimitratos, Liouka e Young (2014) mostraram que a aprendizagem é uma competência chave para a subsidiária desenvolver suas iniciativas empreendedoras, as quais expressam-se a partir da exploração dos conhecimentos locais onde a subsidiária atua constituindo-se numa vantagem competitiva para a MNC. Esse conhecimento pode ser acessado a partir da rede em 
que a subsidiária está inserida, nesse sentido os autores afirmam que as redes de empresas são o principal direcionador e impulsionador das iniciativas empreendedoras.

Portanto, a partir da necessidade de ter que tomar a decisão num ambiente mais familiar a subsidiária do que a matriz, explorar as oportunidades locais e buscar parcerias que auxiliem no processo de desenvolvimento de inovações, espera-se que uma maior orientação empreendedora impacte positivamente numa maior inserção nas redes de empresas. Assim propõem-se:

H3a: A orientação empreendedora da subsidiária impacta positivamente no enraizamento na rede

Ademais, as inovações da subsidiária nem sempre precisam atender uma demanda interna da MNC, ou seja, pode ser uma iniciativa de mercado, para solucionar um problema especifico da demanda do mercado competitivo externo (BIRKINSHAW, 1997; BORINI; FLEURY; FLEURY; OLIVEIRA JR, 2009; DELANY, 2000; SCHMID et al., 2014).

Isso pode impactar no desenvolvimento de inovações globais. A orientação empreendedora, em vez de estimular como enfoque o mercado interno da MNC (BOUQUET; BIRKINSHAW, 2008), ela estimula iniciativas mais atreladas ao mercado externo, logo:

H3b: A orientação empreendedora da subsidiária impacta positivamente no desenvolvimento de inovações globais

Entretanto, conforme advogam Govindarajan e Trimble (2012) a subsidiária pode primeiramente desenvolver um produto localmente para num segundo momento transferi-lo para matriz, assim:

H3c: A orientação empreendedora da subsidiária impacta positivamente no desenvolvimento de inovações locais 


\subsection{O porte das multinacionais}

O porte das empresas tem sido tema de muitas discussões e está presente seja como variável dependente, independente, variável de controle ou moderadora. O pressuposto é de que empresas de grande porte possuem mais recursos e, portanto, estariam mais dispostas a investirem mais intensamente em inovações, ademais empresas de grande porte possuem uma infraestrutura superior o que lhes permitem competir em vantagem de condições. Essa tese utilizou a classificação do porte da empresa baseada no número de funcionários, o que está em acordo com o IBGE (2013), o qual classifica as empresas com mais de quinhentas pessoas ocupadas como sendo de grande porte.

Frost (2001) mostrou que empresas de grande porte são mais propensas a fazerem parte de centros de excelência tecnológicos. Nesse sentido, Kogut e Singh (1988) acrescentam que quanto maior o porte da firma maior a sua capacidade de realizar projetos complexos, uma vez que a empresa possui mais recursos.

Assim, a hipótese é de que as subsidiárias de maior porte possuem mais recursos e estão mais propensas a se relacionarem com empresas tecnológicas, o que impactaria positivamente na inserção em redes de empresas bem como no desenvolvimento de inovações.

\subsection{Considerações finais do capítulo e proposição do modelo teórico}

Esse capítulo construiu um mapa teórico que apresentou as correlações entre as temáticas estudas. Particularmente, foi construído o entendimento de que os dois tipos de inovações mais pesquisados são as inovações em produto e processo (HAMEL; BREEN, 2007) e nesse sentido essa pesquisa foca nas inovações em produto e processo. Quanto a fonte da inovação, ela pode se originar de duas formas distintas (CHESBROUGH, 2006):

i. de dentro da empresa, baseado principalmente no P\&D interno e outras funções organizacionais;

ii. de fontes externas à empresa, baseado nas parcerias e redes de colaboração. 
Assim, a inovação proveniente das subsidiárias pode ser uma importante fonte de vantagem competitiva, desde que ela seja capaz de ser usada em outras unidades corporativas, ou seja, a inovação precisa configurar uma capacidade não local (RUGMAN; VERBEKE, 2001). Essa perspectiva da transferência do conhecimento e inovação é fonte de grande discussão na literatura de gestão das subsidiárias na última década (MICHAILOVA; MUSTAFFA, 2012). Os estudos mostram a associação entre inovações locais e inovações globais (BIRKINSHAW, 2001; BIRKINSHAW et al., 1998a; BIRKINSHAW; HOOD; YOUNG, 2005; FROST et al., 2002), inclusive com subsidiárias estrangeiras localizadas no Brasil (BORINI; OLIVEIRA JUNIOR; SILVEIRA; CONCER, 2012; COSTA; BORINI; AMATUCCI, 2013; OLIVEIRA JR; BOEHE; BORINI, 2009). Dessa maneira, o debate na literatura reside no processo de desenvolvimento da inovação local para se tornar uma inovação global (CIABUSCHI; DELLESTRAND; HOLM, 2012; DELLESTRAND, 2011; MEYER et al., 2011; NARULA, 2014).

Mostrou-se que as iniciativas da subsidiária impactam no desenvolvimento de inovações e na inserção em redes de empresas, evidenciando a importância dos relacionamentos de negócios entre as subsidiárias estrangeiras instaladas no país e os parceiros locais para o desenvolvimento de inovações. Nesse sentido Kleindorfer, Wind e Gunther (2012) argumentam que com um mundo cada vez mais interligado as competências realmente importantes já não são as que a empresa possui, mas aquelas a que pode se conectar.

A orientação empreendedora da subsidiária está relacionada com o apoio recebido da matriz, a predisposição para correr riscos e a inovação por conta própria, a qual está interligada com a habilidade de aprender.

A aprendizagem é uma competência chave para a subsidiária desenvolver suas iniciativas empreendedoras, as quais expressam-se a partir da exploração dos conhecimentos locais onde a subsidiária atua constituindo-se numa vantagem competitiva para a MNC. Esse conhecimento pode ser acessado a partir da rede em que a subsidiária está inserida. As redes de empresas são o principal direcionador e impulsionador das iniciativas empreendedoras. 
Foram apresentados os fatores (Quadro 1) que indicam uma forte inserção das subsidiárias estrangeiras em redes locais no país e que compõem o conceito de embeddedness. Uma forte inserção na rede pode impactar significativamente no desenvolvimento de inovações pela subsidiária.

\section{Quadro 1 - Fatores preponderantes e característicos da Rede}

\begin{tabular}{|c|c|c|c|}
\hline & \multicolumn{3}{|c|}{ Forte inserção na rede (Embeddedness) } \\
\hline & Confiança & Adaptação & Laços Estruturais \\
\hline Ideia Central & $\begin{array}{l}\text { A forte inserção na rede traduz-se na } \\
\text { relação entre os parceiros e a geração } \\
\text { da confiança nas transações } \\
\text { comerciais, levando ao entendimento } \\
\text { de que a ação econômica só pode ser } \\
\text { compreendida quando observada a } \\
\text { partir das relações sociais. }\end{array}$ & $\begin{array}{l}\text { As empresas se beneficiam da } \\
\text { inserção na rede externa quando o } \\
\text { relacionamento é caracterizado por } \\
\text { uma forte adaptação de } \\
\text { comportamentos de ambas as partes } \\
\text { (Ex.: rotinas de negócios, sistemas de } \\
\text { planejamento, informações) }\end{array}$ & $\begin{array}{l}\text { A força do laço é } \\
\text { representada pelo } \\
\text { investimento das partes no } \\
\text { desenvolvimento e } \\
\text { manutenção do } \\
\text { relacionamento como: tempo } \\
\text { dispendido com o } \\
\text { relacionamento, frequência e } \\
\text { reciprocidade das relações } \\
\text { onde altos níveis de difusão } \\
\text { de conhecimentos são } \\
\text { esperados. }\end{array}$ \\
\hline Autores & $\begin{array}{l}\text { GRANOVETTER, 1985; } \\
\text { JOHANSON; VAHLNE, } 2009\end{array}$ & $\begin{array}{l}\text { LI, 2012; ANDERSSON; } \\
\text { FORSGREN; HOLM, 2002; HALLIN } \\
\text { et al., } 2011\end{array}$ & $\begin{array}{l}\text { GRANOVETTER, 1985; } \\
\text { LAKSHMAN E PARENTE, } \\
2008\end{array}$ \\
\hline
\end{tabular}

Fonte: Autor

A construção do referencial teórico possibilitou embasar as hipóteses da pesquisa, propor o modelo a ser testado e confeccionar o questionário a ser aplicado com as multinacionais estrangeiras instaladas no país. A Ilustração 5 apresenta o modelo proposto e as hipóteses a serem testadas. 


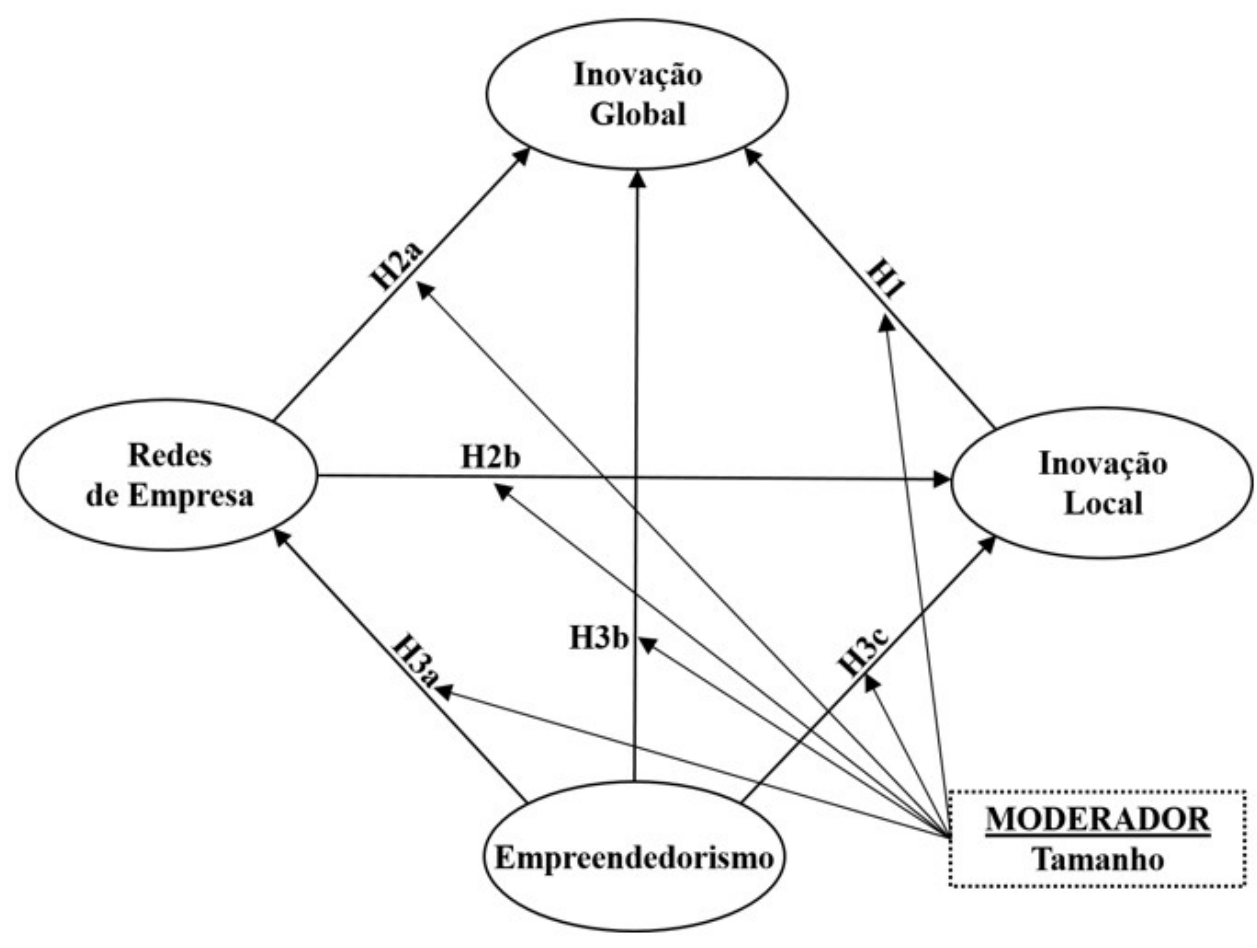

Ilustração 5 - Modelo proposto e hipóteses

FONTE: o autor

\section{HIPOTESES:}

H1: O desenvolvimento de inovações locais impacta positivamente no desenvolvimento de inovações globais

H2a: O enraizamento na rede pela subsidiária impacta positivamente no desenvolvimento de inovações globais

H2b: O enraizamento na rede pela subsidiária impacta positivamente no desenvolvimento de inovações locais

H3a: A orientação empreendedora da subsidiária impacta positivamente no enraizamento na rede

H3b: A orientação empreendedora da subsidiária impacta positivamente no desenvolvimento de inovações globais

H3c: A orientação empreendedora da subsidiária impacta positivamente no desenvolvimento de inovações locais 


\section{ASPECTOS METODOLÓGICOS DA PESQUISA}

A partir do referencial teórico desenvolvido foi construído um mapa da literatura (CRESWELL, 2010), onde foram identificados os conceitos chave e estabelecido um diálogo entre campos distintos e emergentes em negócios internacionais, sugerindo que as inovações desenvolvidas na subsidiária podem estar positivamente associadas a iniciativas empreendedoras das subsidiárias e a uma forte inserção nas redes locais no país hospedeiro. Essa etapa qualitativa subsidiou o desenvolvimento das hipóteses, do questionário e o modelo teórico da pesquisa. Realizada a etapa qualitativa, partiu-se para a etapa quantitativa e a aplicação de diversas técnicas estatísticas, utilizando-se para o teste de hipóteses a modelagem de equações estruturais. Essa etapa quantitativa é detalhada nesse capítulo, onde são discutidos os aspectos procedimentais e o embasamento teórico-conceitual para as análises subsequentes, buscando-se assim estruturar o conhecimento que se pretende reconhecer como científico (DEMO, 1981).

\subsection{Procedimentos Metodológicos: Descrição Sumária}

O Quadro 2 sintetiza os procedimentos metodológicos adotados e sua relação com os objetivos da pesquisa apresentados no capítulo introdutório.

\section{Quadro 2 - Sumário das etapas da pesquisa}

\begin{tabular}{|c|c|c|c|}
\hline Método & Fonte dos dados & Procedimentos & Objetivos \\
\hline Qualitativo & $\begin{array}{c}\text { Ebsco; Scopus; } \\
\text { Google Scholar e } \\
\text { ScienceDirect }\end{array}$ & $\begin{array}{l}\text { - Construção do referencial teórico; } \\
\text { - Formulação das hipóteses e do modelo a ser testado; } \\
\text { - Desenvolvimento do questionário. }\end{array}$ & OE1 \\
\hline Quantitativo & Survey & $\begin{array}{l}\text { - Estabelecimento dos critérios metodológicos. } \\
\text { - Coleta e tratamento dos dados; } \\
\text { - Exploração dos dados a partir da modelagem de equaçi } \\
\text { estruturais, de estatísticas descritivas, gráficos e tabelas. }\end{array}$ & $\mathrm{OE} 2$ \\
\hline Quali-Quantitativo & $\begin{array}{c}\text { Referêncial } \\
\text { teórico e Survey }\end{array}$ & $\begin{array}{l}\text { - Análise, interpretação dos dados e desenvolvimento } \\
\text { das conclusõs da pesquisa. }\end{array}$ & OE3 \\
\hline
\end{tabular}

FONTE: o autor. 
A seguir são operacionalizados os procedimentos referentes a etapa quantitativa (OE04). A etapa quali-quantitativa (OE05) é desenvolvida nos capítulos subsequentes.

\subsubsection{Procedimentos Metodológicos: Aplicação}

Essa pesquisa se caracteriza como sendo quantitativa, pois segundo Creswell (2009) diversas variáveis foram coletadas e relacionadas entre si e em quantidade suficiente para atender aos requisitos de análises estatísticas. A pesquisa foi realizada a partir de dados primários coletados por meio da aplicação de um survey, técnica utilizada para procurar explicar as razões e as fontes de eventos, assim como suas características e correlações.

A pesquisa é do tipo descritiva, técnica que procura saber com a precisão possível qual a frequência do fenômeno e suas possíveis relações com outros (CERVO; BERVIAN; SILVA, 2007). Este tipo de pesquisa analisa um fenômeno ou situação mediante um estudo realizado em determinado espaço-tempo. Enfim, a pesquisa descritiva permite estudar detalhadamente uma determinada situação-problema ou fato e relacionar as variáveis (VIANNA, 2001). Neste caso, a situação-problema é o impacto das redes interorganizacionais sobre o desenvolvimento de inovações nas subsidiárias estrangeiras. Para este estudo será empregado o corte-transversal (cross-sectional), que segundo Sampieri (1991), ocorre quando a coleta dos dados acontece em um só momento, pretendendo descrever e analisar o estado de uma ou de diversas variáveis em um dado momento, em outras palavras, trata-se de uma fotografia de um dado momento do fenômeno de interesse onde são observados seus efeitos (GROENLAND e STALPERS, 2012).

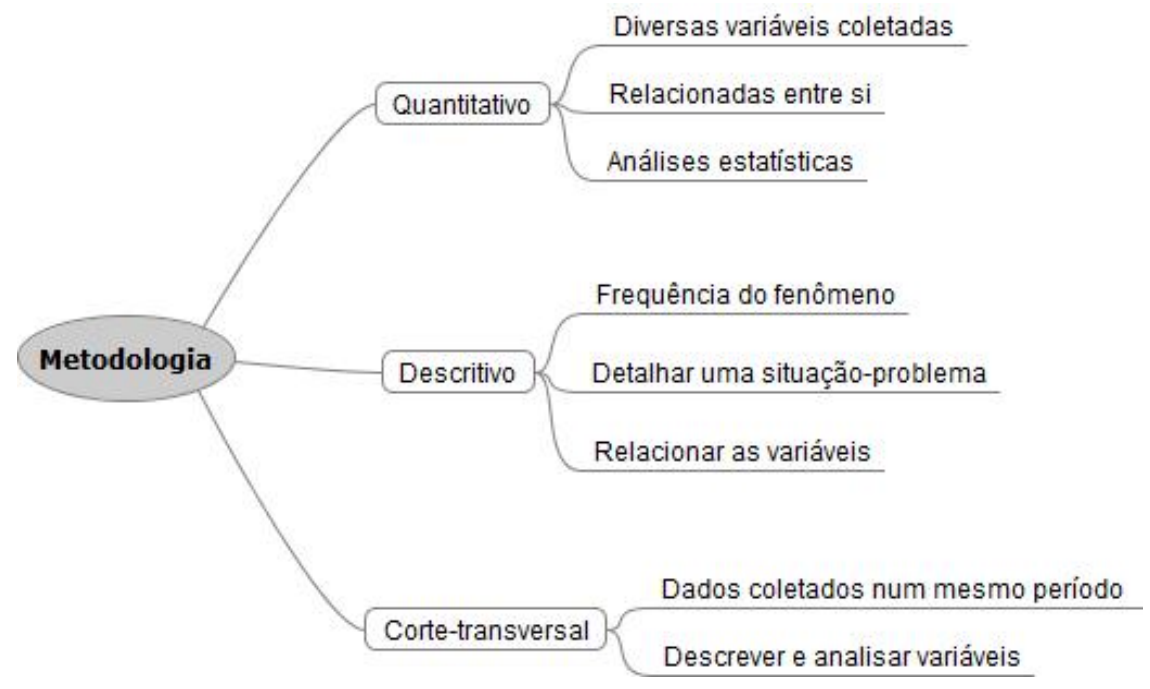

Ilustração 6 - Metodologia da pesquisa

FONTE: o autor 
O instrumento utilizado para a coleta dos dados primários foi o questionário, muito utilizado em conjunto com surveys, os quais fornecem uma descrição numérica ou quantitativa de tendências, atitudes ou opiniões de uma amostra de uma população (NEWMAN, 2006; COLLIS; HUSSEY, 2006; CRESWELL, 2009). Para a análise dos dados foi utilizada a técnica estatística de Modelagem de Equações Estruturais (Structural Equation Modeling SEM) que segundo Byrne (2010) é uma metodologia estatística de abordagem confirmatória para analisar a teoria sobre algum fenômeno. Entre as vantagens na utilização da SEM estão (GEFEN, RIGDON e STRAUB, 2011):

* Análise de modelos complexos com múltiplos indicadores;

* As estimativas provenientes da SEM são melhores que as produzidas pela regressão linear;

* CB-SEM 6 é uma metodologia que testa e confirma teorias.

As análises feitas nessa pesquisa foram realizadas a partir dos resultados obtidos pela utilização dos softwares IBM SPSS statistics v.22, IBM AMOS v.22 e Microsoft Excel 2013.

\subsection{Seleção da amostra e coleta de dados}

A amostra utilizada nessa pesquisa é não-probabilística por conveniência, uma vez que utilizou informações/contatos os quais foram previamente estabelecidos em pesquisas anteriores. Inicialmente planejou-se fazer uso de amostragem probabilística estratificada, entretanto, devido à dificuldade em se obter respostas válidas para os questionários essa técnica foi descontinuada. Com base numa lista, adquirida junto ao jornal Gazeta Mercantil, contendo as mil e duzentas maiores multinacionais instaladas no país segundo o critério de faturamento, procedeu-se uma primeira triagem. Onde, foi constatado que a lista estava desatualizada o que resultou na eliminação de duzentas empresas restando então mil multinacionais. O respondente do questionário foi o principal executivo da subsidiária ou algum membro da diretoria designado por esse executivo.

O questionário foi escolhido por ser um instrumento de coleta de dados associado a métodos positivistas e usado comumente em surveys de larga escala (COLLIS; HUSSEY, 2006). As perguntas usadas são fechadas (COLLIS; HUSSEY, 2006; COOPER; SCHINDLER, 2006).

\footnotetext{
${ }^{6}$ CB-SEM: Equação estrutural baseada em covariâncias
} 
O processo de coleta foi compartilhado. Optou-se por uma pesquisa através de um servidor online e de uma pesquisa por meio do telemarketing, considerado como o principal meio de coleta dos dados. O survey ficou hospedado no site: http://www.fia.com.br/multinacionais. Essa metodologia foi escolhida devido a variedade de recursos disponíveis nessa plataforma. Também foi colocado à disposição em arquivo Microsoft Word (APÊNDICE I) e enviado por e-mail para os que assim desejassem.

Um pré-teste do questionário foi conduzido junto aos alunos do curso de pós-graduação da FEA/USP e empregados de multinacionais, o que possibilitou que se realizassem refinamentos no questionário. Após essa etapa, um e-mail formal foi enviado as subsidiárias constantes no mainling das mil maiores MNCs instaladas no Brasil. Passados dez dias fez-se um acompanhamento telefônico a fim de incrementar as chances de participação. O período de coleta foi de 01 de novembro a 15 de dezembro de 2009. Após este período, o survey retornou um total de cento e oitenta e um questionários, sendo que nove foram excluídos por preenchimento incompleto ou errado. Desse modo a amostra da pesquisa é de cento e setenta e duas empresas, um percentual de dezessete por cento de respostas, o que similar a outras pesquisas realizadas no Brasil (COSTA; BORINI; AMATUCCI, 2013) e no mundo (FOSS; LAURSEN; PEDERSE, 2011; CHANG; CHENG; WU, 2012; LI; WANG; HUANG; BAI, 2013).

\subsection{Construção das Variáveis de Pesquisa}

Todos os construtos utilizados nessa pesquisa são formados a partir de uma métrica categórica, de maneira que as variáveis utilizadas na pesquisa estão medidas numa escala Likert de cinco pontos, tendo-se num extremo o valor " 1 " indicando discordo totalmente e "5" indicando concordo totalmente e caracterizam-se como sendo do tipo ordinal, cuja transformação numérica permite estimar os construtos latentes (construtos não observáveis diretamente). As escalas são úteis quando se deseja mensurar como um indivíduo pensa sobre determinado assunto, produzem medidas quantitativas e podem ser utilizadas para testar hipóteses (NEWMAN, 2006).

A pesquisa utiliza também variáveis do tipo dummy que distinguem as subsidiárias com menos de quinhentos funcionários $(57 \%$ da amostra) das com mais de quinhentos funcionários (43\% da amostra). Assim, entende-se como sendo uma variável dummy uma 
variável binária ou dicotômica a qual assume os valores 0 ou 1 . No caso específico dessa pesquisa os valores assumidos foram:

$\left\{\begin{array}{l}1, \text { se a subsidiária tiver mais de } 500 \text { funcionários } \\ 0 \text {, caso contrário. }\end{array}\right.$

Essa classificação está em acordo com o IBGE (2013), o qual classifica as empresas com mais de quinhentas pessoas ocupadas como sendo de grande porte.

Devido a impossibilidade de uma medida direta, o construto latente é representado por uma ou mais variáveis latentes ou por indicadores, que se constituem nas variáveis observáveis (BYRNE, 2009; HAIR et al., 2009; KLINE, 2005). O modelo apresentado nesse estudo (Ilustração 7) caracteriza-se como sendo reflexivo, uma vez que a direção de causalidade vai do construto para seus indicadores. Em outras palavras, neste tipo de modelo, mudanças no construto causam mudanças nos itens (JARVIS; MACKENZIE; PODSAKOFF, 2003).

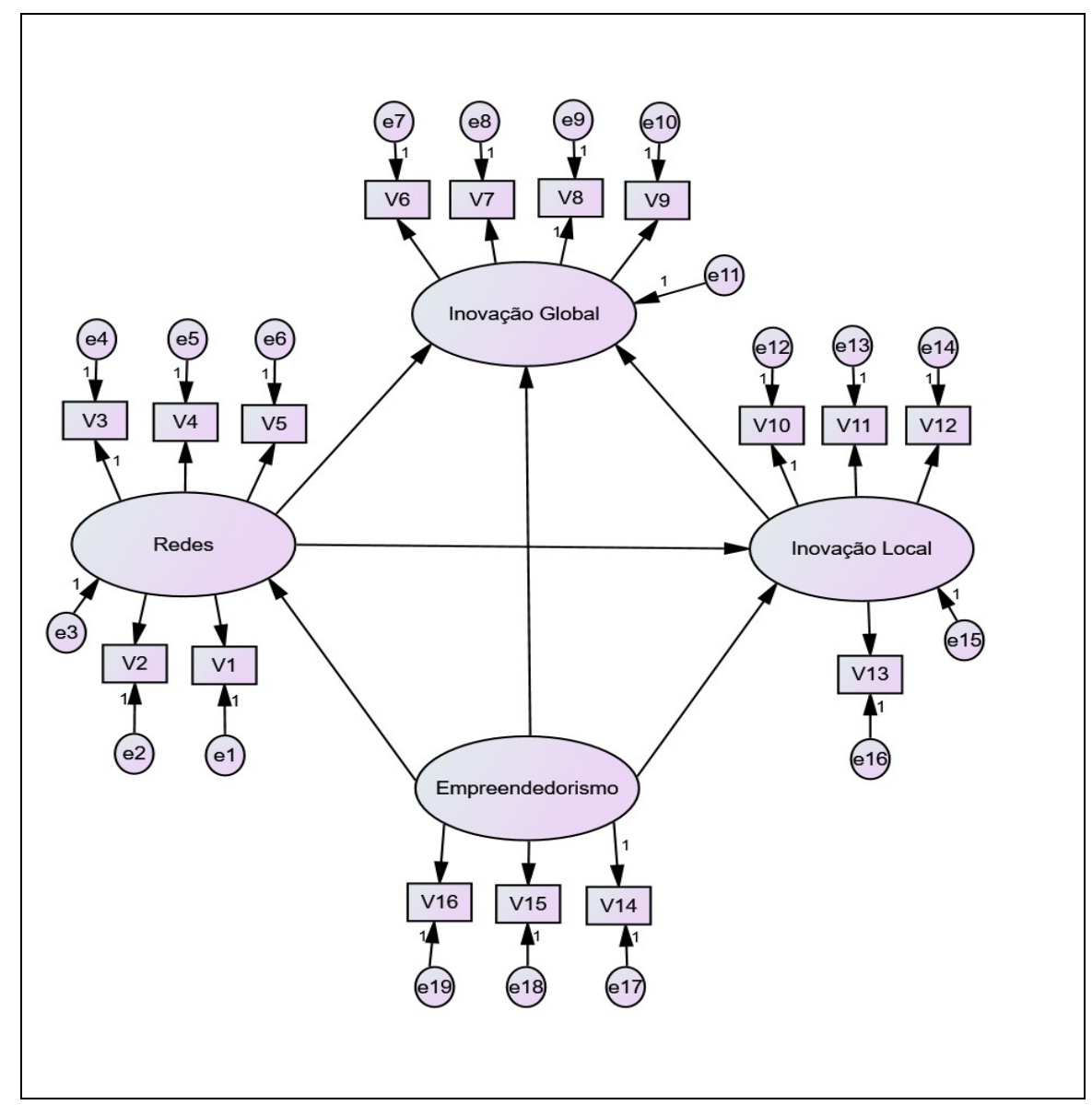

Ilustração 7 - Modelo de equações estruturais

FONTE: o autor 
Desse modo, são propostos quatro construtos: redes de empresas, orientação empreendedora, inovação local e inovação global, conforme o Quadro 3.

Quadro 3 - Composição dos construtos da pesquisa

\begin{tabular}{|c|c|c|}
\hline CONSTRUTO & VARIÁVEIS & AUTORES \\
\hline \multirow{7}{*}{ Redes interorganizacionais } & $\begin{array}{c}\text { v1) Nossa subsidiária tem larga experiência com parcerias e } \\
\text { alianças estratégicas com nossos fornecedores; v2) Nossa } \\
\text { subsidiária tem uma longa história na preparação e } \\
\text { desenvolvimento de parcerias no passado; v3) Desenvolver } \\
\text { parcerias é uma prática comum da nossa subsidiária; v4) } \\
\text { Nossa subsidiária está sempre procurando por oportunidades } \\
\text { de fazer novas alianças e parcerias estratégicas e v5) Nossa } \\
\text { subsidiária considera parcerias e alianças estratégicas assuntos } \\
\text { de vital importância para nosso negócio. }\end{array}$ & $\begin{array}{c}\text { Dililiansons (2001); } \\
\text { Anderson, Forsgreen } \\
\text { e Holm (2002) e } \\
\text { Lakshman e Parente } \\
\text { (2008). }\end{array}$ \\
\hline Inovação Global & $\begin{array}{c}\text { v6) desenvolveu produtos que hoje são vendidos por outras } \\
\text { subsidiárias; v8) desenvolveu processos organizacionais que } \\
\text { hoje são adotados em outras subsidiárias e v9) desenvolveu } \\
\text { produtos/processos organizacionais em parceria com } \\
\text { fornecedores e que hoje são adotados em outras subsidiárias. }\end{array}$ & $\begin{array}{c}\text { Birkinshaw, Hood e } \\
\text { Frost, Birkinshaw e } \\
\text { Ensign (2002) }\end{array}$ \\
\hline Inovação Local & $\begin{array}{c}\text { v10) Sua subsidiária alterou o design dos produtos / serviços } \\
\text { oferecidos; v11) criou novos produtos/serviços; v12) entrou } \\
\text { em novos mercados dentro do país e v13) alterou os processos } \\
\text { de produção }\end{array}$ & $\begin{array}{c}\text { Birkinshaw, Hood e } \\
\text { Jonsson (1998) }\end{array}$ \\
\hline Empreendedorismo & $\begin{array}{c}\text { v15) No relacionamento da matriz com a s sua subsidiária } \\
\text { subsidiária; v16) apoio para as atividades empreendedoras e } \\
\text { v17) forte confiança da matriz na sua subsidiária. }\end{array}$ & $\begin{array}{c}\text { Jonsson (1998); } \\
\text { Birkinshaw (1997) } \\
\text { Birkinshaw, Hood e }\end{array}$ \\
\hline
\end{tabular}

FONTE: o autor

A partir da Ilustração 7 percebe-se que há um relacionamento de causalidade entre os construtos o que justifica a utilização da modelagem de equações estruturais, a qual assenta-se em relações causais. Nesse sentido, o pesquisador tem de especificar essas relações, definindo quais as variáveis são dependentes e quais são independentes. A escolha das variáveis e das relações causais é efetuada com base no arcabouço teórico desenvolvido no capítulo dois dessa tese, o qual possibilitou especificar as relações entre as variáveis latentes, identificar e caracterizar os indicadores que compõem os construtos e por fim especificar o modelo. $\mathrm{O}$ modelo então será testado, confirmado ou não pelos resultados da estimação do modelo estrutural (BOLLEN, 1989). 
São três as variáveis dependentes que constituem o modelo de análise:

* Redes;

* Inovação Global e

* Inovação Local.

Entretanto, uma peculiaridade da modelagem de equações estruturais é que as variáveis podem tanto funcionar como dependentes quanto independentes dentro do mesmo modelo. No caso específico em questão, duas das três variáveis dependentes também se caracterizam como sendo independentes, são elas:

* Redes;

* Inovação Local e

* Empreendedorismo.

\subsection{Modelagem de Equações Estruturais (Structural Equation Modeling - SEM)}

A modelagem de equações estruturais tem apresentado um crescimento significativo no contexto das pesquisas em ciências sociais (MATSUEDA, 2012). Seu desenvolvimento tem sido tamanho que alguns editores de renomadas revistas internacionais têm feito esforços no sentido de padronizar a sua análise e o registro dos resultados (GEFEN, RIGDON e STRAUB, 2011). Hair Jr. et al. (2013) vai mais longe e diz que a SEM é a técnica de análise estatística mais avançada que apareceu na última década em ciências sociais.

A técnica de equações estruturais assenta-se sobre os modelos clássicos lineares generalizados, em especial a SEM congrega a análise fatorial e a regressão múltipla, sendo considerada como uma extensão dessas técnicas multivariadas (KLINE, 2011; BYRNE, 2010). Entretanto, o racional da SEM é diferente daquele empregado na estatística clássica onde procura-se um modelo teórico que descreva os dados, ou seja, os dados levam à dedução de novas teorias. De forma oposta, a análise de equações estruturais baseia-se num quadro teórico estabelecido a priori e somente então recolhe dados que confirmem ou não esse quadro teórico (MAROCO, 2010). Para tanto, a SEM é capaz de estimar uma série de regressões múltiplas interdependentes, simultaneamente, pela especificação de um modelo estrutural e por meio da análise fatorial confirmatória, permitindo ao pesquisador testar a 
teoria por inteiro (HAIR et al., 2009; KLINE, 2010). O Quadro 4 posiciona a SEM entre as demais técnicas multivariadas de primeira e segunda geração:

Quadro 4 - Organização dos métodos multivariados

\begin{tabular}{|c|l|l|}
\hline & Essencialmente Exploratório & Essencialmente Confirmatório \\
\hline $\begin{array}{c}\text { Técnicas de } \\
\text { primeira } \\
\text { geração }\end{array}$ & $\begin{array}{l}\text { - Análise de cluster } \\
\text { - Enálise fatorial exploratória multidimensional }\end{array}$ & $\begin{array}{l}\text { - Análise de variância } \\
\text { - Regressão logística } \\
\text { - Regressão linear múltipla }\end{array}$ \\
\hline $\begin{array}{c}\text { Técnicas de } \\
\text { segunda } \\
\text { geração }\end{array}$ & • PLS-SEM & $\begin{array}{l}\text { CB-SEM } \\
\text { (incluindo confirmatória) }\end{array}$ \\
\hline
\end{tabular}

FONTE: adaptado de Hair Jr. et al. (2013)

Todavia, é importante salientar que a modelagem de equações estruturais não estabelece a causalidade entre os construtos, sendo a causalidade uma proposição do modelo e não uma propriedade do output ou uma consequência inferencial da técnica ou do software utilizado. Deve-se também ressaltar que qualquer modelo de equações estruturais é apenas uma aproximação da realidade, tendo a significância estatística do modelo a capacidade de demonstrar apenas a falsidade do modelo e nunca a veracidade das relações causais previstas (MAROCO, 2010). Entretanto, a SEM pode fornecer alguma evidência necessária para embasar uma inferência causal (HAIR et al., 2009).

Dentre as características que distinguem a SEM destacam-se:

A SEM possibilita a estimação de relações de dependência múltiplas e inter-relacionadas

SEM

A SEM é capaz de representar conceitos não observados nessas relações e corrigir erro de mensuração no processo de estimação

A SEM pode definir um modelo para explicar um conjunto inteiro de relações

\section{Ilustração 8 - Características da SEM}

FONTE: o autor com base em Hair Jr. et. al. (2009) 
Para a análise de equações estruturais duas abordagens podem ser seguidas (HAIR Jr. et al., 2013):

i) CB-SEM (Modelagem de equações estruturais baseada em covariâncias) e

ii) PLS-SEM (Modelagem de equações estruturais baseada em variância).

A CB-SEM é mais aplicável para a análise fatorial confirmatória, ou seja, mais indicada para o teste de teorias. Enquanto que a PLS-SEM é mais adequada para o trabalho exploratório, quando se tem muitos dados e pouca teoria. O Quadro 5 apresenta as principais diferenças e aplicações entre as duas técnicas:

\section{Quadro 5 - Regras para escolher entre PLS-SEM e CB-SEM}

\begin{tabular}{|l|l|}
\hline \multirow{1}{*}{ PLS-SEM } & $\begin{array}{l}\text { Use PLS-SEM quando: } \\
\text { — O objeito principal é predizer os principais construtos ou identificá-los; } \\
\text { — Quando há construtos formativos no modelo, embora também possam ser } \\
\text { utilizados na CB-SEM. Todavia, CB-SEM irá requerer modificações no construto; } \\
\text { — O modelo estrutural é complexo (muitos construtos e indicadores); } \\
\text { - A amostra é pequena e/ou os dados não são normais; } \\
\text { — O plano é usar o resultado das variáveis latentes em análises subsequentes. }\end{array}$ \\
\hline CB-SEM & $\begin{array}{l}\text { Use CB-SEM quando: } \\
\text { - O objetivo principal é realizar um teste da teoria, ou uma comparação com } \\
\text { teorias alternativas; } \\
\text { - Quando o modelo requer uma especificação adicional nos erros (covariação); } \\
\text { - A pesquisa requer um critério global de ajuste (Goodness-of-fit). }\end{array}$ \\
\hline
\end{tabular}

FONTE: adaptado de Hair Jr. et al. (2013)

É do escopo dessa tese testar os relacionamentos provenientes do mapa teórico desenvolvido previamente e verificar quão bem os dados coletados junto as subsidiárias estrangeiras que operam no país se ajustam. Ademais, são verificados vários índices de ajustamento do modelo (Goodness-of-fit) a fim de satisfazer os critérios de aceitação do modelo. Assim, a técnica de modelagem de equações estruturais baseada em covariâncias é mais adequada aos objetivos da presente pesquisa. 
A execução metodológica da técnica de equações estruturais seguiu as recomendações de Kline (2011) dispostas na Ilustração 9, onde primeiramente identificou-se o modelo teórico a ser testado e então foram selecionadas as questões do survey para a coleta das variáveis, posteriormente os dados foram submetidos ao software IBM Amos onde constatou-se a necessidade de reespecificação do modelo. Feita a reespecificação do modelo, foram analisadas as estimativas e então comparadas ao modelo alternativo. Por fim, os resultados foram reportados.

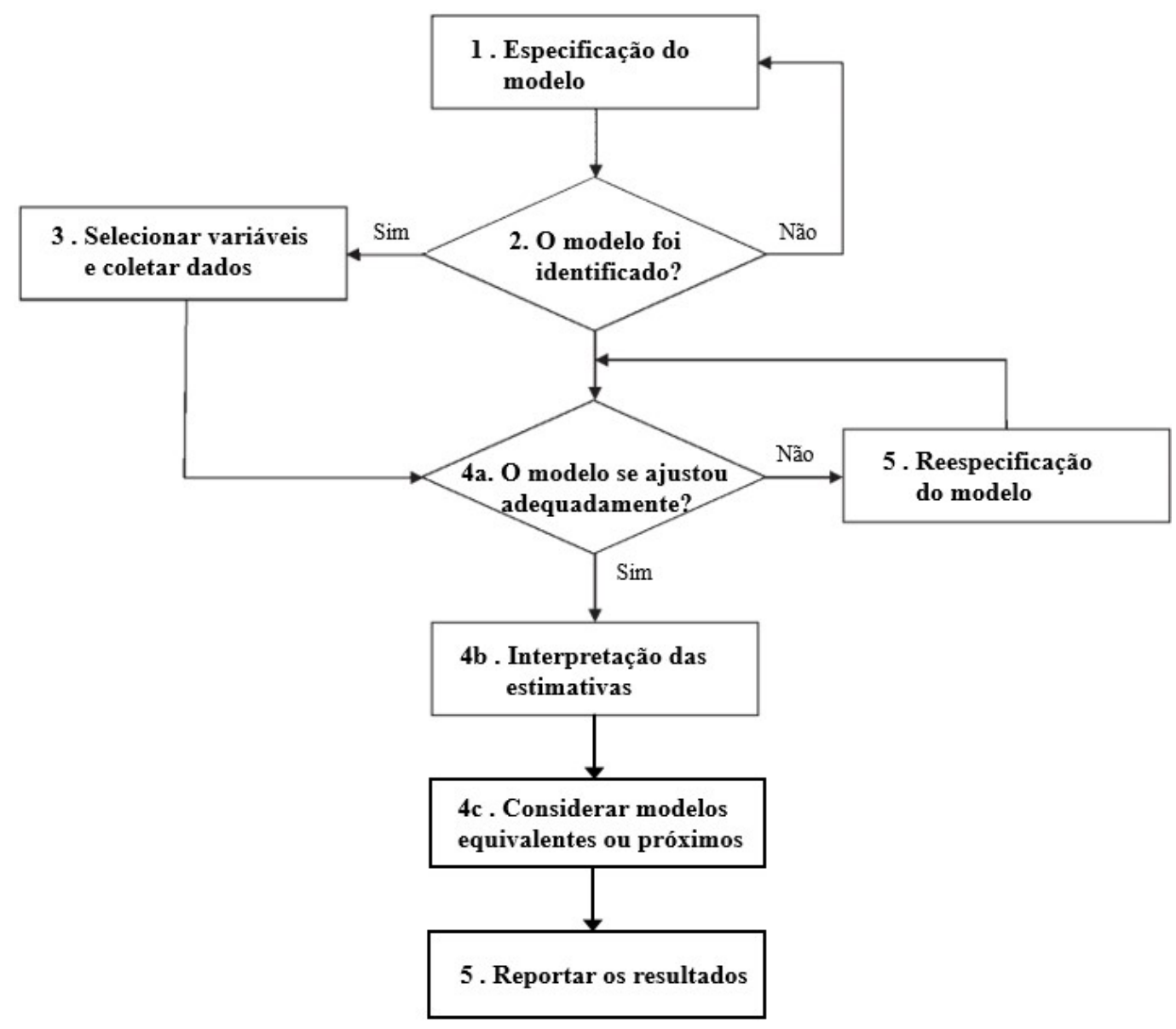

Ilustração 9 - Passos para execução da modelagem de equações estruturais FONTE: adaptado de Kline (2011)

\subsubsection{Pressupostos do Modelo de Equações Estruturais}

A partir do interesse em fortalecer e subsidiar os resultados e conclusões apresentados nessa tese, é imperativo para a realização de qualquer análise estatística, em particular de equações estruturais, que sejam realizadas as devidas validações de um conjunto de pressupostos que verificarão a plausibilidade do modelo teórico (MAROCO, 2010). Essa etapa é imprescindível para as técnicas multivariadas de dados, pois proporciona ao pesquisador um 
poder analítico que sustenta os cálculos estatísticos e a confirmação teórica a partir da verificação das características e do ajuste dos dados coletados (HAIR Jr. et al., 2009). Assim, foram realizadas as seguintes validações: Tamanho amostral; Dados perdidos; Pontos fora da curva; Linearidade; Normalidade e Multicolinearidade. Adicionalmente, também é verificada a questão do viés do método comum (CMB - Common Method Bias) a partir da análise de fator de Harman (PODSAKOFF; ORGAN, 1986).

\subsubsection{Tamanho amostral}

Segundo Hair Jr. et al. (2009), em geral, a SEM requer uma amostra maior em comparação com outras técnicas multivariadas. Muitos fatores impactam no tamanho amostral, dentre eles estão:

1. Entretanto, modelos SEM com até cinco construtos, com no mínimo três itens por construto e comunalidades elevadas (acima de 0.6) podem ser adequadamente estimados com amostras tão pequenas quanto 100;

2. Outro fator que impacta no tamanho amostral é o tipo de procedimento de estimação utilizado na SEM. O procedimento mais comumente utilizado é a estimação de máxima verossimilhança (MLE), o qual segundo os autores fornece resultados válidos com tamanhos amostrais tão pequenos quanto cinquenta;

3. É recomenda que a amostra atenda ao parâmetro de dez casos para cada variável da escala (HAIR et al., 2009).

Esses fatores direcionaram as análises amostrais da pesquisa.

\subsubsection{Dados perdidos (Missing)}

Os dados perdidos ou dados ausentes (Missing Values) ocorrem quando valores válidos sobre uma ou mais variáveis não estão disponíveis para análise. A preocupação com esses dados perdidos deve ser a de manter a distribuição original dos dados através da aplicação de ações corretivas evitando que afetem a generalização dos resultados. Deve-se verificar se a eliminação dos dados perdidos provoca uma redução acentuada na amostra, evitando que haja uma eliminação tendenciosa (HAIR Jr. et al., 2009). 


\subsubsection{Inexistência de pontos fora da curva (Outliers)}

Pontos fora da curva são aqueles que tem uma combinação única de características identificáveis como sendo perceptivelmente diferentes das outras observações. Ocorrem devido a problemas de registro das variáveis ou podem ser extremos que ocorrem naturalmente (HAIR Jr. et al., 2009; MAROCO, 2010). Essas observações atípicas não se configuram de pronto como benéficas ou problemáticas ao modelo devendo-se analisar o contexto e informações que possam oferecer.

A dicotomia apresentada pelo ponto fora da curva pode por um lado ser indicativa de características da população que não seriam descobertas no curso da análise e por outro não representar a população, sendo contrária aos objetivos da análise de maneira a distorcer seriamente os testes estatísticos (HAIR Jr. et al., 2009). Os pontos fora da curva classificamse como moderados e severos, de acordo com o grau de afastamento relativo às outras observações (PESTANA; GAGEIRO, 2008). Quanto à eliminação ou à retenção dos outliers, Hair Jr. et al. (2009) defendem sua manutenção, a menos que se demonstre sua anormalidade e que não são representativas de quaisquer observações da população.

\subsubsection{Linearidade}

O modelo de máxima verossimilhança, o qual será discutido mais detalhadamente a frente, não exige linearidade, entretanto as variáveis do tipo ordinal somente poderão ser tratadas como variáveis quantitativas ao comportarem-se linearmente (MAROCO, 2010). Para averiguar se a relação entre as variáveis é do tipo linear realizou-se o teste de coeficiente de correlação de Pearson, que varia de -1 a +1 . Quanto mais próximo a esses valores for o resultado da relação, maior o grau de associação entre as variáveis, e quanto mais próximo de zero, menor a relação, indicando que não existe correlação entre elas. A relação positiva indica que quando uma variável aumenta de valor a outra acompanha esse aumento (HAIR Jr. et al., 2009).

\subsubsection{Normalidade}

A distribuição normal é necessária em muitos procedimentos estatísticos. Por ser simétrica, a distribuição normal permite o cálculo da média e do desvio padrão como valores mais 
representativos quanto a localização e dispersão respectivamente. Quando a distribuição é normal $68,3 \%$ das observações estarão contidas a um desvio padrão da média.

\subsubsection{Ausência de multicolinearidade}

Segundo Kline (2005), existe multicolinearidade quando as variáveis com correlação de Pearson são maiores que 0,85 . Outra maneira de detectar a presença de multicolinearidade é a partir da análise de VIF (Variance Inflation Factor) a qual não tolera valores superiores a cinco $(\mathrm{VIF}<5)$.

\subsubsection{Análise do viés do método comum (Common Method Bias - CMB)}

As pesquisas empíricas atuais frequentemente utilizam surveys para coletar os dados das variáveis dependentes e independentes simultaneamente em pesquisas do tipo cross-sectional. Tal procedimento traz consigo a possibilidade de enviesar as informações. Esse enviesamento chama-se Common Method Bias - CMB e pode impactar significativamente nas medidas dos erros no modelo estudado. A CMB gera uma falsa consistência interna podendo estabelecer uma correlação aparente entre variáveis decorrente da origem comum dos dados.

No entanto, algumas técnicas foram desenvolvidas para avaliar a CMB, entre elas destaca-se a análise de fator de Harman, a qual consiste em verificar todas as medidas utilizadas na pesquisa a partir da análise de um fator exploratório com a premissa de que a presença de CMB será evidenciada pelo aparecimento de um único fator geral representando a maioria das covariâncias entre as medidas (PODSAKOFF et al. 2003). Embora, a técnica de análise do fator de Harman possua algumas limitações e não seja indicada a sua análise isoladamente, o seu emprego é recomendada para evitar a CMB desde que o modelo em questão seja complexo, uma vez que a CMB costuma aparecer mais frequentemente em modelos simplórios (CHANG; WITTELOOSTUIJIN e EDEN, 2010). Nesse sentido, ressalta-se que o modelo proposto nessa tese contempla quatro construtos interligados, os quais ora comportam-se como variáveis independentes ora como variáveis dependentes, havendo duas variáveis mediadoras e duas moderadoras, esses fatores em conjunto caracterizam um modelo complexo (CHANG; WITTELOOSTUIJIN e EDEN, 2010; HAIR JR. et al., 2009). 


\subsubsection{Especificação do modelo geral}

A partir do modelo teórico proposto foi feita a especificação do modelo que resultou no diagrama de caminhos a ser testado na modelagem de equações estruturais (KLINE, 2010).

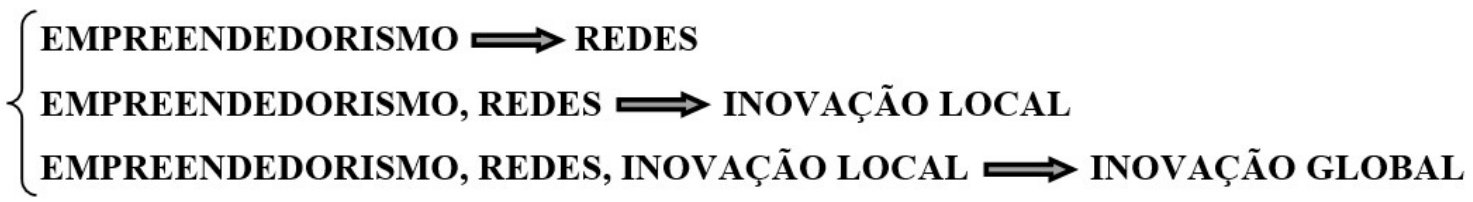

Definidas as relações causais, o próximo passo é determinar as equações estruturais do modelo:

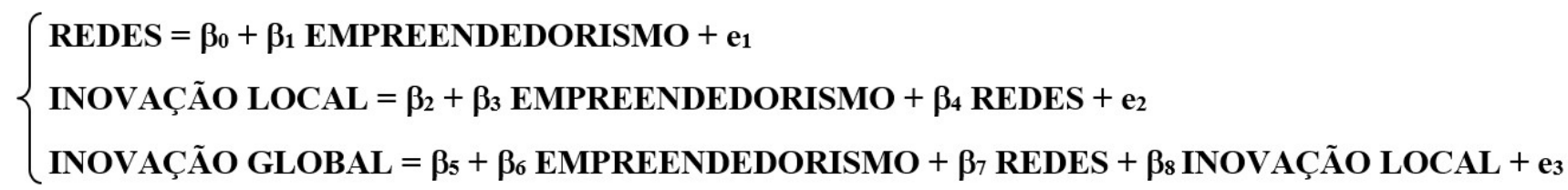

O mapa teórico desenvolvido anteriormente está representado nesse modelo estrutural por meio de um conjunto de equações estruturais que pode ser descrito por meio de um diagrama visual que representa as inter-relações de dependência entre os construtos (KLINE, 2011; BYRNE, 2010).

\subsubsection{Matriz de entrada dos dados e método de estimação do modelo}

A matriz de entrada dos dados refere-se ao método pelo qual serão estimados os parâmetros do modelo (HAIR Jr. et al., 2009), onde a matriz pode ser de covariância ou de correlação, sendo mais indicada, e portanto utilizada, a matriz de covariância em modelagem de equações estruturais. Isso acontece devido a maior flexibilidade propiciada pela matriz de covariância e a possibilidade de se comparar amostras diferentes (BYRNE, 2010; KLINE, 2011). Assim, nesse estudo o método de entrada escolhido foi a matriz de covariância.

Essa pesquisa utilizou a análise fatorial confirmatória (CFA), a qual demonstra como processos confirmatórios podem testar uma teoria, permitindo ao pesquisador averiguar o quão bem as variáveis mensuradas representam os construtos. Isso é feito a partir da validação 
estatística da qualidade do ajustamento do modelo teórico à estrutura correlacional observada entre as variáveis manifestas (MAROCO, 2010; BYRNE, 2009).

Para a estimação das variáveis foi utilizado o método de máxima verossimilhança (MLE), o qual fornece resultados válidos mesmo para amostras pequenas. MLE é o método de estimação mais utilizado, eficiente e sem vieses, ademais permite o uso de índices para adequação (MAROCO, 2010; HAIR Jr. et al., 2009)

\subsubsection{Validação do Modelo Estrutural}

Os modelos de equações estruturais baseados em covariância são avaliados a partir das medidas de qualidade de ajuste - Goodnes-of-fit - GoF (HAIR Jr. et al., 2013).

Estas medidas representam (HAIR Jr. et al., 2009; BYRNE, 2010):

* O grau com que o modelo especificado prediz a matriz de covariância observada;

* O ajuste da teoria aos dados da amostra;

* O quanto um modelo especificado se ajusta a algum modelo alternativo de referência;

* Qual modelo é melhor e

* Compara diferentes modelos e complexidades.

Essas medidas bem como os parâmetros utilizados como referência para avaliar o modelo estrutural apresentado na tese podem ser visualizadas no Quadro 6.

Quadro 6: Referencias adotadas para a SEM

\begin{tabular}{|l|l|l|}
\hline \multicolumn{1}{|c|}{ Estatística } & \multicolumn{1}{|c|}{ Valores de referência } & \multicolumn{1}{c|}{ Descrição } \\
\hline \multirow{2}{*}{$\mathrm{X}^{2}$ e P-value } & Quanto menor melhor; $\mathrm{p}>0.05$ & $\begin{array}{l}\mathrm{X}^{2}: \text { qui-quadrado é a medida } \\
\text { fundamental usada em SEM para } \\
\text { quantificar diferenças entre } \\
\text { matrizes de covariância } \\
\text { observada e estimada. } \\
\end{array}$ \\
& & $\begin{array}{l}\text { P-value: nível de significância } \\
\text { do teste qui-quadrado. }\end{array}$ \\
\hline & $>5-$ Ajustamento ruim & $\mathrm{X}^{2} / \mathrm{gl}$ indica a diferença entre as \\
\hline
\end{tabular}




\begin{tabular}{|c|c|c|}
\hline $\mathrm{X}^{2} / \mathrm{gl}$ & $\begin{array}{l}\text { ]2;5] - Ajustamento sofrível } \\
\text { ]1;2] - Ajustamento bom } \\
\sim 1 \text { - Ajustamento muito bom }\end{array}$ & $\begin{array}{l}\text { matrizes de covariância } \\
\text { observada e estimada. }\end{array}$ \\
\hline $\begin{array}{l}\text { CFI } \\
\text { GFI } \\
\text { AGFI } \\
\text { TLI } \\
\text { RNI }\end{array}$ & $\begin{array}{l}<0.8-\text { Ajustamento ruim } \\
{[0.8 ; 0.9[- \text { Ajustamento sofrível }} \\
{[0.9 ; 0.95[- \text { Ajustamento bom }} \\
\geq 0.95-\text { Ajustamento muito bom }\end{array}$ & $\begin{array}{l}\text { CFI: grau de adequação do } \\
\text { modelo em relação ao modelo } \\
\text { independente. } \\
\text { GFI: grau de adequação do } \\
\text { modelo em relação ao modelo } \\
\text { nulo. } \\
\text { AGFI: índice baseado no GFI } \\
\text { que mede diferentes graus de } \\
\text { complexidade do modelo. } \\
\text { TLI: comparação matemática de } \\
\text { um modelo teórico } \\
\text { mensuração especificado com } \\
\text { um modelo nulo de referência. } \\
\text { RNI: compara o quiquadrado do } \\
\text { modelo estimado com o modelo } \\
\text { nulo. }\end{array}$ \\
\hline RMSEA & $\begin{array}{l}>0.10-\text { Ajustamento ruim } \\
\text { ]0.05;0.08] - Ajustamento bom } \\
\leq 0.05-\text { Ajustamento muito bom }\end{array}$ & $\begin{array}{l}\text { RMSEA: representa o quanto } \\
\text { um modelo se ajusta a uma } \\
\text { população e não apenas a uma } \\
\text { amostra usada para estimação. }\end{array}$ \\
\hline
\end{tabular}

FONTE: Maroco (2010); Hair et al. (2009) e Gefen, Rigdon e Straub (2011).

Entretanto, ressalta-se que, ainda que o modelo apresente as medidas de qualidade do ajuste satisfatória $(\mathrm{GoF} \geq 0.90)$ que esta não deva ser uma regra absoluta. Uma vez que outros fatores como o tamanho da amostra e os estimadores podem influenciar no resultado do modelo. É necessária uma avaliação conjunta das medidas. Nesse sentido, Mulaik et al. (1989) acrescentam que deve-se considerar a razoabilidade da pesquisa bem como a contribuição ao campo de estudos. Hair et al. (2009) entendem que nenhum valor único mágico para os índices de ajuste separa os modelos bons dos ruins, de maneira que a qualidade do ajuste depende consideravelmente da complexidade do modelo. 
A fim de maximizar o ajuste do modelo aos dados seguiu-se as recomendações de alguns autores (HOOPER, COUGHLAN e MULLEN, 2009; HAIR Jr. et al., 2009), retirando-se consecutivamente algumas variáveis do modelo e então efetuando-se os cálculos estruturais novamente.

\subsubsection{Comparação de modelos (Modelos alternativos)}

Kline (2011) diz que, em geral, as pesquisas que utilizam a técnica de equações estruturais falham por não compararem o modelo defendido com outros modelos equivalentes ou próximos. Segundo esse autor, ignorar modelos equivalentes é uma maneira de enviesar a pesquisa, uma vez que o teste de um único modelo exclui outras explicações para os dados. Modelos alternativos podem ajustarem-se de maneira próxima ao modelo escolhido, porém não de maneira exata ou adequada. Nesse intuito, foi realizada uma comparação com um modelo próximo ao desenvolvido na tese utilizando-se os mesmos construtos, porém com uma configuração de causalidade diferente conforme a Ilustração 10: 


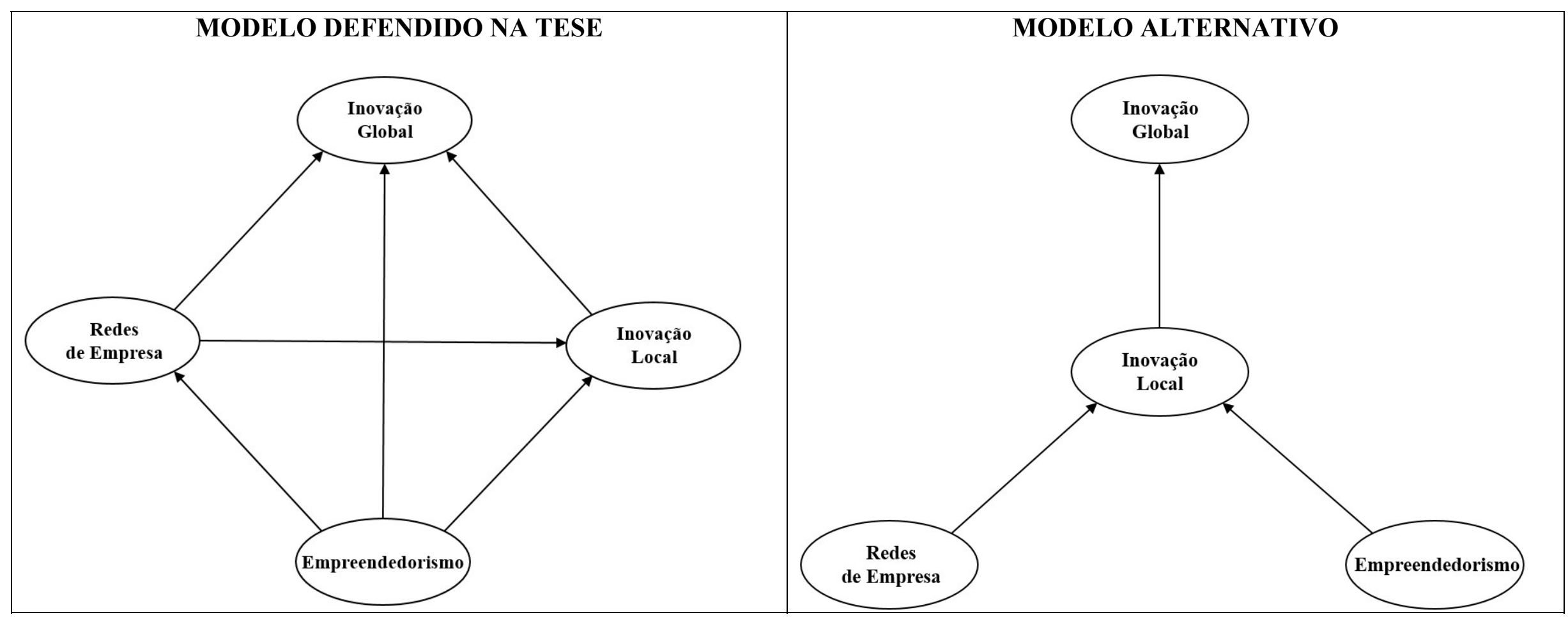

Ilustração 10 - Comparação entre modelos (Modelo alternativo)

FONTE: o autor 


\subsubsection{Análise de mediação em equações estruturais}

A avaliação dos fatores que levam ao desenvolvimento e transferência das inovações realizadas nas subsidiárias conta com dois elementos mediadores: Inserção nas redes interorganizacionais e o Desenvolvimento de inovações locais. Para uma variável ser considerada mediadora é necessário que ela atenda as seguintes condições (BARON e KENNY, 1986):

* Variações na variável independente implicam variações significantes na variável mediadora (A);

* Variações na variável mediadora implicam variações significantes na variável dependente (B);

* Quando os caminhos A e B são controlados, uma relação previamente significante entre a variável independente e a dependente não é mais significante.

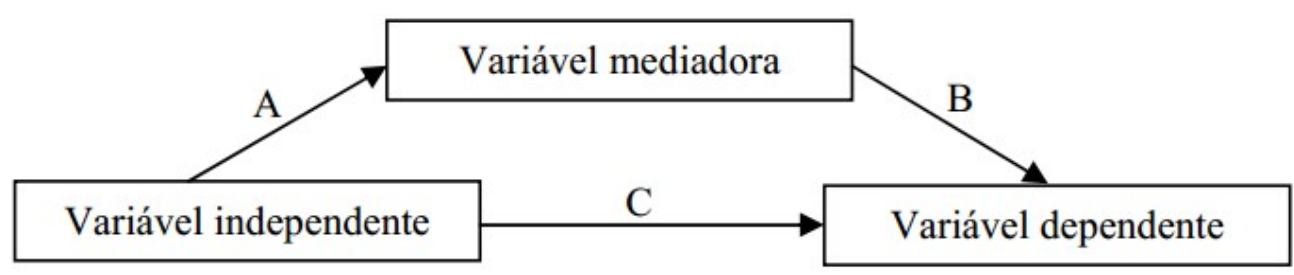

Ilustração 11 - Variável mediadora

FONTE: Baron e Kenny (1986)

A mediação é realizada por uma terceira variável pela qual a variável independente influencia a variável dependente (BARON e KENNY, 1986), em outras palavras, na presença da variável mediadora a relação entre a variável independente e a variável dependente se modifica.

De acordo com Iacobucci, Saldanha e Deng (2007) essa mediação pode ser parcial ou total. Parcial quando apenas diminui a magnitude da associação e total quando elimina a significância existente entre as variáveis independentes e dependentes. Hair Jr. et al. (2009) estabelecem quatro critérios para avaliar se de fato existe um efeito mediador no modelo, deve-se avaliar se: 
1.1 Há correlação significante entre a variável independente e a variável dependente;

1.2 Há correlação significante entre a variável independente e a variável mediadora;

1.3 Há correlação significante entre a variável moderadora e a variável independente;

2. O caminho "C" continua significante e inalterado com a inclusão da mediadora então não existe mediação;

3. "C" é reduzido, mas se mantém significante com a inclusão da mediadora então a mediação é parcial;

4. "C" é reduzido e não é significante com a inclusão da mediadora então a mediação é total.

Ademais, um modelo estrutural com um suposto efeito mediador pode produzir efeitos diretos e indiretos. Efeitos diretos são as relações que conectam dois construtos interligados com apenas uma única seta, enquanto que efeitos indiretos envolvem uma sequência de relações com pelo menos um construto intermediário. Assim, um efeito indireto é uma sequência de dois ou mais efeitos diretos, sendo representado por múltiplas setas.

Essas condições são testadas para os supostos construtos mediadores presentes no modelo proposto, avaliando-se as cargas e suas significâncias para o modelo com mediação e sem a variável mediadora. Nessa tese os construtos mediadores são: Redes de empresa e Inovação local, conforme a Ilustração 12:

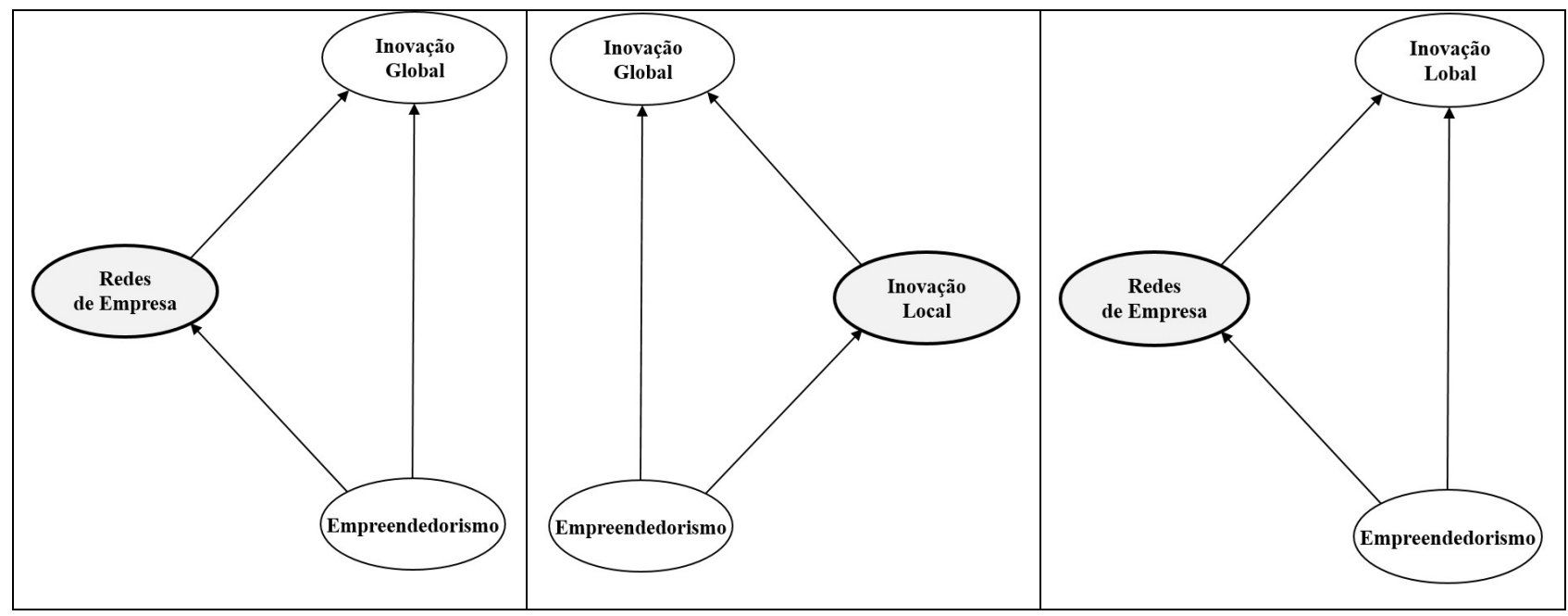

\section{Ilustração 12 - Variáveis mediadoras do modelo proposto}

FONTE: o autor 


\subsubsection{Análise de moderação em equações estruturais}

Além das variáveis mediadoras o modelo proposto apresenta também variáveis moderadoras. Uma distinção entre variável moderadora e variável mediadora é que as variáveis de moderação sempre funcionam como variáveis independentes, enquanto que as variáveis mediadoras podem ter papel de causa ou efeito (BARON e KENNY, 1986).

Efeitos moderadores ocorrem quando uma variável moderadora influencia o nível dos efeitos diretos entre uma variável independente e uma variável dependente (HENSELER e FASSOT, 2010).

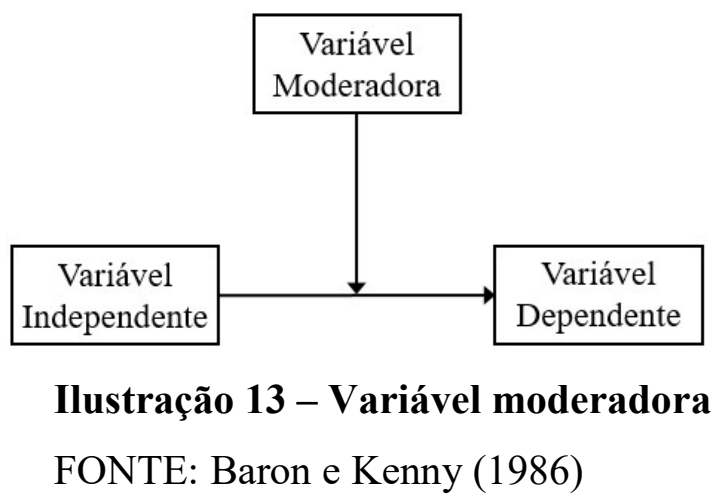

Em outras palavras, uma variável moderadora afeta a direção ou a força da relação entre duas outras variáveis, podendo a variável moderadora ser qualitativa ou quantitativa, sendo que muitas das variáveis são discretas e nominais (BARON; KENNY, 1986; SAUER e DICK, 1993). Quando uma ou ambas as variáveis que estão interagindo são discretas pode-se utilizar a abordagem multigrupos, com os efeitos de interação se revelando quando o mesmo modelo é aplicado para conjuntos de dados distintos, porém relacionados (RIGDON et al., 1998). Quando a variável moderadora é categórica pode ser utilizado o agrupamento de variáveis sem refinamentos adicionais. Entretanto, quando uma variável métrica contínua é utilizada como variável agrupadora, é necessário inicialmente transformá-la em uma variável categórica dicotomizando-a em dois valores.

Esse procedimento foi realizado na variável utilizada nesse estudo: variável tamanho (Ilustração 14). A variável "tamanho" é uma dummy, onde 0 representa as pequenas e médias empresas e 1 representa as empresas de grande porte. Esses indicadores se diferenciam e, por isso, são denominados multigrupos. A variável tamanho refere-se ao porte da subsidiária em termos de funcionários, de maneira que empresas com mais de 500 funcionários foram 
classificadas como de grande porte e as com menos de 500 foram enquadradas como sendo de pequeno e médio porte. Assim a amostra foi dividida em duas partes e procedeu-se um teste de significância a fim de detectar possíveis diferenças entre as amostras a partir da comparação multigrupos efetuada no software IBM Amos em conjunto com o Microsoft Excel. Nesse sentido, a abordagem de comparação multigrupos é a escolha mais acertada quando as variáveis são discretas ou categóricas (RIGDON et al., 1998). Os modelos que utilizam variáveis moderadoras têm como objetivo verificar se a relação entre a variável independente e a variável dependente é reduzida, nula ou invertida a partir da troca do sinal da relação.

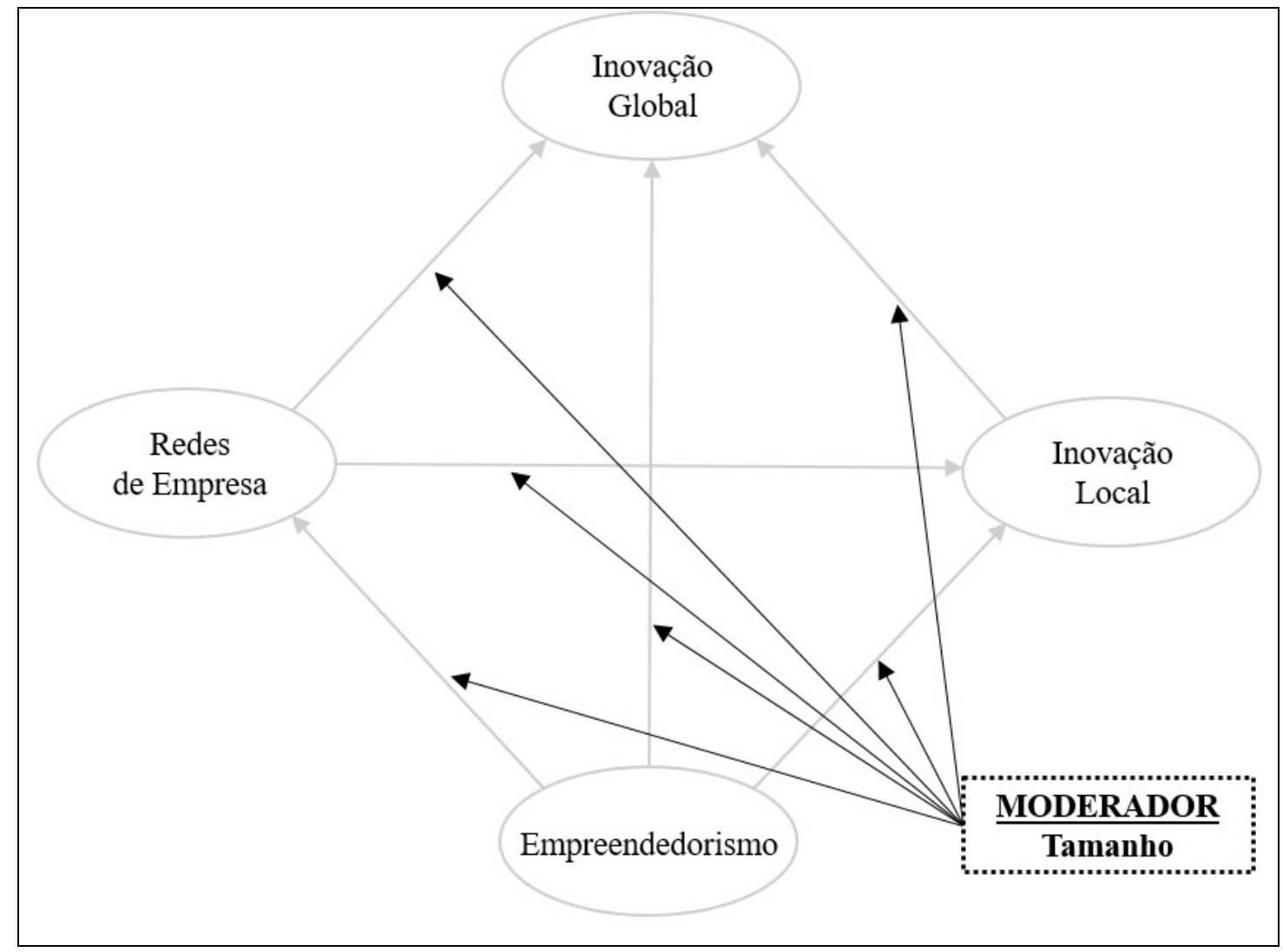

Ilustração 14 - Variável moderadora do modelo proposto

FONTE: o autor

A análise do efeito moderador pode contribuir com um melhor entendimento das relações entre as variáveis estudadas. 


\subsubsection{Limitações do Método de pesquisa}

$\mathrm{O}$ uso de amostragem probabilística estratificada teria aumentado o alcance dos resultados e por conseguinte das conclusões aqui apresentadas. No entanto, devido a dificuldades inerentes a coleta dos dados, em particular a partir de surveys, utilizou-se nessa tese uma amostra nãoprobabilística por conveniência, o que dificulta que se façam generalizações com os achados da pesquisa.

Nesse sentido, outro fator limitador é que essa tese apoia se num estudo quantitativo o qual faz uso de dados provenientes de um questionário aplicado com empresas multinacionais estrangeiras que operam apenas no Brasil. O que também não permite que se façam generalizações para outros países com economia, tamanho ou nível de desenvolvimento semelhante.

Ainda sob o ponto de vista da amostra, o objeto de pesquisa: subsidiárias de corporações multinacionais, traz consigo uma limitação quanto a impossibilidade de cruzar as percepções das subsidiárias com as da matriz. Entretanto, essa é uma limitação que permeia os trabalhos em negócios internacionais (MINBAEVA, 2007).

O questionário aplicado não visou analisar especificidades setoriais da economia. Ademais, outra questão relacionada ao questionário aplicado são os respondentes (presidentes, CEO, vice-presidentes, diretores, e cargos similares), os quais podem trazer consigo um viés no tocante ao não conhecimento de todas as questões abordadas, a pesar da assunção de que os membros da cúpula diretiva conheçam de forma profunda as atividades estratégicas desenvolvidas pelas empresas. Entretanto, o viés pode existir caso o questionário tenha sido respondido por outros integrantes da empresa que não aqueles que compõem a cúpula diretiva. Há que se levar em conta também a qualidade das informações ainda que essas tenham sido respondidas por membros da alta direção. A fim de reduzir o problema do viés, essa pesquisa conduziu a análise de fator de Harman (PODSAKOFF; ORGAN, 1986). 


\section{APRESENTAÇÃO E ANÁLISE DOS RESULTADOS}

Esse capítulo apresenta os resultados da pesquisa, sua análise e interpretação a partir, sobretudo, da modelagem de equações estruturais. A fim de validar a amostra e o modelo proposto foram realizados, num primeiro momento, muitos testes estatísticos auxiliares, como a análise de dados perdidos; análise de pontos fora da curva; linearidade; normalidade; multicolinearidade e de viés do método. Num segundo momento, outras validações foram executadas pela modelagem de equações estruturais. A SEM também foi utilizada para testar as hipóteses da pesquisa. A apresentação dos resultados leva em conta que o modelo proposto na pesquisa apresenta seis hipóteses que visam aumentar o entendimento sobre os fatores que auxiliam no desenvolvimento de inovações com escopo global, interpretando-se separadamente as hipóteses pertinentes a cada fator.

\subsection{Estatísticas Descritivas}

O survey foi respondido por 181 subsidiárias de empresas multinacionais instaladas no Brasil, tendo resultado em uma base de dados composta por 172 questionários válidos. A amostra é composta por diferentes perfis de subsidiárias, havendo diferenças quanto ao porte; data da implantação da subsidiária no Brasil e quanto ao macro-setor econômico em que a subsidiária opera.

Do total de 172, 74\% (127 casos) são empresas do setor industrial, 24\% (41 casos) do setor de serviços e 2\% (4 casos) referentes ao setor agronegócio.

\section{AMOSTRA: MACRO-SETORES DA ECONOMIA}

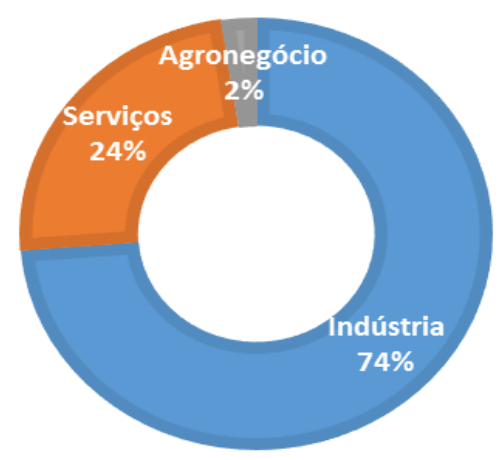

\section{Gráfico 5 - Setores econômicos de atuação das MNCs}

FONTE: o autor com base nos dados da pesquisa 
A origem das subsidiárias é: África e Oceania (2\%), América Latina (5\%), Ásia (6\%), América do Norte (29\%) e Europa (58\%).

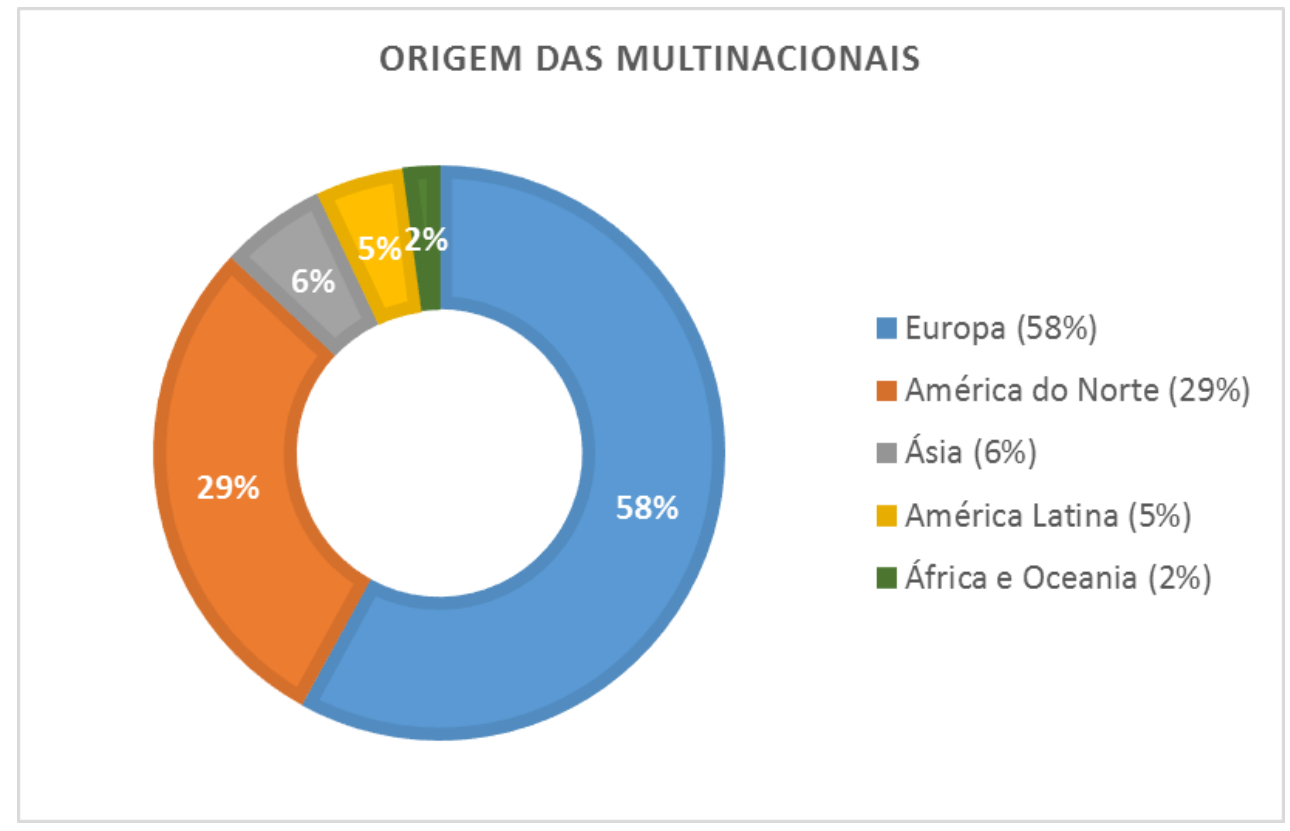

\section{Gráfico 6 - Origem das MNCs}

FONTE: o autor com base nos dados da pesquisa

Quanto ao porte das subsidiárias, 44\% da amostra é composta por grandes empresas (mais de 500 funcionários) e $56 \%$ é composta por pequenas e médias empresas (menos de 500 funcionários).

\section{TAMANHO DA SUBSIDIÁRIA}

Menos que 500 funcionários (56\%) Mais que 500 funcionários (44\%)

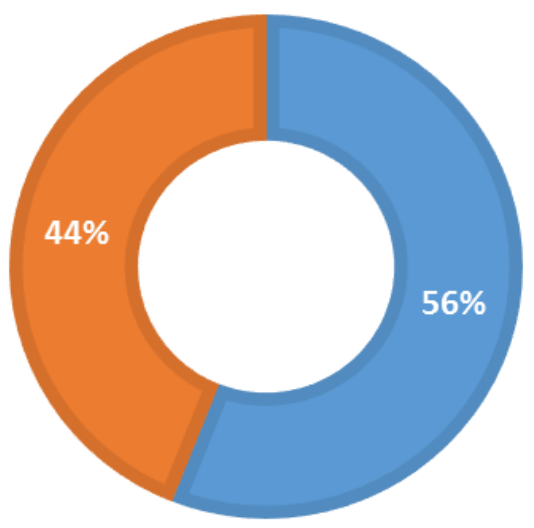

\section{Gráfico 7 - Tamanho da subsidiária}

FONTE: o autor com base nos dados da pesquisa 


\subsection{Análise dos Pressupostos da SEM}

O tamanho da amostra utilizada nessa tese atende aos requisitos necessários para a modelagem de equações estruturais (HAIR JR et al., 2009):

1. O modelo possui quatro construtos compostos por três itens cada e com comunalidades superiores a 0.6 conforme APÊNDICE III;

2. O método de estimação utilizado é o de máxima verossimilhança (MLE);

3. O número de variáveis utilizadas no modelo final são 12 , multiplicando-se o número de variáveis por 10 tem-se 120 como o tamanho mínimo para amostra, sendo que a amostra utilizada nesse estudo é composta por 172 questionários válidos.

Ademais, muitas pesquisas em negócios internacionais e que endereçam temática semelhante têm sido desenvolvidas com amostras semelhantes, por exemplo: $\mathrm{n}=169$ em Foss, Laursen e Pedersen (2011), $\mathrm{n}=104$ em Chang, Cheng e Wu (2012) e n = 158 em Li, Wang, Huang e Bai (2013).

Quanto aos dados ausentes e fora da curva (APÊNDICE II), o teste executado pelo software IBM SPSS não detectou nenhum dado ausente, porém detectou $11 \%$ de dados fora da curva. Esses valores extremos retratam a diversidade da amostra representando a sua realidade e, portanto, foram mantidos na amostra (HAIR JR. et al., 2009).

A Tabela 1 apresenta os coeficientes de correlação de Pearson e o teste de Variance Inflation Factor - VIF, onde os coeficientes de correlação possuem valores positivos menores que 0,85 (KLINE, 2005) e o teste VIF atende ao parâmetro recomendado pela literatura: VIF $<5$ (MAROCO, 2010).

Tabela 1 - Correlações e teste VIF

\begin{tabular}{lccccccc}
\hline & VIF & Média & Desvio & I & II & III & IV \\
\hline I - Redes de empresas & 1.15 & 3.80 & 0.69 & 1 & & & \\
II - Inovação Local & 1.06 & 3.70 & 0.78 & $0.23^{* *}$ & 1 & & \\
III - Inovação Global & 1.15 & 2.90 & 0.77 & $0.41^{* *}$ & $0.24^{* *}$ & 1 & \\
IV - Empreendedorismo & 1.16 & 4.00 & 0.64 & $0.37^{* *}$ & $0.24^{* *}$ & $0.23^{* *}$ & 1 \\
\hline \hline
\end{tabular}

$* * \mathrm{P}<0.01$ e $* \mathrm{P}<0.05$

FONTE: o autor com base nos dados da pesquisa 
Dado o fato de que as variáveis dependentes e independentes são provenientes de um questionário, a questão do viés do método comum (CMB - Common Method Bias) pode ocorrer. Nesse sentido, foi conduzida a análise de fator de Harman (PODSAKOFF; ORGAN, 1986), o qual apresentou uma variância comum de 31.90\% (<50\%), sugerindo não haver viés do método na pesquisa (APÊNDICE II).

Além dos testes de linearidade, multicolinearidade e de detecção de CMB, os dados também foram submetidos ao teste de normalidade, conforme o APÊNDICE II. As variáveis que compõem os construtos apresentaram valores de curtose $(k u)$ e assimetria $(s k)$ dentro dos parâmetros estatísticos sugeridos por Kline (2005):

$$
\left\{\begin{array}{l}
k u<|2| \\
s k<|1|
\end{array}\right.
$$

\section{3 Índices de ajuste do modelo (Validação do modelo estrutural)}

Realizados esses testes, duas outras validações se fazem necessárias para o modelo: validade convergente e validade discriminante. Para a validade convergente são sugeridos como ideais (HAIR JR. et al., 2009): Confiabilidade Composta (CC > 0,7) e Variância Extraída (AVE > 0,5). Após a obtenção dos coeficientes de regressão padronizados, iniciou-se o cálculo da CC e da AVE. A partir da análise das cargas de cada indicador (v1, v2, v3...v16) optou-se pela remoção do indicador de menor carga, pois segundo Hooper, Coughlan e Mullen (2009) e Hair Jr. et al. (2009) é uma boa prática acessar os ajustes individuais de cada construto para determinar qual item é o mais fraco e então removê-lo da análise. Feita a remoção, o modelo foi recalculado e assim gerado novos coeficientes de regressão padronizados os quais foram novamente usados para o cálculo da $\mathrm{CC}$ e da AVE até que fossem satisfeitos os índices sugeridos conforme apresentado na Ilustração 15, onde restaram três itens por construtos totalizando doze variáveis no modelo final. Isso atende a recomendação de Hair Jr. et al. (2009) que orientam que se tenha ao menos três variáveis por construto. 


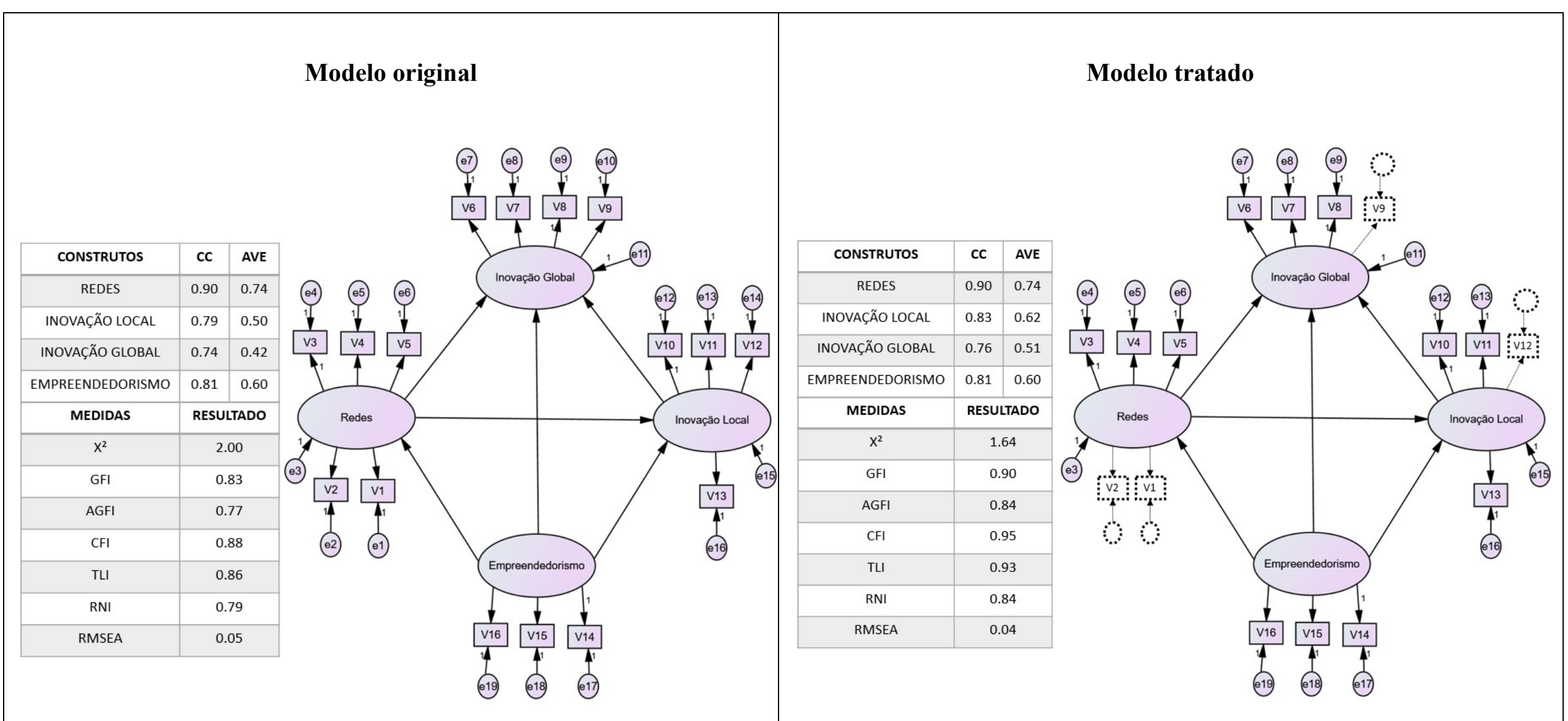

Ilustração 15 - Comparação do modelo original com o modelo tratado

FONTE: o autor com base nos dados da pesquisa. 
Uma vez verificada a validade convergente faz-se necessário verificar também a validade discriminante a qual consiste em medir a diferença entre os construtos. Para realizar tal aferição, utilizou-se o cálculo das variâncias compartilhadas (Tabela 2), método sugerido por Fornell e Larcker (1981). Verifica-se que os construtos atendem as especificidades do método proposto por Fornell e Larcker (1981), uma vez que os $\mathrm{R}^{2}$ são inferiores aos valores de AVE (em negrito), demonstrando que a validação discriminante é aceita para todos os construtos.

Tabela 2 - Validade Discriminante: Critério de Fornell e Lacker (1981)

\begin{tabular}{lcccc}
\hline & I & II & III & IV \\
\hline I - Redes de empresas & $\mathbf{0 . 7 4}$ & & & \\
II - Inovação Local & 0.02 & $\mathbf{0 . 6 2}$ & & \\
III- Inovação Global & 0.03 & 0.05 & $\mathbf{0 . 5 1}$ & \\
IV - Orientação Empreendedora & 0.01 & 0.01 & 0.01 & $\mathbf{0 . 6 0}$ \\
\hline \hline
\end{tabular}

FONTE: o autor com base nos dados da pesquisa

Por fim, o modelo estrutural resultante apresentou os índices de ajustes adequados a complexidade do modelo. A saber: $\mathrm{X}^{2} / \mathrm{gl}=1.64 ; \mathrm{CFI}=0.95$; $\mathrm{GFI}=0.90 ; \mathrm{AGFI}=0.84$; $\mathrm{TLI}=$ 0.93; RNI $=0.84$ e RMSEA $=0,04$. Os resultados atendem as referências sugeridas por Hair Jr. et al. (2009) e Maroco (2010), onde: $\mathrm{X}^{2} / \mathrm{gl}<2.0$; CFI > 0.90; GFI > 0.90; AGFI > 0.90; TLI $>0.90 ;$ RNI $=0.90$ e RMSEA $<0.08$.

Embora as medidas AGFI e RNI tenham apresentado valores abaixo dos índices recomendados, ressalta-se a recomendação de Hair Jr. et al. (2009) que orientam a não utilizar as regras de medida de qualidade do ajuste (Goodnes-of-fit $\geq 0.90)$ como uma regra absoluta, uma vez que outros fatores como o tamanho da amostra e os estimadores podem influenciar no resultado do modelo. Mulaik et al. (1989) acrescentam que deve-se considerar a razoabilidade da pesquisa bem como a contribuição ao campo de estudos. Hair Jr. et al. (2009) entendem que nenhum valor único mágico para os índices de ajuste separa os modelos bons dos ruins, de maneira que a qualidade do ajuste depende consideravelmente da complexidade do modelo, de maneira que modelos mais simples demandam padrões mais estritos do que modelos mais complexos. 
Nesse sentido, ressalta-se que o modelo testado nessa tese contempla quatro construtos interligados, os quais ora comportam-se como variáveis independentes ora como variáveis dependentes, havendo duas variáveis mediadoras e duas moderadoras, o que caracteriza um modelo complexo (CHANG; WITTELOOSTUIJIN e EDEN, 2010). Ademais, essa pesquisa endereça três temáticas emergentes em negócios internacionais as quais devem ser melhor compreendidas, em particular, em contextos de nações em desenvolvimento onde poucas foram as pesquisas que lançaram luz sobre o assunto utilizando-se da percepção de altos executivos de multinacionais.

A seguir, a Tabela 3 apresenta os modelos estruturais contendo as medidas para os construtos e as variáveis que compõem o modelo.

Tabela 3 - Medidas

\begin{tabular}{|c|c|c|c|c|c|c|c|}
\hline \multicolumn{8}{|c|}{ Subsidiárias estrangeiras $(n=172$ ou $17 \%)$} \\
\hline Construto & Variáveis & $\lambda^{\mathbf{a}}$ & t Value & $\mathbf{R}^{2}$ & $\boldsymbol{\alpha}^{\mathbf{b}}$ & $\mathbf{C C}$ & AVE \\
\hline \multirow{3}{*}{$\begin{array}{l}\text { Redes de } \\
\text { empresas }\end{array}$} & V3 & 0.89 & 1.00 & 0.78 & \multirow{3}{*}{0.89} & \multirow{3}{*}{0.90} & \multirow{3}{*}{0.74} \\
\hline & V4 & 0.91 & 15.18 & 0.83 & & & \\
\hline & V5 & 0.79 & 12.72 & 0.62 & & & \\
\hline \multirow{3}{*}{ Inovação Global } & V6 & 0.66 & 7.00 & 0.44 & \multirow{3}{*}{0.75} & \multirow{3}{*}{0.76} & \multirow{3}{*}{0.51} \\
\hline & V7 & 0.68 & 7.10 & 0.46 & & & \\
\hline & V8 & 0.79 & 1.00 & 0.62 & & & \\
\hline \multirow{3}{*}{ Inovação Local } & V10 & 0.92 & 1.00 & 0.85 & \multirow{3}{*}{0.82} & \multirow{3}{*}{0.83} & \multirow{3}{*}{0.62} \\
\hline & V11 & 0.78 & 9.62 & 0.61 & & & \\
\hline & V13 & 0.64 & 8.17 & 0.41 & & & \\
\hline \multirow{3}{*}{$\begin{array}{c}\text { Orientação } \\
\text { empreendedora }\end{array}$} & V14 & 0.72 & 1.00 & 0.52 & \multirow{3}{*}{0.80} & \multirow{3}{*}{0.81} & \multirow{3}{*}{0.60} \\
\hline & V15 & 0.93 & 8.70 & 0.87 & & & \\
\hline & V16 & 0.63 & 7.80 & 0.39 & & & \\
\hline
\end{tabular}

Nota: (a) Item padronizado;(b) Alfa de Cronbach.

FONTE: o autor com base nos dados da pesquisa

A partir da Tabela 3, é possível verificar o relacionamento entre as variáveis do modelo, bem como seus respectivos pesos sobre cada construto. Os altos valores das cargas padronizadas ( $\lambda$ ) que constituem os construtos sugerem a importância dessas variáveis para a predição do modelo. Segundo Hair Jr. et al (2009), também sugerem um bom ajuste do modelo uma vez que as comunalidades são elevadas (acima de 0.6). 


\subsection{Comparação de Modelos}

A partir da recomendação de Kline (2010) foi realizada uma comparação entre o modelo defendido na tese e outro modelo alternativo equivalente. A importância desse teste está em diminuir o viés da pesquisa ao não ignorar outras explicações para os dados a partir de um outro modelo.

Os resultados (APÊNDICE IV) demonstram que o modelo escolhido pela pesquisa apresenta índices de ajustamento superiores ao modelo alternativo, sugerindo ser de fato o mais adequado à pesquisa.

\subsection{Testes de Hipóteses}

As hipóteses de teste podem ser enunciadas da seguinte forma:

* Hipóteses nulas (H0): $\left\{\begin{array}{l}\text { - a variável independente não influencia no desenvolvimento e } \\ \text { transferência de inovações globais; } \\ \text { - a variável independente não influencia na inserção em redes } \\ \text { interorganizacionais; } \\ \text { - a variável independente não influencia no desenvolvimento de } \\ \text { inovações locais. }\end{array}\right.$

* Hipóteses alternativas (H1): $\left\{\begin{array}{l}\text { - a variável independente influencia no desenvolvimento e } \\ \text { transferência de inovações globais; } \\ \text { - a variável independente influencia na inserção em redes } \\ \text { interorganizacionais; } \\ \text { - a variável independente influencia no desenvolvimento de } \\ \text { inovações locais. }\end{array}\right.$ 
A tabela 4 apresenta os testes de significância das hipóteses bem como o peso de cada relação no modelo estrutural.

Tabela 4 - Teste de Hipóteses

\begin{tabular}{ccccccccc}
\hline Hipótese & \multicolumn{2}{c}{ Relacionamento entre os construtos } & $\lambda^{\mathbf{a}}$ & $\mathbf{C . R}^{\mathbf{b}}$ & Sig. (p) & Resultados \\
\hline $\mathrm{H} 1$ & Inovação Global & $\leftarrow$ & Inovação Local & 0.15 & 2.44 & 0.01 & Aceita \\
$\mathrm{H} 2 \mathrm{a}$ & Inovação Global & $\leftarrow$ & Redes de empresas & 0.32 & 3.04 & 0.00 & Aceita \\
$\mathrm{H} 2 \mathrm{~b}$ & Inovação Local & $\leftarrow$ & Redes de empresas & 0.31 & 2.03 & 0.04 & Aceita \\
$\mathrm{H} 3 \mathrm{a}$ & Redes de empresas & $\leftarrow$ & Empreendedorismo & 0.47 & 4.07 & 0.00 & Aceita \\
$\mathrm{H} 3 \mathrm{~b}$ & Inovação Global & $\leftarrow$ & Empreendedorismo & 0.24 & 1.70 & 0.09 & Rejeitada \\
$\mathrm{H} 3 \mathrm{c}$ & Inovação Local & $\leftarrow$ & Empreendedorismo & 0.30 & 1.47 & 0.14 & Rejeitada \\
\hline \hline
\end{tabular}

Nota: (a) Pesos padronizados; (b) Critical Ratio.

FONTE: o autor com base nos dados da pesquisa

Em termos de indicadores, para aceitação das hipóteses, o Critical Ratio (C.R.) deve ser superior a 1.96 para uma significância em nível 0.05 e acima de 2.58 para uma significância em nível 0.01. As hipóteses: H1, H2a, H2b e H3a foram suportadas, atendendo aos índices estatísticos. Enquanto que as hipóteses: H3b e H3c não atenderam aos índices estatísticos e, portanto, foram rejeitadas.

A hipótese H1 expressa a relação entre o desenvolvimento de inovações locais e inovações globais. Essa hipótese foi suportada $(\mathrm{p}<0.05)$ e apresentou um impacto de 0.15 .

As relações entre a rede interorganizacional na qual a subsidiária está inserida e o desenvolvimento de inovações globais e locais estão expressas nas hipóteses H2a e H2b, as quais foram suportadas $(\mathrm{p}<0.01 \mathrm{e} p<0.05)$, apresentando um impacto substancial de 0.32 para as inovações globais e de 0.31 para as inovações locais conforme a Tabela 4 .

Por fim, as hipóteses H3a, H3b e H3c expressam a relação entre a orientação empreendedora que a subsidiária possui e o seu impacto sobre: a inserção na rede de empresas; o desenvolvimento de inovações globais e o desenvolvimento de inovações locais. Somente a 
hipótese referente ao relacionamento entre o empreendedorismo e a inserção na rede (H3a) foi suportada ( $\mathrm{p}<0.001)$, apresentando o maior impacto no modelo 0.47 .

\subsection{Análise do Efeito Mediador dos construtos: Redes de empresas e Inovação local}

Seguindo-se os critérios estipulados por Hair Jr. et al. (2009) e por Iacobucci, Saldanha e Deng (2007), constatou-se que apenas o construto de Redes interorganizacionais funciona como variável mediadora. O construto de Inovação Local não possui efeito mediador no modelo, uma vez que a mediação requer correlação significante entre as variáveis independente e mediadora. Teoricamente, um construto mediador facilita a relação entre a variável independente e dependente (HAIR JR. et al., 2009).

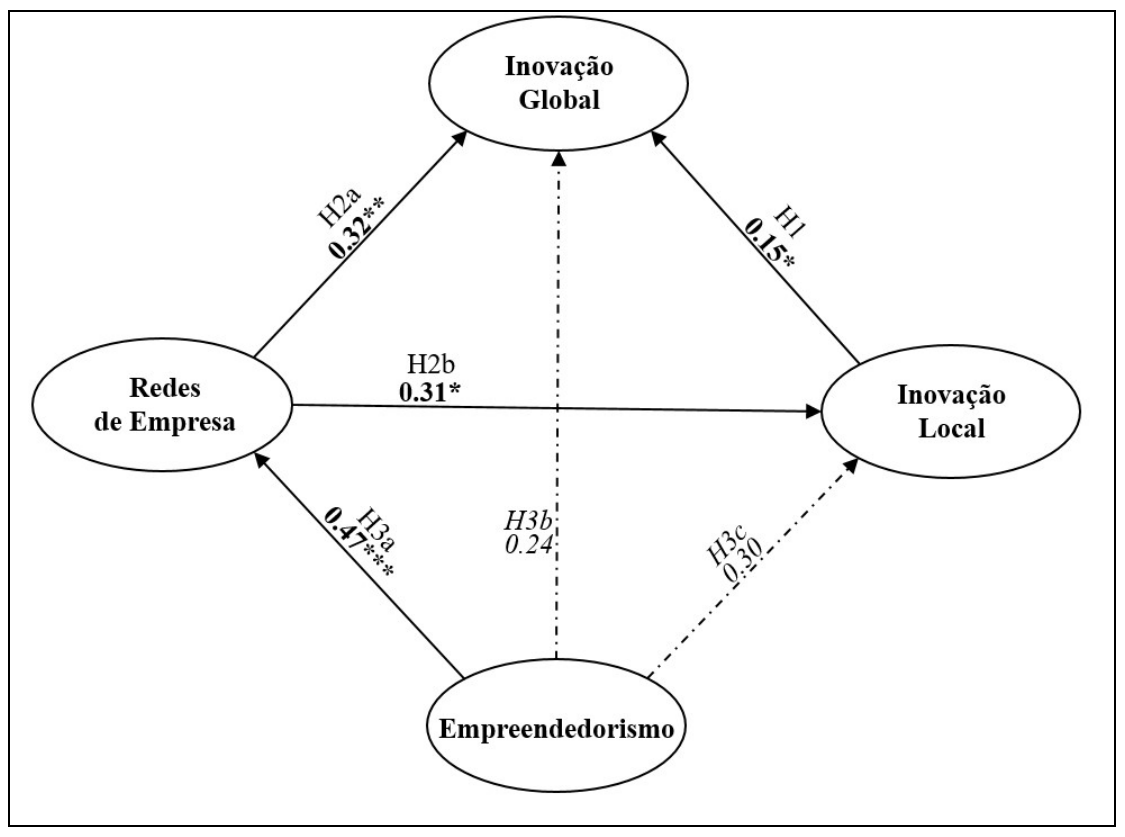

\section{Ilustração 16 - Sumário dos resultados da SEM}

Nota: $\quad * p<0.05 ; \quad * * p<0.01 ; \quad * * * p<0.001 ; \rightarrow \quad$ indica que o caminho é significativo; $\cdots>$ indica que o caminho é não significativo.

FONTE: o autor com base nos dados da pesquisa

Ao se analisar as tríades de construtos é possível constatar que:

- O relacionamento entre as variáveis independente e dependente já não mais são significativos (Empreendedorismo $\rightarrow$ Inovação Global), indicando que a variável mediadora (Redes) exerce mediação total no modelo. 
- O relacionamento entre as variáveis independente e mediadora (Empreendedorismo $\rightarrow$ Inovação Local) não são significantes, não satisfazendo o pressuposto inicial para o efeito mediador.

Assim, verificasse que a variável Redes exerce uma dupla mediação no modelo analisado, mediando ora a relação entre o Empreendedorismo e Inovação Global e ora a relação entre Empreendedorismo e Inovação Local.

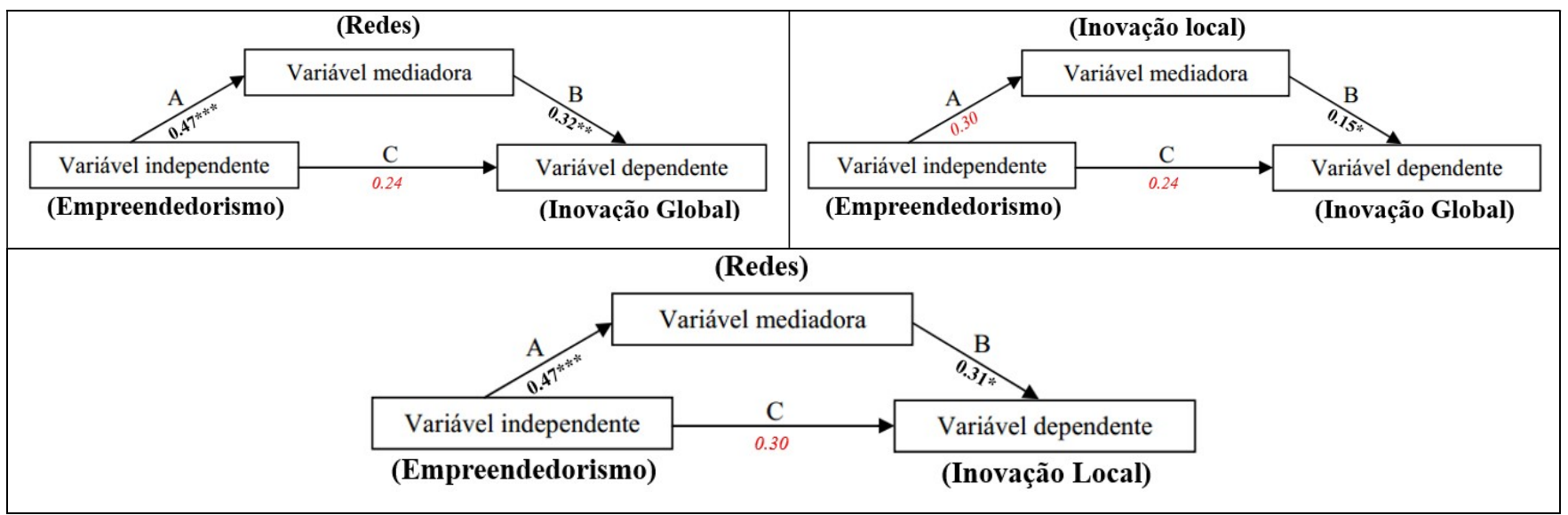

\section{Ilustração 17 - Variável mediadora (Resultados)}

FONTE: o autor com base nos dados da pesquisa

\subsection{Análise do Efeito Moderador da Variável: Tamanho}

Complementarmente ao teste das hipóteses foi verificado o efeito moderador da variável "tamanho". A variável tamanho refere-se ao porte da subsidiária em termos de funcionários, de maneira que empresas com mais de 500 funcionários foram classificadas como de grande porte e as com menos de 500 foram enquadradas como sendo de pequeno e médio porte. Assim a amostra foi dividida em duas partes e procedeu-se um teste de significância a fim de detectar possíveis diferenças entre as amostras.

Para verificar essas diferenças procedeu-se uma análise de multigrupos. Os resultados na Tabela 5 mostram que os subgrupos (Grande porte e Pequeno e Médio porte) não possuem diferenças que impactem no modelo, de maneira que não exercem um efeito moderador sobre nenhum caminho do modelo estrutural. 
Tabela 5 - Efeito Moderador: resultados da análise de multigrupos

\begin{tabular}{|c|c|c|c|c|c|c|}
\hline \multirow[b]{2}{*}{$\mathrm{H} 1$} & \multicolumn{2}{|c|}{ Variável moderadora: Tamanho } & \multirow{2}{*}{$\frac{>\mathbf{5 0 0}}{0.04}$} & \multirow{2}{*}{$\frac{<500^{b}}{0.17^{*}}$} & \multirow{2}{*}{$\frac{\text { Z-score }}{0.71}$} & \multirow{2}{*}{$\frac{\text { Significante }}{\text { Não }}$} \\
\hline & Inovação Global & $\leftarrow \quad$ Inovação Local & & & & \\
\hline $\mathrm{H} 2 \mathrm{a}$ & Inovação Global & $\leftarrow$ Redes de empresas & 0.15 & $0.33 *$ & 0.53 & Não \\
\hline $\mathrm{H} 2 \mathrm{~b}$ & Inovação Local & $\leftarrow$ Redes de empresas & 0.40 & 0.23 & 0.64 & Não \\
\hline $\mathrm{H} 3 \mathrm{a}$ & Redes de empresas & $\leftarrow$ Empreendedorismo & $0.59 * *$ & $0.39 * *$ & 0.99 & Não \\
\hline $\mathrm{H} 3 \mathrm{~b}$ & Inovação Global & $\leftarrow$ Empreendedorismo & 0.50 & 0.14 & 0.72 & Não \\
\hline $\mathrm{H} 3 \mathrm{c}$ & Inovação Local & $\leftarrow$ Empreendedorismo & 0.11 & 0.39 & 1.03 & Não \\
\hline
\end{tabular}

Nota: (a) Empresas grandes com mais de 500 funcionários; (b) Pequenas e médias empresas com menos de 500 funcionários; $* * \mathrm{P}<0.01$ e $* \mathrm{P}<0.05$

Os Quadros 7 e 8 apresentam a síntese dos resultados obtidos com os testes de hipóteses e dos efeitos mediador e moderador.

\section{Quadro 7 - Resumo dos resultados dos testes de hipóteses}

\begin{tabular}{|c|c|c|c|c|}
\hline \multirow{2}{*}{ Hipóteses } & Resumo & Relação & \multicolumn{2}{|c|}{ Resultado do teste } \\
\cline { 3 - 5 } & esperada & Relação obtida & Significância \\
\hline $\mathrm{H} 1$ & Inovações locais em produto e processo podem \\
tornarem-se globais & + & + & $<0.05$ \\
\hline $\mathrm{H} 2 \mathrm{a}$ & Empresas parceiras ajudam a inovar globalmente & + & + & $<0.01$ \\
\hline $\mathrm{H} 2 \mathrm{~b}$ & Empresas parceiras ajudam a inovar localmente & + & + & $<0.05$ \\
\hline $\mathrm{H} 3 \mathrm{a}$ & Iniciativas da subsidiária levam a cooperar & + & + & $<0.001$ \\
\hline $\mathrm{H} 3 \mathrm{~b}$ & Iniciativas da subsidiária levam a inovar globalmente & + & Não significante \\
\hline $\mathrm{H} 3 \mathrm{c}$ & Iniciativas da subsidiária levam a inovar localmente & + & & Não significante \\
\hline
\end{tabular}

FONTE: o autor com base nos dados da pesquisa

\section{Quadro 8 - Resumo dos resultados dos efeitos mediadores e moderadores}

\begin{tabular}{|c|c|l|}
\hline \multirow{2}{*}{ Tipo de efeito } & Variáveis & Resultado dos testes \\
\hline \multirow{2}{*}{ Mediador } & Redes & Efeito existente \\
\cline { 2 - 3 } & Inovação local & Efeito inexistente \\
\hline \multirow{2}{*}{ Moderador } & Subsidiárias de grande porte & Efeito inexistente \\
\cline { 2 - 3 } & Subsidiárias de pequeno e médio porte & Efeito inexistente \\
\hline
\end{tabular}

FONTE: o autor com base nos dados da pesquisa. 


\section{DISCUSSÃO E CONCLUSÃO}

O capítulo final da tese traz as considerações gerais sobre a pesquisa. Abordando todo o processo desde a sua concepção, escolha das abordagens teóricas, desenvolvimento do modelo, resultados, conclusões e contribuições. A partir da trajetória realizada ao longo do desenvolvimento dessa pesquisa, foram constatadas algumas limitações as quais serão devidamente reportadas. Por fim, são enumeradas algumas sugestões e recomendações para estudos futuros mais aprofundados sobre o tema.

\subsection{Contexto Geral da Tese}

Essa pesquisa teve como foco principal contribuir para o conhecimento existente sobre o desenvolvimento de inovações em subsidiárias estrangeiras e sua transferência para as matrizes. O pressuposto era de que tanto a orientação empreendedora da subsidiária quanto a sua inserção em redes de empresas influenciariam substancialmente no desenvolvimento de inovações que pudessem ser comercializadas não somente localmente, mas também globalmente tornando-se inovações globais. Basicamente, a tese visou contribuir em três frentes:

* Teórica, ao promover um diálogo entre abordagens teóricas distintas e examinar como essas abordagens se relacionam e influenciam no desenvolvimento de inovações;

* Empírica, ao analisar estatisticamente os dados primários provenientes da percepção de executivos do alto escalão das multinacionais estrangeiras instaladas no país;

* Metodológica, a partir do rigor metodológico com que foi conduzida a pesquisa e as diversas validações, comparações e refino dos construtos de mensuração.

São crescentes os estudos que abordam as temáticas aqui endereçadas (SCOPUS, 2016). Entretanto, a presente tese contribui ao analisar essas teorias em conjunto num contexto de economia em desenvolvimento. Essas temáticas necessitam ser mais exploradas e compreendidas, em particular em contextos de economias em desenvolvimento, onde muitas multinacionais estão aumentando os seus investimentos (UNCTAD, 2015) em busca de uma classe média emergente e fugindo da saturação de seus mercados de origem. 
Outro fator que justifica a exploração dos mercados emergentes é a questão da inovação. Govindarajan e Trimble (2012) explicam que as diferenças de necessidade, infraestrutura, poder aquisitivo entre outras, impulcionam inovações direcionadas para as necessidades e características dos mercados emergentes. Essas inovações podem também ser exploradas em mercados desenvolvidos a aprtir de poucas modificações. Assim, os mercados emergentes podem ser fontes de inovações que podem se tornar globais.

As questões que envolvem a inovação são foco não apenas da academia como também da indústria e do governo. As empresas já entenderam que a inovação é o caminho pelo qual todas as empresas devem trilhar a fim de manterem o sucesso ou mesmo sobreviverem (HAMEL; BREEN, 2007) de maneira que, não raro, empresas novatas tornam-se multibilionárias a partir de uma inovação que as diferenciou gerando uma enorme base de clientes, assim como de modo contrário, empresas perdem a sua base de clientes em virtude de não terem inovado. Do ponto de vista dos governos, a inovação também é vista com prioridade, prova disso são os inúmeros programas de fomento a inovação que envolvem a indústria, as universidades e o governo como o programa NAGI (Núcleo de Apoio à Gestão da Inovação) e o Inovar-Auto. O Inovar-Auto, em particular, visa não somente fomentar a inovação na indústria automotiva como também investir na capacitação da rede de empresas fornecedoras (MDIC, 2016), o que sugere a importância das redes de empresas para o desenvolvimento industrial. Assim, percebe-se a relevância da temática e a motivação para aprofundar e discutir as questões que envolvem a inovação nas multinacionais, em particular, a tese buscou compreender a influência exercida pelo empreendedorismo da subsidiária e a sua inserção em redes de empresas sobre o desenvolvimento de inovações. Uma vez que, o empreendedorismo em MNCs é associado a iniciativas da subsidiária o que pode ser entendido como alguma atividade inovadora realizada com os recursos e sob a responsabilidade da própria subsidiária estrangeira (BIRKINSHAW, 1997). Essas inovações podem ser transferidas a partir de uma forte inserção na rede de empresas (BARTLETT; GHOSHAL, 1986; ANDERSSON; FORSGREN; HOLM, 2002).

A partir da identificação desses relacionamentos de causalidade entre o empreendedorismo, a inserção em redes de empresas e o desenvolvimento de inovações, foram propostas as hipóteses. Entre as pesquisas que embasaram as hipóteses e o survey aplicado com as maiores multinacionais que operam no Brasil destacam-se a pesquisa desenvolvida por Birkinshaw, 
Hood e Jonsson (1998) sobre inovação e empreendedorismo em MNCs, a pesquisa desenvolvida por Andersson, Forsgren e Holm (2002) sobre redes interorganizacionais e os estudos relacionados com as inovações desenvolvidas em mercados emergentes (GOVINDARAJAN E TRIMBLE, 2012). 


\subsection{Conclusões da Pesquisa}

Embora sejam as temáticas aqui tratadas emergentes e importantes dentro do cenário acadêmico, poucos estudos empíricos foram realizados, particularmente aqueles que buscam correlacionar essas temáticas sob o enfoque das multinacionais estrangeiras que atuam em contextos de economias em desenvolvimento. Essa pesquisa buscou não somente correlacionar e estabelecer vínculos entre as temáticas, buscou evidenciar o impacto do empreendedorismo da subsidiária e a sua inserção em redes de empresas sobre o desenvolvimento de inovações. Realizada a ponte entre as temáticas aqui abordadas e a mensuração do impacto entre as variáveis da pesquisa, foram alcançados os dois primeiros objetivos da tese (OE1 e OE2).

A pesquisa ressalta a importância de alguns fatores que caracterizam as redes de empresas e que impactam positivamente nas inovações ocorridas nas subsidiárias. Nesse contexto, a inserção em redes colaborativas pode desempenhar papel fundamental ao tornar possível o acesso a certos recursos e conhecimentos, tornando-se assim fundamental a compreensão dos relacionamentos interorganizacionais. Em busca de minimizar a desvantagem de serem estrangeiras, as multinacionais procuram se inserir nas redes de negócio do país hospedeiro. A inserção da subsidiária nas redes externas permite suplantar problemas institucionais (KHANA; PALEPU; BULLOK, 2010) além da utilização dos parceiros como intermediadores (LONDON; HART, 2004), situações que costumam ocorrer com as multinacionais oriundas de países desenvolvidos atuando em mercados emergentes (EYRING et al., 2011). Ademais, a qualidade das relações entre os parceiros na rede está associada com o desenvolvimento de inovações que por sua vez impactam no desempenho dos negócios da subsidiária (HALLIN et al., 2011), assim fatores como: adaptação, confiança, troca de informações e um forte relacionamento podem ajudar a entender melhor as questões referentes ao desenvolvimento de inovações nas subsidiárias.

A literatura em negócios internacionais, particularmente a que trata sobre a estratégia e inovação em multinacionais há algum tempo tem analisado e reconhecido a importância do empreendedorismo, do enraizamento das subsidiárias nas redes de empresas e seus desdobramentos sobre o desenvolvimento de inovações. Pesquisas anteriores mostraram que os parceiros ajudam a subsidiária a adaptar-se melhor no local onde atua impactando no 
desenvolvimento de inovações (CHAN; CHONG, 2012), outras pesquisas mostraram que a capacidade empreendedora da subsidiária de explorar as inovações nos locais onde atua (YOUNG; DIMITRATOS; DANA, 2003) trazem não somente vantagens para a MNC como também vantagens específicas para a própria subsidiária (DIMITRATOS; LIOUKA; YOUNG, 2014).

Esta tese dialoga com essas pesquisas e avança com a discussão ao analisar essas questões num mercado emergente, realizando uma comparação multigrupos com o porte das MNCs. Os resultados da SEM sugerem que a orientação empreendedora da subsidiária influência significativamente no aprofundamento das parcerias ou enraizamento na rede de empresas. Esse relacionamento causal apresentou o maior impacto no modelo $(0.47$ em nível de significância $\mathrm{p}<0.001$ ) evidenciando o papel direcionador das parcerias para o desenvolvimento de inovações conforme a Ilustração 17.

Esse enraizamento na rede é um direcionador para o desenvolvimento de inovações locais com potencial para se tornarem globais (impacto de 0.31 em nível de significância $p<0.05$ ). As inovações desenvolvidas localmente pela subsidiária estrangeira são então transferidas para a matriz, ainda que os resultados tenham mostrado um impacto modesto no modelo $(0.15$ em nível de significância $\mathrm{p}<0.05)$. Entretanto, nota-se que os parceiros na rede influenciam mais substancialmente no desenvolvimento de inovações que extrapolam o contexto local para que foram planejadas $(0.32$ em nível de significância $\mathrm{p}<0.01)$, o que concorda com as pesquisas de Govindarajan e Trimble (2012) que explicam que os mercados emergentes são fontes importantes de inovações com potencial para serem comercializadas globalmente. De maneira que as subsidiárias desempenham um papel importante, provendo, não raro, produtos que superam as expectativas locais e se tornam globais. 


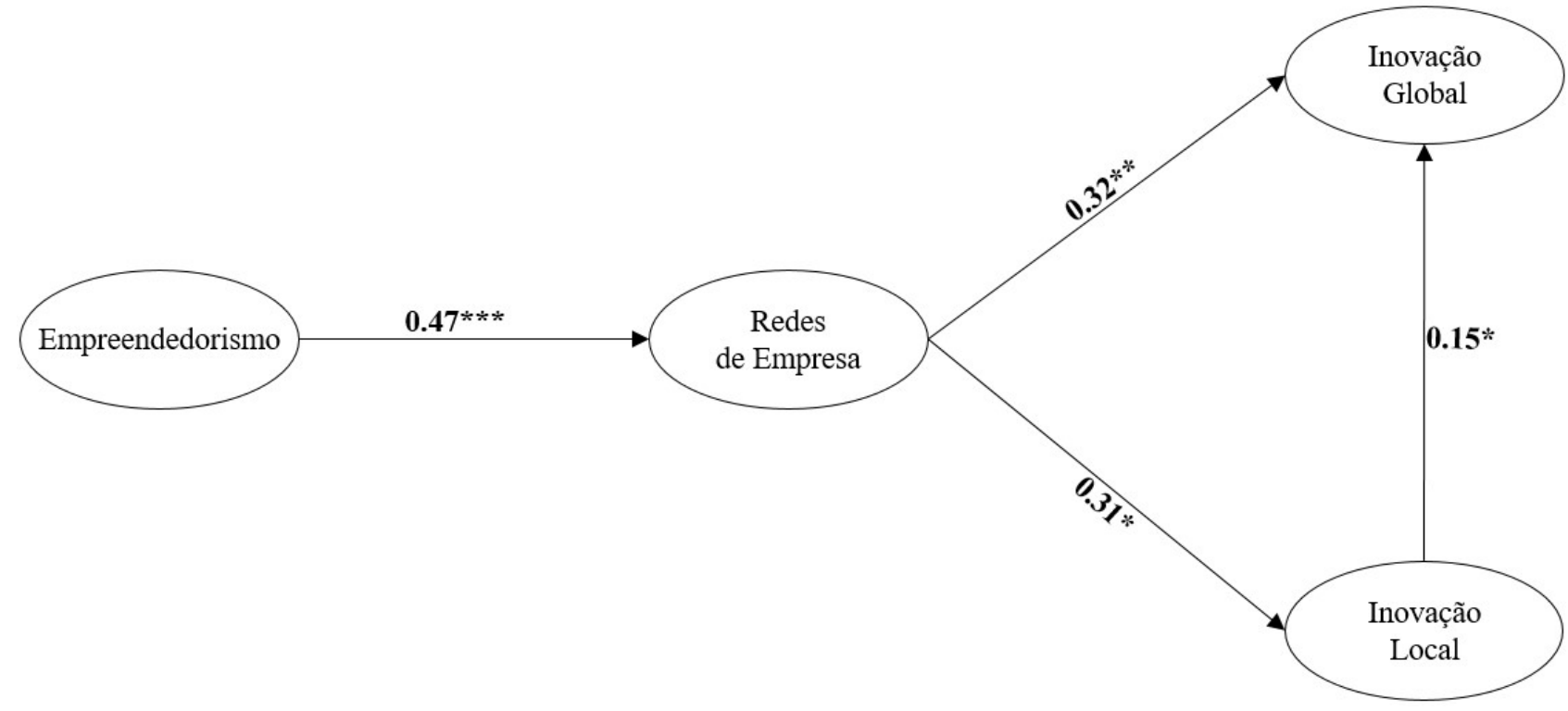

\section{Ilustração 17 - Resumo dos caminhos significativos no teste de hipóteses}

FONTE: o autor

E, embora, tradicionalmente as multinacionais tenham tido sucesso em concentrar suas expertises e pontos fortes na matriz em seus países de origem, a experiência tem apontado novos caminhos sugerindo as MNCs que as estratégias que antes davam lucro e sucesso precisam ser repensadas. $\mathrm{O}$ velho modelo de replicar os conhecimentos e técnicas da matriz ao redor do mundo não é mais a maneira mais eficiente de fazer negócios. Os executivos devem flexibilizar a empresa ao ponto de romper as fronteiras e fazer uso dos conhecimentos e técnicas desenvolvidos em outras regiões no mundo sem perder a visão global de suas operações. E, entender que o uso das estratégias empregadas nos mercados desenvolvidos não é eficiente nos mercados emergentes.

O fato de não haver uma associação entre a orientação empreendedora da subsidiária e o desenvolvimento de inovações locais pode decorrer da orientação estratégica da Matriz, caso a subsidiária desenvolva inovações sem que para isso precise enraizar-se na rede, ou seja, desenvolva as inovações isoladamente então ela cria capacidades locais (RUGMAN; VERBEKE, 2001), que podem ser importantes para a subsidiária, mas não para a transferência dessas inovações. Entretanto, os resultados sugerem uma orientação estratégica diferente, o que a matriz quer é que a subsidiária aprofunde os laços com os parceiros da rede para aprender algo novo e fazer desse algo novo uma capacidade não local, ou seja, que pode ser transferida e talvez tornar-se uma inovação global. 
A análise das variáveis moderadoras não apresenta quaisquer influências sobre o modelo testado. O resultado sugere dois caminhos de interpretação:

- Trata-se de uma peculiaridade restrita as amostras comparadas (Grandes empresas com mais de quinhentos funcionários e Pequenas e Médias empresas com menos de quinhentos funcionários);

- Ou, as subsidiárias de modo geral apresentam uma uniformidade de comportamento estratégico que tenta equilibrar os ditames da matriz com as iniciativas locais da subsidiária não importando o seu porte, uma vez que as subsidiárias por vivenciarem o contexto em que operam possuem mais condições e conhecimentos que lhes permitem serem mais ágeis. Por outro lado, há a preocupação da matriz em manter uma uniformidade estratégica em suas operações espalhadas pelo globo a partir de suas subsidiárias. Esse resultado corrobora o entendimento de que o comportamento de empreendedorismo internacional independe do tamanho da empresa e do seu tempo de existência (MCDOUGALL e OVIATT, 2000).

O modelo proposto nessa tese testou duas variáveis mediadoras, sendo que apenas a variável Redes de empresa atendeu aos requisitos de mediação. Tal resultado sugere a importância dos parceiros para o desenvolvimento de inovações e sua posterior transferência para a matriz. Por um lado, pode-se entender que as redes de empresas exercem uma influência decisiva sobre o desenvolvimento de inovações. Na ausência dos parceiros, a simples iniciativa da subsidiária não seria suficiente para promover inovações. Por outro lado, entende-se que a preocupação estratégica da subsidiária é desenvolver inovações que extrapolem o contexto regional em que a subsidiária está inserida. E para que isso ocorra, as parcerias são um importante estimulo técnico e de conhecimento que gera sinergias que, em isolamento, não poderiam ser obtidas, resultando no desenvolvimento de inovações incrementais e na performance dos produtos sob vários aspectos tais como custo, velocidade de mercado, reputação e maior retorno financeiro (DYER; SINGH, 1998; HALLIN et al., 2011). Ademais, Santangelo (2012) acresce que as forças competitivas afetam positivamente na inserção das subsidiárias nas redes, isso se deve as pressões concorrenciais as quais forçam a busca por recursos distintos que promovam vantagem competitiva. As inovações da subsidiária nem sempre precisam atender uma demanda interna da MNC, ou seja, pode ser uma iniciativa de mercado, para solucionar um 
problema especifico da demanda do mercado competitivo externo (BIRKINSHAW, 1997; BORINI; FLEURY; FLEURY; OLIVEIRA JR, 2009; DELANY, 2000; SCHMID et al., 2014). A orientação empreendedora, em vez de estimular como enfoque o mercado interno da MNC (BOUQUET; BIRKINSHAW, 2008), ela estimula iniciativas mais atreladas ao mercado externo, isso enseja a subsidiária a ter uma maior inserção na rede externa do país hospedeiro (ANDERSSON et al., 2002; FORSGREN, 2008). Logo, a inserção na rede externa exerce um papel mediador essencial para o desenvolvimento e transferência de inovações. Esse resultado concorda com a pesquisa de Dimitratos, Liouka e Young (2014) que afirmam que as redes de empresas são o principal direcionador e impulsionador das iniciativas empreendedoras.

Realizada a análise do modelo proposto e verificado o impacto da orientação empreendedora sobre o enraizamento na rede de empresas e os desdobramentos sobre o desenvolvimento de inovações globais, essa tese alcançou assim o seu objetivo final (OE3).

\section{Contribuições gerenciais:}

Essa tese traz contribuições específicas para os gerentes ao analisar questões que impactam na visibilidade da subsidiária como o desenvolvimento de iniciativas e de parcerias, e que podem auxiliar na compreensão do processo de desenvolvimento das inovações:

- A identificação dos fatores que influenciam no desenvolvimento de inovações nas subsidiárias fornece informações que podem auxiliar na tomada de decisão dos executivos;

- Os investimentos estrangeiros são importantes para o país, de maneira que essa pesquisa sugere aos formuladores de políticas públicas a investirem no parque industrial nacional a fim de desenvolver potenciais parceiros na rede em a subsidiária irá se inserir;

- Essa pesquisa também contribui ao fornecer evidências quanto ao empreendedorismo da subsidiária, uma vez que esse movimento estratégico é importante para aumentar a visibilidade da subsidiária e assim o aumento dos recursos provenientes da matriz. 


\subsection{Reflexões Metodológicas}

Essa tese traz contribuições metodológicas a partir do rigor com que foi conduzida a pesquisa e as diversas validações, comparações e refino dos construtos de mensuração. Inicialmente, foi realizado um intenso estudo bibliográfico o qual identificou as principais variáveis que constituíram o modelo. Esse estudo exploratório subsidiou, além do modelo teórico, também o desenvolvimento do questionário que foi aplicado com as mil maiores subsidiárias estrangeiras instaladas no Brasil.

Por ser de natureza quantitativa, descritiva com corte transversal, essa pesquisa coletou diversas variáveis que foram relacionadas entre si e que forneceram evidências empíricas que contribuem para o conhecimento científico da área. Os construtos foram operacionalizados a partir da modelagem de equações estruturais, técnica estatística que permite realizar um teste da teoria de forma conjunta e simultânea, o que possibilita verificar o relacionamento entre diferentes teorias e construtos.

A amostra coletada foi submetida aos pressupostos necessários para a aplicação da modelagem de equações estruturais, onde foram realizados os testes de tamanho amostral; dados perdidos; pontos fora da curva; linearidade; normalidade e multicolinearidade. Adicionalmente, também foi verificada a questão do viés do método comum a partir da análise de fator de Harman (PODSAKOFF; ORGAN, 1986).

Após a etapa de tratamento dos dados, procederam-se então outras validações inerentes a técnica de equações estruturais, sendo então realizadas as validações convergentes e discriminantes as quais verificaram a confiabilidade e consistência interna. Seguindo-se a recomendação de Kline (2011) foi realizada uma comparação entre o modelo defendido na tese e outro modelo alternativo equivalente a fim de ratificar a adequação do modelo escolhido. Complementarmente foram realizados os testes do efeito mediador e moderador sobre o modelo escolhido. Foram realizadas comparações multigrupos a fim de identificar diferenças significativas entre duas amostras que compunham as variáveis moderadoras.

A aplicação das técnicas de mediação e moderação são consideradas como sendo técnicas avançadas em SEM (KLINE, 2011). Nesse sentido, ressalta-se que o modelo testado nessa tese contempla quatro construtos interligados, os quais ora comportam-se como variáveis 
independentes ora como variáveis dependentes, havendo duas variáveis mediadoras e duas moderadoras, o que caracteriza um modelo complexo (CHANG; WITTELOOSTUIJIN e EDEN, 2010). A complexidade do modelo é um fator relevante para analisar os índices de ajustamento da SEM (HAIR JR. et al., 2009) de maneira que, embora, de modo geral os índices de qualidade do modelo tenham se apresentado dentro dos parâmetros estipulados (Goodnes-of-fit $\geq 0.90$ ) deve-se levar em conta também a razoabilidade da pesquisa bem como a contribuição que foi feita ao campo de estudos (MULAIK et al., 1989).

Essa pesquisa também se preocupou em analisar e reportar a maior quantidade possível de limitações que impactaram no seu desenvolvimento e conclusões.

\subsection{Limitações da pesquisa}

As Ciências Sociais possuem instrumentos e teorias capazes de fazer uma aproximação da realidade ainda que de forma incompleta e imperfeita (MINAYO; DESLANDES, 2009), uma vez que a realidade é inapreensível em sua totalidade. Essa realidade aproximada está sujeita a erros evitáveis e inevitáveis. Os erros evitáveis são aqueles referentes a limitações teóricometodológicas, enquanto que os erros inevitáveis dizem respeito aos limites da racionalidade científica vigente (DESLANDES, 2004). Nesse sentido, cabe aqui nesse espaço registrar algumas limitações dessa pesquisa.

Essa tese apoia-se num estudo quantitativo o qual faz uso de dados provenientes de um questionário aplicado com empresas multinacionais estrangeiras que operam apenas no Brasil. O que não permite fazer generalizações para outros países com economia, tamanho ou nível de desenvolvimento semelhante. O questionário aplicado não visou analisar especificidades setoriais da economia. Outra questão relacionada ao questionário aplicado são os respondentes (presidentes, CEO, vice-presidentes, diretores, e cargos similares), os quais podem trazer consigo um viés no tocante ao não conhecimento de todas as questões abordadas, a pesar da assunção de que os membros da cúpula diretiva conheçam de forma profunda as atividades estratégicas desenvolvidas pelas empresas. Entretanto, o viés pode existir caso o questionário tenha sido respondido por outros integrantes da empresa que não aqueles que compõem a cúpula diretiva. Há que se levar em conta também a qualidade das informações ainda que essas tenham sido respondidas por membros da alta direção. A fim de 
reduzir o problema do viés, essa pesquisa conduziu a análise de fator de Harman (PODSAKOFF; ORGAN, 1986).

Um fator limitador nessa pesquisa é que os resultados podem estar influenciados por fatores específicos de cada empresa como diferenças culturais.

Outra limitação evidente, embora adequada quando comparada a outros estudos e aos parâmetros sugeridos por Hair Jr et al. (2009), a amostra é pequena. E por essa razão outras relações não puderam ser testadas na presente pesquisa.

O uso de amostragem probabilística estratificada teria aumentado o alcance dos resultados e por conseguinte das conclusões aqui apresentadas. No entanto, devido a dificuldades inerentes a coleta dos dados, em particular a partir de surveys, utilizou-se nessa tese uma amostra nãoprobabilística por conveniência, o que dificulta que se façam generalizações com os achados da pesquisa. Ainda sob o ponto de vista da amostra, o objeto de pesquisa: subsidiárias de corporações multinacionais, traz consigo uma limitação quanto a impossibilidade de cruzar as percepções das subsidiárias com as da matriz. Entretanto, essa é uma limitação que permeia os trabalhos em negócios internacionais (MINBAEVA, 2007).

\subsection{Sugestões para Pesquisas Futuras}

A partir das limitações apresentadas nessa pesquisa, outros estudos podem validar e expandir as conclusões aqui apresentadas. Apontam-se as seguintes direções:

- Pesquisas futuras podem comparar dados de diferentes mercados emergentes;

- Pesquisas futuras podem comparar os resultados de subsidiárias pertencentes ao mesmo grupo;

- Também é recomendável que pesquisas futuras incluam outras variáveis moderadoras e mediadoras;

- A fim de expandir as conclusões outras pesquisas podem fazer uso de amostragem probabilística estratificada; 
- Futuras pesquisas podem cruzar as percepções das subsidiárias com as percepções das matrizes e comparar as diferenças;

- Futuras pesquisas podem usar metodologias mistas, buscando triangular os resultados quantitativos com entrevistas qualitativas. 


\section{REFERÊNCIAS}

ACHCAOUCAOU, F., MIRAVITLlES, P., LEON-DARDER. F. Knowledge sharing and subsidiary R\&D mandate development: A matter of dual embeddedness. International Business Review, 2013.

AHARONI, Y.; BROCK, D.M. International business research: Looking back and looking forward, Journal of International Management, v.16, n.1 p.5-15, 2010.

ALDRICH, H.; ELAM, A.; REESE, P. Strong ties, weak ties, and strangers. In: BIRLEY, S.; MACMILLAN, I. (Org.). Entrepreneurship in a global context. New York: Routledge, p. $1-25,1997$.

ALDRICH, H.; ZIMMER, C. Entrepreneurship through Social Networks. In: SEXTON, D.; SMILOR, R. (Org.). The art and science of entrepreneurship. Cambridge, MA: Ballinger, p. 3-23, 1985.

ANDERSSON, U.; FORSGREN, M. Creation and diffusion of competence in MNCs structures, ties and resources at the subsidiary level. In: HADJIKHANI, A.; LEE, J-W; JOHANSON, J. (Eds.). Business networks and international marketing. Seul: Doo Yang Publishing Co., p. 333-346, 2006.

ANDERSSON, U. Managing the transfer of capabilities within multinational corporations: the dual role of the subsidiary. Scandinavian Journal of Management, 19(4), 425-442, 2003.

ANDERSSON, U.; FORSGREN, M.; HOLM, U. The strategic impact of external networks: subsidiary performance and competence development in multinational corporation. Strategic Management Journal, v. 23, p. 979-996, 2002.

ANDERSSON, U.; FORSGREN, M.; HOLM, U. Subsidiary embeddedness and competence development in MNCs a multi-level analysis. Organization Studies, v. 23, n. 22, p. 979996, 2001. 
ARBUCKLE, J. L. IBM SPSS Amos 23 user's guide. Crawfordville: Amos Development Corporation, 2014.

BAGOZZI, Richard P. Structural Equation Models in Marketing Research: Basic Principles. In Principles of Marketing Research, R.P. Bagozzi, ed., Oxford: Blackwell Publishers, 125140, 1994.

BACEN, Banco Central do Brasil. Série histórica dos Fluxos de investimento direto: distribuições por país ou por setor. Disponível em: <http://www.bcb.gov.br/?SERIEFIND>. Acesso em: 19/12/2015.

BARON, R.M.; KENNY, D.A. The Moderator-Mediator Variable Distinction in Social Psychological Research: Conceptual, Strategic, and Statistical Considerations. Journal of Personality and Social Psychology, v.51, n.6, 1986, p.1173-1182.

BARTLETT, C. A.; GHOSHAL, S. Managing innovation in the transnational corporation. In Management the global firm, ed. C.A. Bartlett, Y. Doz, e G. hedlund, 215-55. London: Routledge, 1990.

BARTLETT, C. A.; GHOSHAL, S. Managing across borders: the transnational solution. Boston: Harvard Business School Press, 1989.

BARTLETT, C. A.; GHOSHAL, S. Tap your subsidiaries for global reach. Harvard Business Review, v. 64, n,6, p.87-94, 1986.

BREWER, T. (Eds.). Oxford handbook of international business. Oxford: Oxford University Press, 2001.

BIRKINSHAW, J. Strategy and management in MNE subsidiaries. In A. Rugman \& T. Brewer (Eds.), Oxford handbook of international business (pp. 121-138). Oxford: Oxford University Press, 2001.

BIRKINSHAW, J. Corporate entrepreneurship in network organizations: How subsidiary initiative drives internal market efficiency. European Management Journal, Vol. 16, No. 3, pp. 355-364, 1998. 
BIRKINSHAW, J. Entrepreneuship in Multinational Corporations: The Caracteristics of Subsidiary Initiatives. Strategic Management Journal, 18: 207-229, 1997.

BIRKINSHAW, J.; HOOD, N.; YOUNG, S. Subsidiary entrepreneurship, internal and external competitive forces, and subsidiary performance. International Business Review, 14(2), 227-248, 2005.

BIRKINSHAW, J.; HOOD, N; JONSSON. Building firm-specific advantages in multinational corporations: The role of subsidiary initiative. Strategic Management Journal, v.19, n.3, p.221-242, 1998.

BOEHE, D. M. Captive offshoring of new product development in brazil: how does arbitrage influence local, collaborative relationships? Management International Review, 50(6), 747-773, 2010.

BORINI, F. M.; OLIVEIRA JUNIOR, M. M.; SILVEIRA, F. F.; CONCER, R. O. The Reverse Transfer of Innovation of Foreign Subsidiaries of Brazilian Multinationals. European Management Journal, 30(3), 219-231, 2012.

BORINI, F. M.; FLEURY, M. T. L.; FLEURY, A. C.; OLIVEIRA Jr, M. M. . The relevance of subsidiaries initiatives for Brazilian multinationals. Revista de Administração de Empresas, v. 49, p. 253-265, 2009.

BRASIL. Secretaria de Assuntos Estratégicos - SAE. Marketing - Como Fisgar a nova Classe Média? Brasília: SAE, 2012. Disponível em: $<$ http://www.sae.gov.br/site/?p= 12504>, Acesso em 19 nov. 2013.

BYRNE, B. M. Structural equation modeling with AMOS: basic concepts, applications, and programming. 2nd edition. New York: Taylor \& Francis Group, 2009.

CAPALDO, A. Network structure and innovation: the leveraging of a dual network as a distinctive relational capability. Strategic Management Journal, v. 28, n. 6, p. 585-608, 2007. 
CERVO, A. L.; BERVIAN, P. A.; SILVA, R. Metodologia científica. 6. ed São Paulo: Prentice Hall, 2007.

CHAN, F. T. S.; CHONG, A. Y. L. A SEM-neural network approach for understanding determinants of interorganizational system standard adoption and performances. Decision Support Systems, 54(1), 621-630. 2012.

CHANGA, Man-Ling; CHENG, Cheng-Feng; WU, Wann-Yih. How Buyer-Seller Relationship Quality Influences Adaptation and Innovation by Foreign MNCs' Subsidiaries. Industrial Marketing Management, v. (41), p. 1047-1057, 2012.

CHANG, M-L.; CHENG, C-F.; WU, W-Y. How Buyer-Seller Relationship Quality Influences Adaptation and Innovation by Foreign MNCs' Subsidiaries. Industrial Marketing Management, 41 (7), 2012.

CHANG, Kuang-chi. Close but not Committed? The multiple dimensions of relational embeddedness. Social Science Research, v. 40, n. 4, p. 1214-1235, 2011.

CHANG, S.J; WITTELOOSTUIJIN, A; EDEN, L. From the Editors: Common method variance in international business research. Journal of International Business Studies, v. 41, n. 2, p. 178-184, 2010.

CHESBROUGH, H. (2012a). Inovação aberta: como criar e lucrar com a tecnologia. (L. C. C. Q. Faria, Trad.). Porto Alegre: Bookman.

CHRISTENSEN, K. A classification of the corporate entrepreneurship umbrella: labels and perspectives. International Journal Management Enterprise Development, Vol. 1, No. 4, 2004 .

CHURCHILL Jr., G. A. Marketing research: methodological foundations. Fort Laudardale: Harcourt College Publishers, 1999. 
CASANOVA, L. Las Multinacionales Latinoamericanas en los Albores de una Gran Oportunidad. Revista de Administração de Empresas, São Paulo, v. 50, n. 3, p. 339-455. 2010.

COLLIS, J.; HUSSEY,R. Pesquisa em administração. Porto Alegre: Bookman, 2006.

COSTA, S.; BORINI, F. M.; AMATUCCI, M. Inovação Global de Subsidiárias Estrangeiras Localizadas em Mercados Emergentes. Revista de Administração Contemporânea, v. 17, n. 4, p. 459-478, 2013.

COSTA. S. A influência do determinismo ambiental sobre a estratégia e inovação em subsidiárias estrangeiras. Dissertação de Mestrado. São Paulo: Escola Superior de Propaganda e Marketing, 2012.

CRESWELL, J. W. Research design: qualitative, quantitative, and mixed methods approaches. 3. ed. USA: SAGE Publications, 2009.

D’AGOSTINO, L. M.; SANTANGELO, G. D. Do Overseas R\&D Laboratories in Emerging Markets Contribute to Home Knowledge Creation? Management International Review, 52(2): $251-273,2012$.

DELANY, E. Strategic development of the multinational subsidiary through subsidiary initiative-taking. Long Range Planning, 33(2), 220-244, 2000.

DELLESTRAND, H. Subsidiary embeddedness as a determinant of divisional headquarters involvement in innovation transfer processes. Journal of International Management, v. 17, n. 3, p. 229-242, 2011.

DEMO, P. Metodologia científica em ciências sociais. São Paulo: Atlas, 1981.

DESLANDES, Suely Ferreira. Introdução à metodologia científica da pesquisa. Curso de EAD: Fiocruz, 2004. Disponível em: <http://www.extranet.ead.fiocruz.br/ criacao/qssp/QSSP-PercursoAprendizagem/texto_deslandes.pdf $>$. Acesso em: 31 outubro 2015. 
DIMITRATOS, P.; LIOUKA, I.; YOUNG, S. A missing operationalization: entrepreneurial competencies in multinational enterprise subsidiaries. Long Range Planning, 47(1-2), pp. 64-75, 2014.

DIMITRATOS, P.; PLAKOYIANNAKI, E. Theoretical foundations of international entrepreneurial culture. Journal of International Entrepreneurship, v. 1, n. 2, p. 187-215, 2003.

DOZ, Y.; SANTOS, J.; WILLIAMSON, P. From global to metanational: How companies win in the knowledge economy. Harvard Business School Press, 2001.

DPLP. Dicionário Priberam da Língua Portuguesa. Disponível em: $<$ http://www.priberam.pt/dlpo/premissa> Acesso em: 24/12/2015.

DYER, J.; HATCH, N. Relation specific capabilities and barriers to kmowledge transfers: creating advantage through network relationships. Marriott: Brigham Young, 2006.

DYER, J. H.; NOBEOKA, K. Creating and managing a high-performance knowledge-sharing network: The Toyota case. Strategic Management Journal, v. 21, p. 345-367, 2000.

DYER, J.H.; SINGH, H. The relational view: cooperative strategy and sources of interorganizational competitive advantage. Academy of management, v. 23, n. 4, p. 660-679, 1998.

EYRING, M; JONSSON, M, NAIR, N. New Business Model in Emerging Markets. Havard Business Review. 89(1), 88-95, 2011.

FIGUEIREDO, P. N. The role of dual embeddedness in the innovative performance of MNE subsidiaries: evidence from Brazil. Journal of Management Studies, 48(2), 417-440, 2011. 
FORNELL, C.; FRED L. BOOKSTEIN. Two structural Equation Models: LISREL and PLS Applied to Consumer Exit-Voice Theory. Journal of Marketing Research, XIX (November), 440-452, 1982.

FORNELL, C.; LARCKER, D. F. Evaluating structural equation models with unobservable variables and measurement error: algebra and statistics. Journal of Marketing, v. 18, n. 1, p. 39-59, Feb. 1981.

FORSGREN, M.; HOLM, U.; JOHANSON, J. Managing the embedded multinational: a business network view. Cheltenham: Edward Elgar, 2005.

FOSS, N.; LAURSEN, K.; PEDERSEN, T. Linking customer interaction and innovation: the mediating role of new organizational practices, Organization Science, Vol. 22, pp.980-999, 2011.

FRITSCH, M.; KAUFFELD-MONZ, M. The impact of network structure on knowledge transfer: an application of social network analysis in the context of regional innovation networks. The Annals of Regional Science, Springer, v. 44, n. 1, p. 21-38, 2008.

FROST, T.; BIRKINSHAW, J.; ENSIGN, P. Centers of excellence in multinational corporations. Strategic Management Journal, 23(11), 997-1018, 2002.

FROST, T. The geographic sources of foreign subsidiaries' innovations. Strategic Management Journal, Vol (22)2, 2001.

GAMBARDELlA, A.; HARHOFF, D.; VERSPAGEN, B. The value of European patents. European Management Reviews, 5, 69-84, 2008.

GAULT, F. Handbook of innovation indicators and measurement. Cheltenham: Edward Elgar, 2013.

GEFEN, D., RIGDON, E. E., STRAUB, D. Editor`s comments - An update and extension to SEM guidelines for administrative and social science research. MIS Quarterly, 35(2), iii-xiv, 2011. 
GOLDMAN SACHS. Dreaming with Brics: The Path to 2050. Global Economics Paper, New York, n.99, 2003.

BRIC Monthly. Global Economics, New York, n.10/03, May 20, 2010.

GOVINDARAJAN, V. A Reverse-Innovation Playbook: Insights from a company that developed products for emerging markets and then brought them back home. Harvard Business Review, 2012.

GOVINDARAJAN, V.; TRIMBLE, C. Reverse innovation. Boston: Harvard Business Press, 2012.

GOVINDARAJAN, V.; RAMAMURTI, R. Reverse innovation, emerging markets, and global strategy. Global Strategy Journal, v. 1, p. 191-205, 2011.

GRANOVETTER, M. Economic action and social structure: the problem of embeddedness. American Journal of Sociology, Chicago, v. 91, n. 3, p. 481-510, 1985.

GRANOVETTER, M. The Strength of Weak Ties: a network theory revisited. Sociological Theory, v. 1, n. 2, p. 201-233, 1983.

GROENLAND, E., STALPERS, J. Structural equation modeling: A verbal approach. Nyenrode research paper series. 12, 1-39, 2012.

GUPTA, A.; GOVINDARAJAN, V. Knowledge Flows within Multinational Corporation. Strategic Management Journal, v. 21, n. 4, p. 473-496, 2000.

GULATI, R., NOHRIA, N. E ZAHEER, A. Strategic networks. Strategic Management Journal.1: 203-215, 2000.

HAIR, J. F.; HUlt, T. M.; RINGLE, C. M.; SARSTEDT, M. A Primer on Partial Least Squares Structural Equation Modeling (PLS-SEM). Califórnia: SAGE, 2014 
HAIR J. F.; BLACK, W. C.; BABIN, B. J.; ANDERSON, R. E.; TATHAM, R. L. Análise Multivariada de dados. Trad. Adonai Schlup Sant”Anna. 6ed. Porto Alegre: Bookman, 2009.

HAKANSSON, H.; FORD, D. How Should Companies Interact in Business Networks? Journal of Business Research, v. 55, n. 2, p. 133-139, 2002.

HAKANSON, L.; NOBEL, R. Technology characteristics and reverse technology transfer. Management International Review, 40(1), 29-48, 2000.

HALL, B. H.; HARHOFF, D. Recent Research on the Economics of Patents. Annual Review of Economics, Annual Reviews, v. 4, n.1, p. 541-565, 2012.

HALLIN, CHRISTINA; LIND, C. H. Revisiting the external impact of MNCs: An empirical study of the mechanisms behind knowledge spillovers from MNC subsidiaries. International Business Review, v. 21, n. 2, p. 167-179, 2012.

HALLIN, C.; HOLM, U.; SHARMA, D. Embeddedness of innovation receivers in the multinational corporation: Effects on business performance. International Business Review, v. 20, n. 3, p. 362-373, 2011.

HENSELER, J.; FASSOTT, G. Testing Moderating Effects in PLS Path Models: An Illustration of Available Procedures. (V. Esposito Vinzi, W. W. Chin, J. Henseler, \& H. Wang, Eds.) Handbook of Partial Least Squares, p. 713-735, 2010.

HITT, M.; IRELAND, R.; CAMP, S.; SEXTON, D. Strategic Entrepreneurship: Entrepreneurial Strategies for wealth creation. Strategic Management Journal, 22 (2001). pp. 479-491, 2001.

HOOPER, D.; COUGHLAN, J.; MULLEN, M. Structural Equation Modeling: Guidelines for Determining Model Fit, Electronic Journal of Business Research Methods, 6(1), 2009. 
HOYLE, R. H. Assumptions in Structural Equation Modeling. In: HOYLE, R. H. (Ed.). Handbook of Structural equation modeling. New York: The Guilford Press, 2012. Champter. 8, p. 126-144.

IACOBUCCI, D.; SALDANHA, N.; DENG, X. A meditation on mediation: Evidence that structural equations models perform better than regressions. Journal of Consumer Psychology, v. 17, n. 2, p. 139, 2007.

IBGE. Pesquisa de Inovação 2001. Rio de Janeiro: RJ, 2013.

JARVIS, C. B.; MACKENZIE, S.; PODSAKOFF, P. A critical review of construct indicators and measurement model misspecification in marketing and consumer research. Journal of Consumer Research, 30(2), 199-218, 2003.

JOHANSON, J.; VAHLNE, J. The Uppsala internationalization process model revisited: From liability of foreignness to liability of outsidership, Journal of International Business Studies, v. 40, n. 9, p. 1411-1431, 2009.

KALE, P., SINGH, H., \& PERLMUTTER, H. Learning and protection of proprietary assets in strategic alliances: Building relational capital. Strategic Management Journal, v. 21, p. $217-237,2000$.

KANWAR, S. Business enterprise R\&D, technological change, and intellectual property protection. Economics Letters, v. 96, p.120-126, 2007

KHANNA, T.; PALEPU, K.; BULLOCK, R. Vencendo em mercados emergentes. Harvard Business Review, v. 88, n. 6, p. 80-85, 2010.

KLEINDORFER, P.R.; WIND, Y.J.; GUNTHER, R. E. O desafio das redes: estratégia, lucro e risco em um mundo interligado, Porto Alegre: Bookman, 2012.

KLINE, Rex B. Principles and practice of structural equation modeling. 2nd edition. New York: The Guilford Press, 2005. 
KOGUT, B.; SINGH, H. The effect of national culture on the choice of entry mode. Journal of International Business Studies, v. 19. n. 3, p. 411-432, 1988.

LAKSHMAN, C., PARENTE, R.C. Supplier-Focused Knowledge Management in the Automobile Industry and Its Implications for Product Performace. Journal of Management Studies, 2008.

LI, Y.; WANG, X.; HUANG, L.; BAI, X. How does entrepreneurs' social capital hinder new business development? A relational embeddedness perspective. Journal of Business Research, 2013.

LI, Chia-Ying. Knowledge stickiness in the buyer-supplier knowledge transfer process: The moderating effects of learning capability and social embeddedness. Expert Systems with Applications, v. 39, n 5, p. 5396-5408, 2012.

LI, Yongqiang; WANG, Xuehua; HUANG, Lily; BAI, Xuan. How does entrepreneurs' social capital hinder new business development? A relational embeddedness perspective. Journal of Business Research. v. 66, 2013.

LIN, Julia L.; FANG, Shih-Chieh; FANG, Shyh-Rong; TSAI, Fu-Sheng. Network embeddedness and technology transfer performance in R\&D consortia in Taiwan. Technovation, v. 29, n. 11, p. 763-774, 2009.

LONDON, T. HART, S. Reinventing strategies for emerging markets: beyond the transnational model.Journal of International Business Studies v.35, p. 350-370, 2004.

MCDOUGALL, P.P.; OVIATT, B.M. International entrepreneurship: the intersection of two research paths. Academy of Management Journal, vol. 43, n. 5, p. 902-906, 2000.

MALHOTRA, N. K.; BIRKS, D.; WILLS, P. Marketing research: applied approach. 4. ed. New York: Pearson, 2012.

MAROCO, João. Análise Estatística com o PASW Statistics (ex-SPSS). $1^{\text {a }}$ Ed. Portugal, Lisboa: Editora ReportNumber, 2010. 
MATSUEDA, R. L. Key advances in the history of structural equation modeling. In: HOYLE, R. H. (Ed.). Structural Equation Modeling: concepts, issues, and applications. Thousand Oaks: Sage Publications, 2012, cap. 2, p. 17-42.

MCGUINESS M.; DEMIRBAG M.; BANDARA S. Towards a Multi-perspective Model of Reverse Knowledge Transfer in Multinational Enterprises: A Case Study of Coats plc. European Management Journal, Vol. 31, No. 2, pp. 179-195, 2013.

MDIC, Ministério do Desenvolvimento Indústria e Comércio Exterior. Notícias. 2012. Disponível em: <http://www.desenvolvimento.gov.br/sitio/interna/noticia.php?area=1\& noticia=11857> Acesso em: 10 Jan 2016.

MEYER, K. E. Perspectives on multinational enterprises in Emerging Economies, Journal of International Business Studies v.35, n.4, p.259-276, 2004.

MICHAILOVA, S.; MUSTAFFA, Z. Subsidiary knowledge flows in multinational corporations: Research accomplishments, gaps, and opportunities. Journal of World Business, v. 47, n. 3, p. 383-396, 2012.

MINAYO, M. C. S.; DESLANDES, S. F. Pesquisa social: teoria, método e criatividade. 28. ed. Petrópolis, RJ: Vozes, 2009.

MINBAEVA, D. B. Knowledge Transfer in Multinational Corporations. Management International Review, v. 47, p. 567-593, 2007.

MOON, H. C.; RUGMAN, A. M.; VERBEKE, A. A generalized double diamond approach to the global competitiveness of Korea and Singapore. International Business Review, 7: 135$150,1998$.

MU, S.; GNYAWALI, D. R.; HATFIELD, D. E. (2007). Foreign Subsidiaries' Learning from Local Environments: An Empirical Test. Management International Review, 47, 1: 79-102, 2007. 
MULAIK, Stanley A.; JAMES, Larry R.; Van ALSTINE, Judith; BENNETT, Nathan; LIND, Sherri; STILWELL, C. Dean. Evaluation of goodness-of-fit indices for structural equation models. Psychological Bulletin, v. 105, n. 3, p. 430-445, 1989.

NAJAFI-TAVANI, ZH.; GIROUD, A.; ANDERSSON, U. The Interplay of Networking Activities and Internal Knowledge Actions for Subsidiary Influence within MNCs. Journal of World Business, 2013.

NAMBISAN, S.; MOHANBIR, S. Cérebro global: como inovar em um mundo conectado por redes. São Paulo: Évora, 2011.

NARULA, R. Exploring the Paradox of Competence-creating Subsidiaries: Balancing Bandwidth and Dispersion in MNEs. Long Range Planning, 47(1-2), 4-15, 2014.

OLIVEIRA JR.; M. M.; BOEHE, D.M.; BORINI, F.M. Estratégia e Inovação em corporações multinacionais: a transformação das subsidiárias brasileiras. $1^{\circ}$ ed. São Paulo: Saraiva; 2009.

ORGANIZAÇÃO PARA A COOPERAÇÃO E O DESENVOLVIMENTO ECONÔMICO OCDE. Manual de Oslo: Proposta de Diretrizes para Coleta e Interpretação de Dados sobre Inovação Tecnológica. Tradução: Financiadora de Estudos e Projetos - FINEP. $3^{\text {a }}$ edição. 2004.

OVIATT, B.M.; MCDOUGALL, P.P. Global start-ups: entrepreneurs on a worldwide stage. Academy of Management Executive, v. 9, n.2, p. 30-43, 1995.

PINTEC. Pesquisa de Inovação Tecnológica 2011. Rio de Janeiro: IBGE, 2013.

PORTER, M. A vantagem competitiva das nações. In: Montgomery, C.; Porter, M. (Eds.). Estratégia - A busca da vantagem competitiva. Ed. Campus, 1998.

PODSAKOFF, P. M.; ORGAN, D. W. Self-reports in organizational research: problems and prospects. Journal of Management, 12(4), 531-544, 1986. 
PODSAKOFF, P. M.; MACKENZIE, S. B.; LEE, J. Y.; PODSAKOFF, N. P. Common method biases in behavioral research: A critical review of the literature and recommended remedies. Journal of Applied Psychology, 88(5): 879-903, 2003.

REZENDE, S.F.L.; VERSIANI, A. Relacionamentos intersubsidiárias e processos de internacionalização de multinacionais. Revista de Administração da Universidade de São Paulo (RAUSP), São Paulo, v.42, n.2, p.155-166, abr./maio/jun. 2007.

RIGDON, E. E.; SCHUMACKER, R. E.; WOTHKE, W. A comparative review of interaction and nonlinear modeling. In: R. E. Schumacker; George A Marcoulides (Eds.); Interaction and Nonlinear Effects in Structural Equation Modeling. p.1-16, 1998.

RUGMAN, A.; VERBEKE, A.; YUAN, W. Re-conceptualizing Bartlett \& Goshal's Classification of National Subsidiary Roles in the Multinational Enterprise. Journal of Management Studies, v. 48, n. 2, p. 253-277, 2011.

SANTANGELO, G. D. The tension of information sharing: Effects on subsidiary embeddedness. International Business Review. v. 21, n. 2, p. 117-310, 2012.

SAUER, Paul L.; DICK, Alan. Using moderator variables in structural equation models. In: ADVANCES IN CONSUMER RESEARCH, 1993. Proceedings.. Provo, UT: Association for Consumer Research, v.20, p.636-640, 1993.

SBRAGIA, R., LIMA, G. O. Orientação para mercado e interface funcional: evidências em projetos de desenvolvimento de novos produtos. Revista de administração e inovação RAI. v. 10, n.3, 2013.

SCHMID, S.; DZEDEK, L. R.; LEHRER, M. From Rocking the Boat to Wagging the Dog: A Literature Review of Subsidiary Initiative Research and Integrative Framework. Journal of International Management, 20(2), 201-218, 2014.

SCHUMPETER, J., Capitalismo, Socialismo e Democracia, Rio de Janeiro: Jorge Zahar Editor, 1984. 
SCHUMPETER, J. A. Teoria do Desenvolvimento Econômico. Rio de Janeiro: Editora Fundo de Cultura, 1951.

SCOPUS. Base de dados na Internet. Rio de Janeiro: Elsevier. Disponível em: $<$ http://www.scopus.com/> Acesso em: 01 Jan 2016.

SHARMA, S.; DURAND, R.M.; GUR-ARIE, O. Identification and Analysis of Moderator Variables. Journal of Marketing Research, v.18, 1981, p. 291-300.

TANG, F.; MU, J.; MACLACHLAN, D. L. Implication of network size and structure on organizations' knowledge transfer. Expert Systems with Applications, v. 34, p. 1109-1114, 2008.

TIDD, J.; BESSANT, J.; PAVITT, K.H. Gestão da Inovação. Porto Alegre: Bookman, 2008

UNCTAD. World Investment Report 2015: reforming international investment governance. New York and Geneva: United Nations, 2015.

UNCTAD. World Investment Report 2010: investing in a low-carbon economy. New York and Geneva: United Nations, 2010.

UZZI, B.; LANCASTER, R. Relational embeddedness and learning: The case of bank loan managers and their clients. Management Science, v. 49, p. 383-399, 2003.

UZZI, B. The sources and consequences of embeddedness for the economic performance of organizations: The network effect. American Sociological Review, v. 61, p. 674-698, 1996. WILLIAMSON, Oliver E. Calculativeness, trust and economic organization. Journal of law and economics, v.36, n.1, p.453-486, 1993.

WINTER, Amos e GOVINDARAJAN, Vijay. Engineering reverse innovations. Harvard Business Review, 2015. 
YOUNG, S.; TAVARES, A. T. Centralization and autonomy: back to the future. International Business Review, Vol. 13 No. 2, pp. 215-37, 2004.

YOUNG, S.; DIMITRATOS, P.; DANA, L-P. International entrepreneurship research: what scope for International Business Theories? Journal of International Entrepreneurship, v. 1, n.1, p. 31-42, 2003.

YUAN, Ke-Hai; KOUROS, C.; KELLEY, Ken. Diagnosis for Covariance Structure Models by Analyzing the Path. Structural Equation Modeling, 15 (4), 564-602, 2008.

ZHAO, F. Exploring the synergy between entrepreneurship and innovation. International Journal of Entrepreneurial Behaviour \& Research, Vol. 11 No. 1, pp. 25-41, 2005. 


\section{APÊNDICES}

APÊNDICE I - INSTRUMENTO DE PESQUISA

APÊNDICE II - PREPARAÇÃO DOS DADOS DA PESQUISA: ESTATÍSTICAS DESCRITIVAS

APÊNDICE III - ESTIMATIVAS E PESOS DAS VARIÁVEIS DO MODELO DE EQUAÇÕES ESTRUTURAIS

APÊNDICE IV - COMPARAÇÃO ENTRE MODELOS 


\section{APÊNDICE I - INSTRUMENTO DE PESQUISA}

\section{Parte 1 - INFORMACÕES GERAIS}

Empresa:

Nome do respondente:

E-mail:

Cargo:

4. Continente de Origem da Multinacional

\begin{tabular}{|l|l|}
\hline & América Latina \\
\hline & América do Norte \\
\hline & Europa \\
\hline & Ásia \\
\hline & África \\
\hline & Oceania \\
\hline
\end{tabular}

5. Setor de atuação

\begin{tabular}{|l|l|}
\hline & Indústria \\
\hline & Serviço \\
\hline & Agronegócio \\
\hline
\end{tabular}

6. Tamanho da Subsidiária no Brasil

\begin{tabular}{|l|l|}
\hline & Menos que 100 funcionários \\
\hline & Entre 100 e 500 funcionários \\
\hline & Mais que 500 funcionários \\
\hline
\end{tabular}


Parte 2: Avaliação das funções organizacionais de sua subsidiária.

7. Essa questão diz a respeito as inovações globais realizadas pela a sua subsidiária. Nos últimos anos sua subsidiária

\section{Discordo \\ Concordo \\ Totalmente \\ Totalmente}

\begin{tabular}{|l|c|c|c|c|c|}
\hline $\begin{array}{l}\text { desenvolveu produtos que hoje são vendidos por } \\
\text { outras subsidiárias }\end{array}$ & 1 & 2 & 3 & 4 & 5 \\
\hline $\begin{array}{l}\text { desenvolveu processos organizacionais que hoje são } \\
\text { adotados em outras subsidiárias }\end{array}$ & 1 & 2 & 3 & 4 & 5 \\
\hline $\begin{array}{l}\text { desenvolveu produtos/processos organizacionais em } \\
\text { parceria com FORNECEDORES e que hoje são } \\
\text { adotados em outras subsidiárias }\end{array}$ & 1 & 2 & 3 & 4 & 5 \\
\hline $\begin{array}{l}\text { desenvolveu produtos/processos organizacionais em } \\
\text { parceria com UNIVERSIDADES BRASILEIRAS e } \\
\text { que hoje são adotados em outras subsidiárias }\end{array}$ & 1 & 2 & 3 & 4 & 5 \\
\hline
\end{tabular}

8. Essa questão diz a respeito as inovações locais realizadas pela a sua subsidiária.

Sua subsidiária realizou inovações que visaram

\section{Discordo \\ Concordo \\ Totalmente \\ Totalmente}

\begin{tabular}{|l|l|l|l|l|l|}
\hline alterar o design dos produtos / serviços oferecidos & 1 & 2 & 3 & 4 & 5 \\
\hline criar novos produtos/serviços & 1 & 2 & 3 & 4 & 5 \\
\hline entrar em novos mercados dentro do país & 1 & 2 & 3 & 4 & 5 \\
\hline alterar os processos de produção & 1 & 2 & 3 & 4 & 5 \\
\hline desenvolver novos fornecedores e parceiros & 1 & 2 & 3 & 4 & 5 \\
\hline
\end{tabular}

9. Essa questão diz a respeito à orientação empreendedora da sua subsidiária.

No relacionamento da matriz com a sua subsidiária existe: 
Discordo

Concordo

Totalmente

Totalmente

apoio para as decisões de risco dos executivos da subsidiária

apoio para as atividades empreendedoras

forte confiança da matriz na sua subsidiária

10. Essa questão diz a respeito as parcerias e inserção em redes de empresas.

Discordo

Totalmente
Concordo

Totalmente

\begin{tabular}{|l|c|c|c|c|c|}
\hline $\begin{array}{l}\text { Nossa subsidiária tem larga experiência com parcerias e } \\
\text { alianças estratégicas com nossos fornecedores }\end{array}$ & 1 & 2 & 3 & 4 & 5 \\
\hline $\begin{array}{l}\text { Nossa subsidiária tem uma longa história na preparação e } \\
\text { desenvolvimento de parcerias no passado }\end{array}$ & 1 & 2 & 3 & 4 & 5 \\
\hline $\begin{array}{l}\text { Desenvolver parcerias é uma prática comum da nossa } \\
\text { subsidiária. }\end{array}$ & 1 & 2 & 3 & 4 & 5 \\
\hline $\begin{array}{l}\text { Nossa subsidiária está sempre procurando por } \\
\text { oportunidades de fazer novas alianças e parcerias } \\
\text { estratégicas }\end{array}$ & 1 & 2 & 3 & 4 & 5 \\
\hline $\begin{array}{l}\text { Nossa subsidiária considera parcerias e alianças } \\
\text { estratégicas assuntos de vital importância para nosso } \\
\text { negócio. }\end{array}$ & 1 & 2 & 3 & 4 & 5 \\
\hline
\end{tabular}




\section{APÊNDICE II - PREPARAÇÃO DOS DADOS DA PESQUISA: ESTATÍSTICAS DESCRITIVAS}

\begin{tabular}{|c|c|c|c|c|c|}
\hline \multirow{2}{*}{} & $\mathrm{N}$ & \multicolumn{2}{|c|}{ Assimetria } & \multicolumn{2}{c|}{ Curtose } \\
\cline { 2 - 6 } & Estatística & Estatística & $\begin{array}{c}\text { Erro } \\
\text { Padrão }\end{array}$ & Estatística & $\begin{array}{c}\text { Erro } \\
\text { Padrão }\end{array}$ \\
\hline V3 & 172 &,- 210 &, 185 &,- 009 &, 368 \\
V4 & 172 &,- 181 &, 185 &,- 210 &, 368 \\
V5 & 172 &,- 212 &, 185 &,- 258 &, 368 \\
V6 & 172 &,- 050 &, 185 &,- 674 &, 368 \\
V7 & 172 &,- 064 &, 185 &,- 353 &, 368 \\
V8 & 172 &, 053 &, 185 &,- 235 &, 368 \\
V10 & 172 &,- 059 &, 185 &,- 759 &, 368 \\
V11 & 172 &,- 188 &, 185 &,- 557 &, 368 \\
V13 & 172 &,- 162 &, 185 &,- 576 &, 368 \\
V14 & 172 &,- 243 &, 185 &, 294 &, 368 \\
V15 & 172 &,- 244 &, 185 &, 100 &, 368 \\
V16 & 172 &,- 428 &, 185 &,- 319 &, 368 \\
N válido (de lista) & 172 & & & & \\
\hline
\end{tabular}

Estatísticas univariadas

\begin{tabular}{|c|c|c|c|c|c|c|c|}
\hline & \multirow{2}{*}{$\mathrm{N}$} & \multirow{2}{*}{ Média } & \multirow{2}{*}{$\begin{array}{l}\text { Desvio } \\
\text { Padrão }\end{array}$} & \multicolumn{2}{|c|}{ Ausente } & \multicolumn{2}{|c|}{$\mathrm{N}$ de extremos ${ }^{\mathrm{a}}$} \\
\hline & & & & Contagem & Porcentagem & Baixo & Alto \\
\hline Inovação Global & 172 & 2,9337 & ,75681 & $\overline{0}$ & 0,0 & $\overline{0}$ & $\overline{0}$ \\
\hline Inovação Local & 172 & 3,5615 &, 84131 & 0 & 0,0 & 2 & 0 \\
\hline Empreendedorismo & 172 & 4,0021 & ,60561 & 0 & 0,0 & 0 & 0 \\
\hline Redes & 172 & 3,7932 & 66297 & 0 & 0,0 & 4 & 13 \\
\hline
\end{tabular}

a. Número de casos fora do intervalo (Q1 - 1,5*IQR, Q3 + 1,5*IQR). 
Variância total explicada

\begin{tabular}{|c|c|c|c|c|c|c|}
\hline \multirow{2}{*}{ Componente } & \multicolumn{3}{|c|}{ Valores próprios iniciais } & \multicolumn{3}{c|}{$\begin{array}{c}\text { Somas de extração de } \\
\text { carregamentos ao quadrado }\end{array}$} \\
\cline { 2 - 6 } & Total & $\begin{array}{c}\% \text { de } \\
\text { variância }\end{array}$ & $\begin{array}{c}\% \\
\text { cumulativa }\end{array}$ & Total & $\begin{array}{c}\text { \% de } \\
\text { variância }\end{array}$ & $\begin{array}{c}\% \\
\text { cumulativa }\end{array}$ \\
\hline 1 & 5,104 & 31,902 & 31,902 & 5,104 & 31,902 & 31,902 \\
2 & 2,148 & 13,426 & 45,329 & & & \\
3 & 1,735 & 10,846 & 56,175 & & & \\
4 & 1,602 & 10,013 & 66,188 & & & \\
5 &, 961 & 6,004 & 72,192 & & & \\
6 &, 699 & 4,371 & 76,563 & & & \\
7 &, 676 & 4,227 & 80,790 & & & \\
8 &, 572 & 3,572 & 84,362 & & & \\
9 &, 526 & 3,287 & 87,649 & & & \\
10 &, 445 & 2,784 & 90,433 & & & \\
11 &, 436 & 2,722 & 93,155 & & & \\
12 &, 290 & 1,814 & 94,969 & & & \\
13 &, 265 & 1,656 & 96,624 & & & \\
14 &, 222 & 1,386 & 98,011 & & & \\
15 &, 194 & 1,215 & 99,226 & & & \\
16 &, 124 &, 774 & 100,000 & & & \\
\hline
\end{tabular}

Método de Extração: Análise de Componente Principal. 


\section{APÊNDICE III - ESTIMATIVAS E PESOS DAS VARIÁVEIS DO MODELO DE EQUAÇÕES ESTRUTURAIS}

\section{Regression Weights}

\begin{tabular}{|c|c|c|c|c|c|c|c|}
\hline & & & Estimate & S.E. & C.R. & $P$ & Label \\
\hline Redes & $<---$ & $\mathrm{OE}$ & 0,475 & 0,117 & 4,066 & $* * *$ & par_10 \\
\hline $\begin{array}{c}\text { Inovação } \\
\text { Local }\end{array}$ & $<---$ & Redes & 0,307 & 0,152 & 2,026 & 0,043 & par_7 \\
\hline $\begin{array}{c}\text { Inovação } \\
\text { Local }\end{array}$ & $<---$ & $\mathrm{OE}$ & 0,305 & 0,208 & 1,466 & 0,143 & par_9 \\
\hline $\begin{array}{c}\text { Inovação } \\
\text { Global }\end{array}$ & $<---$ & $\begin{array}{c}\text { Inovação } \\
\text { Local }\end{array}$ & 0,148 & 0,06 & 2,441 & 0,015 & par_8 \\
\hline $\begin{array}{c}\text { Inovação } \\
\text { Global }\end{array}$ & $<---$ & Redes & 0,323 & 0,106 & 3,046 & 0,002 & par_11 \\
\hline $\begin{array}{c}\text { Inovação } \\
\text { Global }\end{array}$ & $<---$ & $\mathrm{OE}$ & 0,243 & 0,143 & 1,702 & 0,089 & par_12 \\
\hline V3 & $<---$ & Redes & 1 & & & & \\
\hline V14 & $<---$ & $\mathrm{OE}$ & 1 & & & & \\
\hline V15 & $<---$ & $\mathrm{OE}$ & 1,402 & 0,161 & 8,683 & $* * *$ & par_1 \\
\hline V16 & $<---$ & $\mathrm{OE}$ & 0,874 & 0,112 & 7,799 & $* * *$ & par_2 \\
\hline V10 & $<---$ & $\begin{array}{c}\text { Inovação } \\
\text { Local }\end{array}$ & 1 & & & & \\
\hline V11 & $<---$ & $\begin{array}{c}\text { Inovação } \\
\text { Local }\end{array}$ & 0,77 & 0,08 & 9,627 & $* * *$ & par_3 \\
\hline V8 & $<---$ & $\begin{array}{c}\text { Inovação } \\
\text { Global }\end{array}$ & 1 & & & & \\
\hline V7 & $<---$ & $\begin{array}{c}\text { Inovação } \\
\text { Global }\end{array}$ & 0,92 & 0,13 & 7,089 & $* * *$ & par_4 \\
\hline V6 & $<---$ & $\begin{array}{c}\text { Inovação } \\
\text { Global }\end{array}$ & 1,024 & 0,146 & 6,997 & $* * *$ & par_5 \\
\hline V4 & $<---$ & Redes & 1,006 & 0,066 & 15,18 & $* * *$ & par_6 \\
\hline V5 & $<---$ & Redes & 0,858 & 0,067 & 12,724 & $* * *$ & par_13 \\
\hline V13 & $<---$ & $\begin{array}{c}\text { Inovação } \\
\text { Local }\end{array}$ & 0,617 & 0,076 & 8,171 & $* * *$ & par_14 \\
\hline
\end{tabular}

Legenda: ${ }^{* * *}$ significante a 0.001 e OE $=$ Orientação Empreendedora 
Standardized Regression Weights

\begin{tabular}{|c|c|c|c|}
\hline & & & Estimate \\
\hline Redes & $<---$ & $\mathrm{OE}$ & 0,348 \\
\hline $\begin{array}{c}\text { Inovação } \\
\text { Local }\end{array}$ & $<---$ & Redes & 0,183 \\
\hline $\begin{array}{c}\text { Inovação } \\
\text { Local }\end{array}$ & $<---$ & $\mathrm{OE}$ & 0,133 \\
\hline $\begin{array}{c}\text { Inovação } \\
\text { Global }\end{array}$ & $<---$ & $\begin{array}{c}\text { Inovação } \\
\text { Local }\end{array}$ & 0,222 \\
\hline $\begin{array}{c}\text { Inovação } \\
\text { Global }\end{array}$ & $<---$ & Redes & 0,288 \\
\hline $\begin{array}{c}\text { Inovação } \\
\text { Global }\end{array}$ & $<---$ & $\mathrm{OE}$ & 0,159 \\
\hline V3 & $<---$ & Redes & 0,886 \\
\hline V14 & $<---$ & $\mathrm{OE}$ & 0,724 \\
\hline V15 & $<---$ & $\mathrm{OE}$ & 0,935 \\
\hline V16 & $<---$ & $\mathrm{OE}$ & 0,626 \\
\hline V10 & $<---$ & $\begin{array}{c}\text { Inovação } \\
\text { Local }\end{array}$ & 0,921 \\
\hline V11 & $<---$ & $\begin{array}{c}\text { Inovação } \\
\text { Local }\end{array}$ & 0,779 \\
\hline V8 & $<---$ & $\begin{array}{c}\text { Inovação } \\
\text { Global }\end{array}$ & 0,786 \\
\hline V7 & $<---$ & $\begin{array}{c}\text { Inovação } \\
\text { Global }\end{array}$ & 0,682 \\
\hline V6 & $<---$ & $\begin{array}{c}\text { Inovação } \\
\text { Global }\end{array}$ & 0,664 \\
\hline V4 & $<---$ & Redes & 0,909 \\
\hline V5 & $<---$ & Redes & 0,789 \\
\hline V13 & $<---$ & $\begin{array}{c}\text { Inovação } \\
\text { Local }\end{array}$ & 0,638 \\
\hline
\end{tabular}

Legenda: $\mathrm{OE}=$ Orientação Empreendedora 
APÊNDICE IV - COMPARAÇÃO ENTRE MODELOS

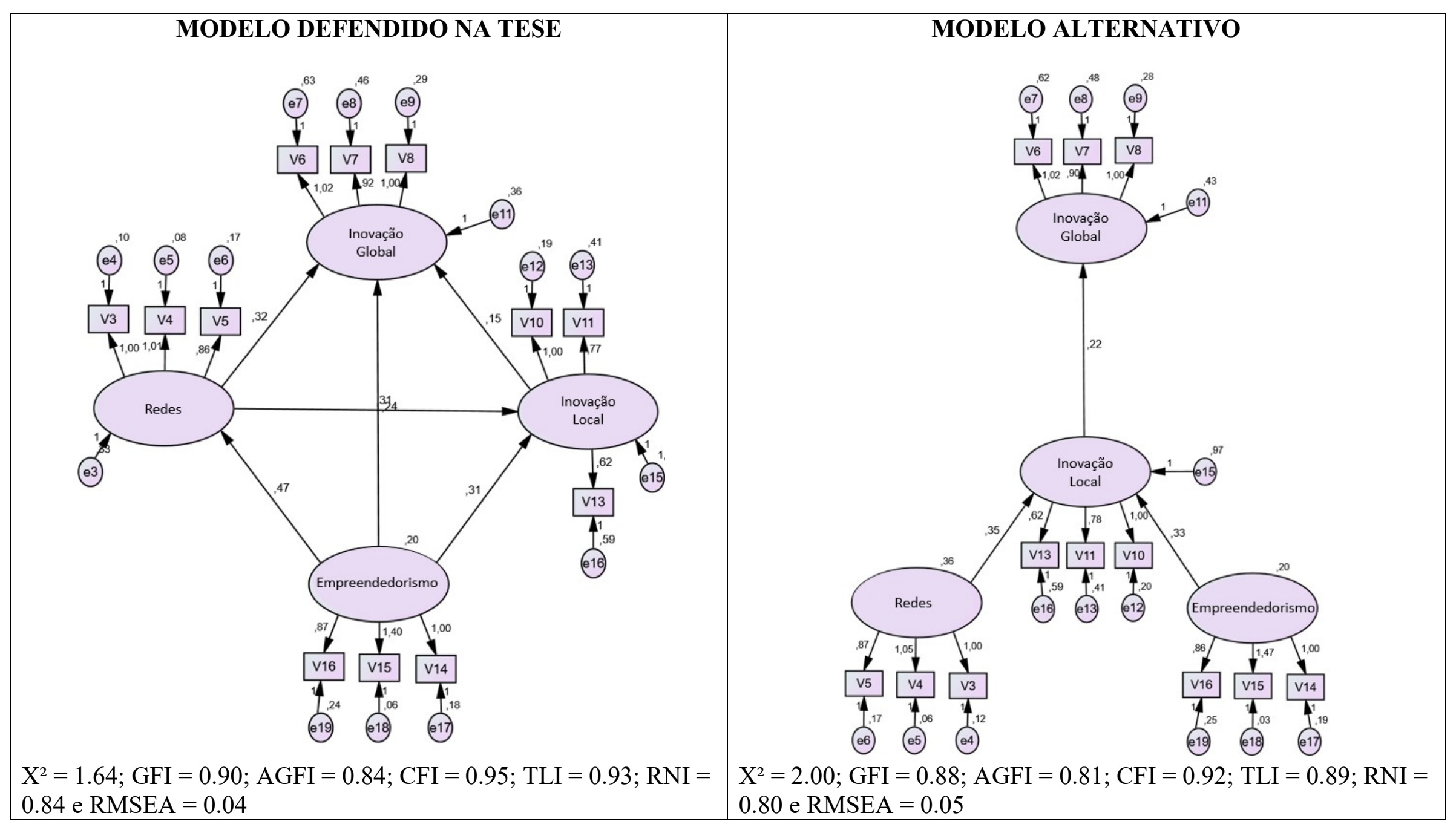

